\title{
The Role of Enforcement in the Decision Making of Preparers and Auditors of Financial Statements
}

\author{
Dissertation \\ zur Erlangung des Doktorgrades \\ der Wirtschaftswissenschaftlichen Fakultät \\ der Georg-August-Universität Göttingen
}

vorgelegt von

Henning Schnack

geboren in Hannover

Göttingen, 2019 
Für meine Familie 


\section{Betreuungsausschuss:}

Erstbetreuer: $\quad$ Prof. Dr. Jörg-Markus Hitz (Erstprüfer)

Weitere Betreuer: Dr. Andreas Hellmann (Zweitprüfer)

Prof. Dr. Olaf Korn ～(Drittprüfer) 


\begin{abstract}
This thesis investigates the role of financial reporting enforcement in the decision making of financial statement preparers and auditors. Enforcement bodies are governmental or private agencies that have the authority to review audited financial statements of listed corporations. Enforcement, in general, describes the supervision of listed firms by such agencies with the objective of ensuring compliance with accounting standards. Prior literature indicates that the introduction of enforcement mechanisms is associated with positive capital market effects such as increasing liquidity. Moreover, error announcements by enforcers result in significant negative market reactions for the censured firms. Hence, enforcement provides additional incentives for firms to prepare error-free financial statements. Moving beyond capital market effects, it is the aim of this thesis to provide evidence on the direct effects of enforcement on the decision making of involved stakeholders. This thesis includes three studies which examine the influence of enforcement on disclosure and accounting choices of managers and auditors.
\end{abstract}

The first study "Firm Disclosures about Enforcement Reviews", in a descriptive and exploratory investigation of the annual reports of German firms subject to enforcement scrutiny from 2006 to 2016, finds that managers voluntarily disclose information about enforcement reviews even when the reviews are still ongoing. Content analyses reveal that these disclosures are potentially associated with strategic considerations. For instance, the study provides weak evidence that market reactions to error announcements are mitigated by pre-emptive voluntary disclosure about the ongoing reviews.

The second study "Auditor Conservatism in the Presence of Financial Reporting Enforcement" utilises an experimental design to test whether the likelihood of being subject to an enforcement review increases an auditor's tendency to require conservative accounting choices from his/her client. The findings suggest that the expectation of an enforcement review and its likelihood are not associated with more conservative behaviour by the auditor. However, auditors who were directly affected by enforcement reviews in the past are more likely to make more conservative decisions.

The third and final study "The Role of Enforcement in Shaping Conservative Accounting Choices" tests and finds in a cross-country setting that substantive changes in enforcement regulation are associated with increases in accounting conservatism. Moreover, findings suggest that the impact of enforcement on accounting conservatism is stronger 
for firms with weak corporate governance than for firms with strong corporate governance.

In conclusion, this thesis supplies evidence that enforcement plays a significant role in the decision making of both managers and auditors. It influences managers' disclosure and accounting choices, while it may have an impact on auditors' accounting choices if auditors have had direct experience with enforcement reviews in the past. The thesis' findings suggest that the strengthening of enforcement institutions is associated with higher accounting conservatism. Increasing the frequency of enforcement reviews, on the other hand, may enhance auditor conservatism as it will result in more auditors having been directly affected by enforcement reviews. 
Table of Contents

Page

Table of Contents................................................................................................................... VI

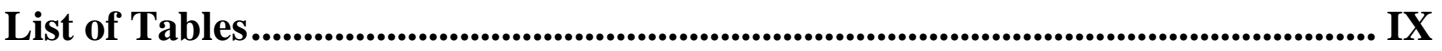

List of Figures ...........................................................................................................

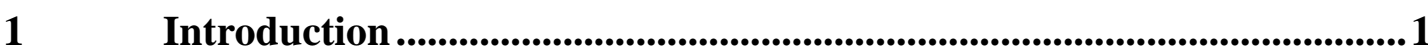

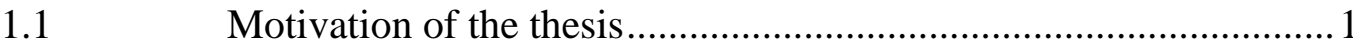

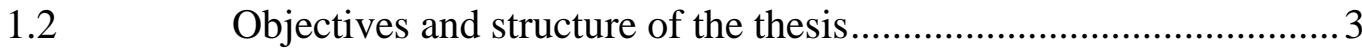

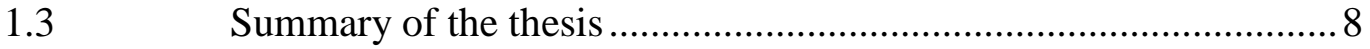

2 Firm Disclosures about Enforcement Reviews .....................................13

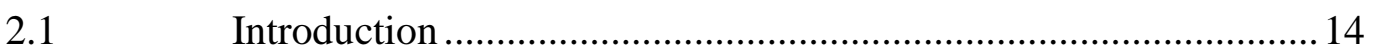

2.2 Background: Enforcement of IFRS in Germany.......................... 16

2.3 Theoretical background: Voluntary disclosures about

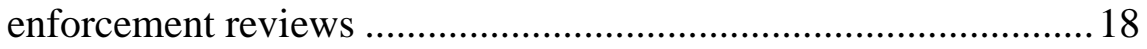

2.4 Empirical evidence on enforcement-related disclosures ...............21

2.4.1 Sample selection and research design ....................................... 21

2.4.2 Frequency and types of enforcement-related disclosures .............23

2.4.3 Characteristics of enforcement-related disclosures.......................24

2.4.4 Characteristics of enforcement reviews subject to disclosure.......29

2.5 Additional analyses of motives for disclosures about ongoing

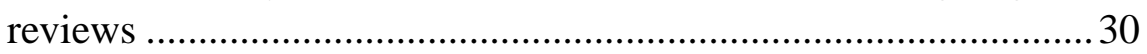

2.5.1 Factors associated with disclosure decisions about ongoing enforcement reviews ............................................................... 31

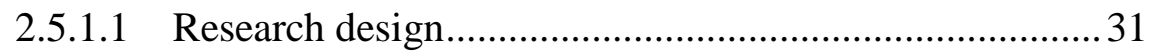

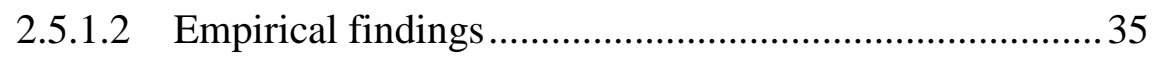

2.5.2 Market reactions to error announcements ........................................ 39

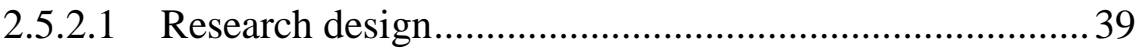

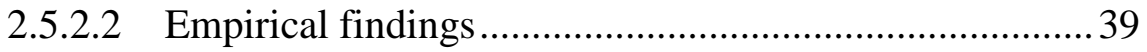

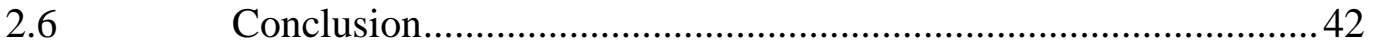

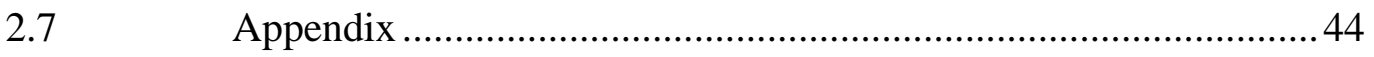

3 Auditor Conservatism in the Presence of Financial Reporting

Enforcement .......................................................................................................................48

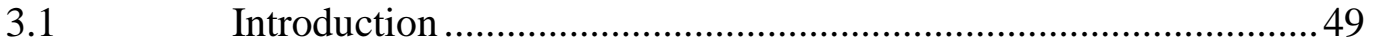

3.2 Literature review and hypotheses development ...........................53 
3.2.1 Influence of enforcement reviews of clients' financial statements on auditor conservatism

3.2.2 Influence of past enforcement reviews of clients' financial statements on auditor conservatism

3.2.3 Joint influence of enforcement reviews and hierarchical level on auditor conservatism .................................................................5

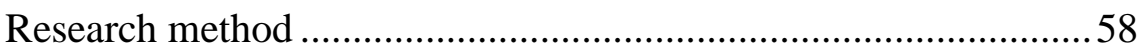

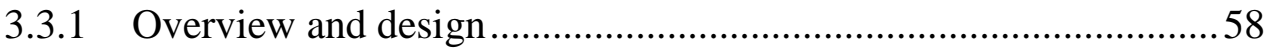

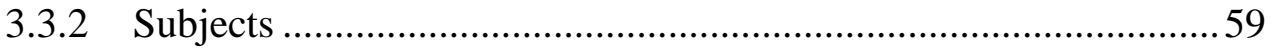

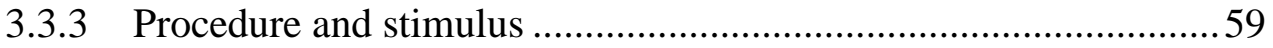

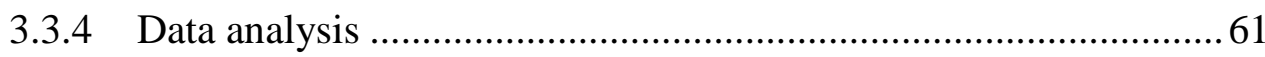

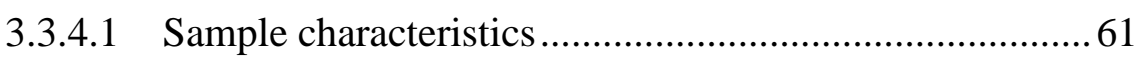

3.3.4.2 Questionnaire data analysis..........................................63

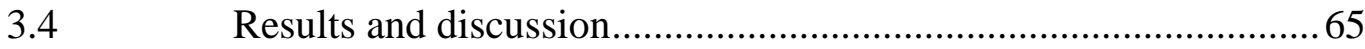

3.4.1 Descriptive statistics and correlations .......................................65

3.4.2 Testing the influence of enforcement on auditor conservatism (H1)

3.4.3 Testing the influence of being affected by enforcement reviews in the past on auditor conservatism (H2) 70

3.4.4 Testing the joint influence of enforcement and hierarchical level on auditor conservatism (H3) ................................................... 71

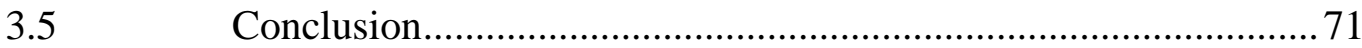

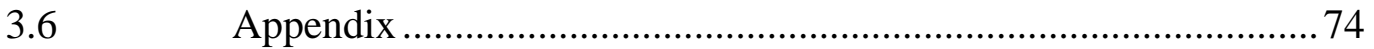

4 The Role of Enforcement in Shaping Conservative Accounting

Choices...........................................................................................................8 85

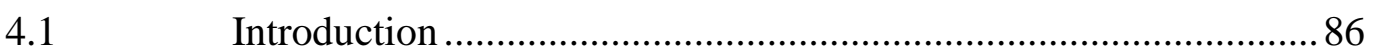

4.2 Literature review and hypotheses development ..........................91

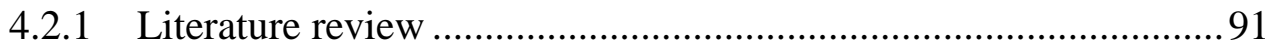

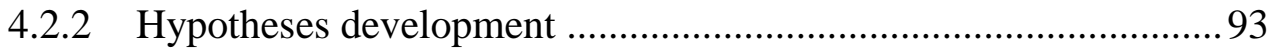

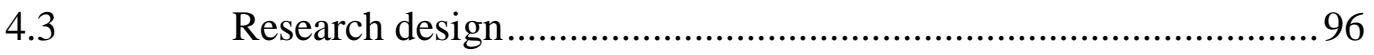

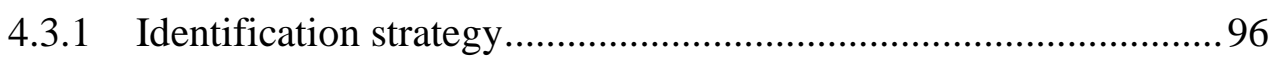

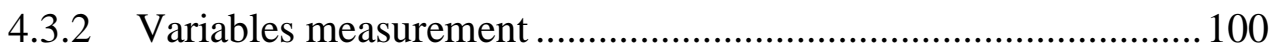

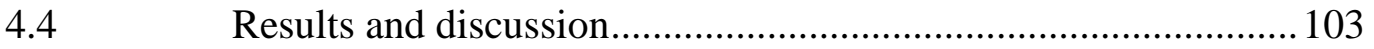

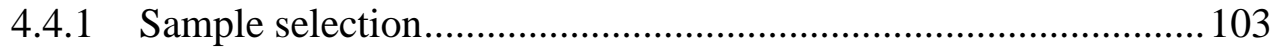

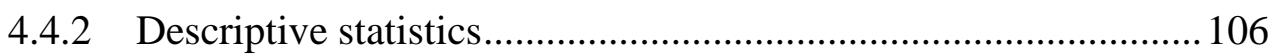

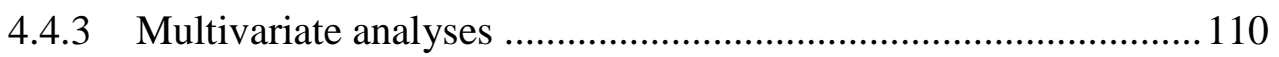




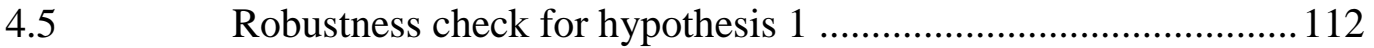

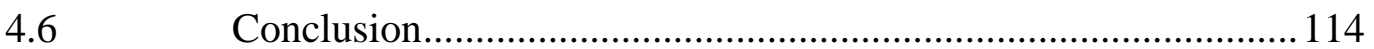

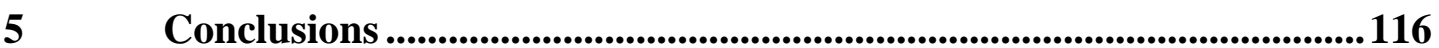

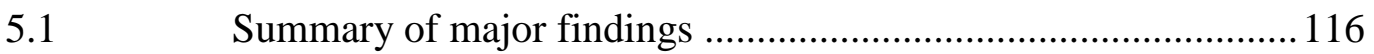

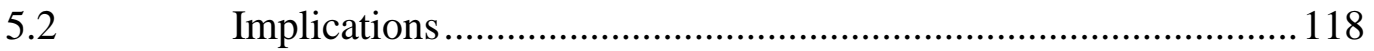

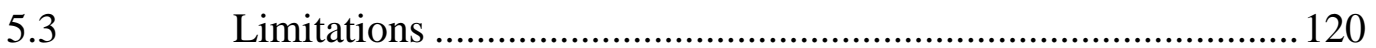

5.4 Avenues for future research ................................................. 121

6 Erklärung über den geleisteten Eigenanteil an der Arbeit .................123

$7 \quad$ Versicherung .............................................................................................. 124

$8 \quad$ Curriculum Vitae ................................................................................... 125

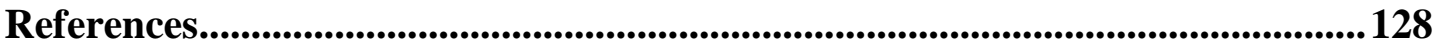




\section{List of Tables}

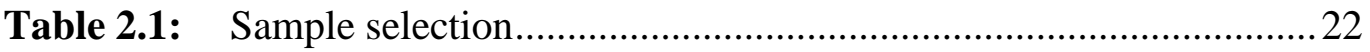

Table 2.2: $\quad$ Enforcement-related disclosures .................................................2 24

Table 2.3: Content analyses: characteristics of voluntary enforcement

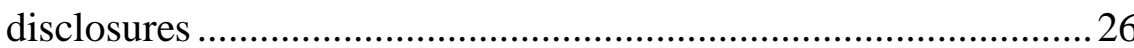

Table 2.4: Content analyses: characteristics of enforcement reviews subject

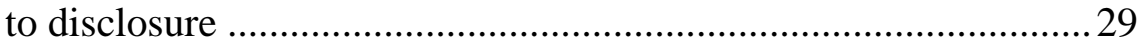

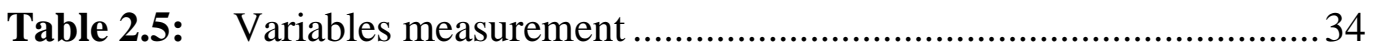

Table 2.6: Descriptives (determinants model) ................................................ 36

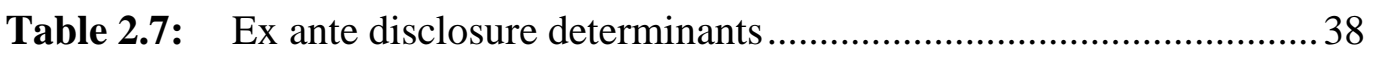

Table 2.8: Short-window market reactions …................................................ 40

Table 2.9: Descriptives of market reaction determinants ...............................46

Table 3.1: Distributions of sample characteristics across the two experimental conditions

Table 3.2: Variables measurement - determinants of conservative disclosure choices

Table 3.3: Descriptive statistics of conservative disclosure choices ...............66

Table 3.4: Correlations of conservative disclosure choices. ...........................67 67

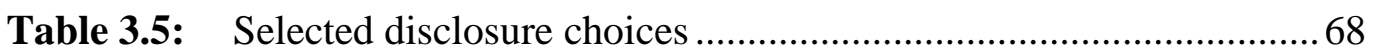

Table 3.6: Determinants of conservative disclosure choices ..........................69

Table 3.7: Selected disclosure choices depending on past enforcement

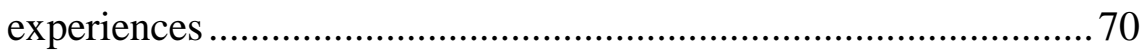

Table 4.1: Composition of treatment and control groups............................... 98

Table 4.2: Variation in first annual report after enforcement change .............99

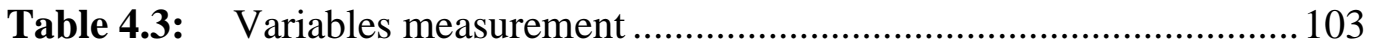

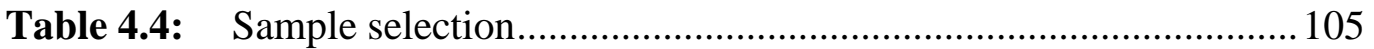

Table 4.5: Descriptive statistics of variables used in the regression models 107

Table 4.6: Correlations of variables used in the regression models .............. 109

Table 4.7: The effect of enforcement on accounting conservatism...............111

Table 4.8: Enforcement's effect on accounting conservatism depending on a firm's governance strength ................................................... 112

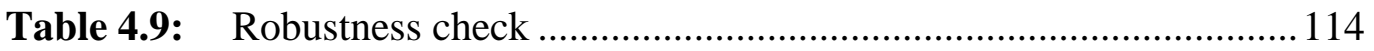




\section{List of Figures}

Page

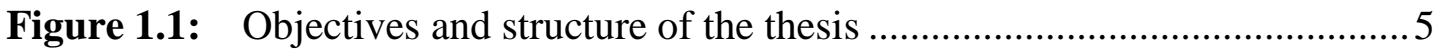

Figure 2.1: Taxonomy of enforcement-related disclosures ................................... 19 


\section{Introduction}

\subsection{Motivation of the thesis}

In recent years, International Financial Reporting Standards (IFRS) have been adopted by the vast majority of countries in the world. As of 2018, IFRS are required for all or most domestic public companies in 144 countries around the globe (IFRS-Foundation, 2018). For instance, the European Union (EU) mandated that its member states require all firms listed on EU-regulated markets to adopt IFRS in their group accounts in 2005 in the context of the so-called International Accounting Standards (IAS) Regulation (Regulation (EC) No. 1606/2002). The main objectives of adopting a common set of accounting standards across the EU were to increase investor transparency and comparability and reduce firms' cost of capital. Moreover, regulators stated that IFRS adoption "should lead to more efficient capital allocation and greater cross-border investment, thereby promoting growth and employment in Europe" (McCreevy, 2005).

In order to achieve these goals, it appears essential that consistent compliance with IFRS be ensured across EU member states. Hence, as in many other countries around the world, the EU accompanied IFRS adoption by mandating that its member states install governmental or private bodies charged with the enforcement of accounting standards. These enforcement mechanisms significantly vary in structure, responsibilities, rights and budgets across countries. However, in most cases, they are charged with reviewing already audited financial statements and publishing the errors found therein. The publication of error announcements serves the "name and shame" purpose of enforcement. Error announcements are associated with significant negative market reactions for the respective firms (Hitz et al., 2012). This should create incentives for firm managers to avoid preparing erroneous financial statements in the first place and, hence, error announcements are believed to improve accounting quality and the consistency of IFRS application. Consequently, both IFRS adoption and the implementation of enforcement institutions in many countries around the world have significantly changed the financial reporting environment.

Prior literature provides a vast amount of evidence on capital market effects associated with enforcement, particularly with regard to substantive changes in enforcement or enforcement actions such as error announcements. Additionally, several studies investigating the capital market effects associated with IFRS adoption find that positive capital market effects are mainly found in jurisdictions with strong enforcement of accounting 
standards. For instance, Daske et al. (2008) find for a sample of 26 IFRS-adopting countries that market liquidity and equity valuations increase while firms' cost of capital decreases when IFRS are adopted. These beneficial capital market effects, however, only occurred in countries with strong legal enforcement. In a similar vein, H. B. Christensen et al. (2013) investigate the liquidity effects of IFRS adoption by examining a large sample of 56 IFRS-adopting and non-IFRS-adopting countries with and without substantive changes in enforcement regulation. They find significant positive liquidity effects only in those IFRS-adopting countries that, at the same time, implemented new enforcement institutions or strengthened already existing ones. Moreover, they find the same positive effects in countries that did not adopt IFRS but that had substantive enforcement changes. Hence, the positive capital market effects of enforcement are well established.

In addition to capital market effects, enforcement also has direct effects on the decision making of involved stakeholders such as managers, auditors and investors. Such direct effects might, at least to some degree, drive capital market effects. It is therefore important that they are investigated to understand what is observed in capital markets. For instance, Ernstberger et al. (2012) find that the introduction of a two-tier enforcement mechanism in Germany in 2005 led to decreasing levels of earnings management. This represents a direct effect of enforcement on managers' decisions and an improvement of accounting quality.

However, most studies on the impact of enforcement on stakeholders' decision making are found to investigate the effects of enforcement actions such as error announcements. As error announcements result in significant negative market reactions for the censured firms (Hitz et al., 2012), enforcement reviews are likely to put increased pressure on managers and auditors as they may be blamed for a review's negative outcome. In fact, prior studies find increased turnover of top management (e.g., Arthaud-Day et al., 2006; Collins et al., 2009; Desai et al., 2006; Land, 2010; Wang and Chou, 2011), members of the board of directors (Johnstone et al., 2011) and audit committee members (Srinivasan, 2005; Carver, 2014) at the censured firms following enforcement actions. Moreover, Mande and Son (2012) and Brocard et al. (2018) find that firms are more likely to change audit firms after censure by an enforcement institution.

While many studies have been conducted on the impact of enforcement on the decision making of stakeholders (e.g., managers) after an error announcement, little is known about the direct effects on their decision making when enforcement reviews are still under 
way and the outcome is not yet certain. I aim to provide exploratory evidence on this matter with this thesis. Specifically, in a novel angle of enforcement research, I examine managerial disclosure decisions pertaining to ongoing and concluded enforcement reviews. In addition, I aim to add more evidence to the streams of literature on the direct effects of the presence of enforcement bodies and of substantive changes in enforcement on accounting properties (e.g., Ernstberger et al., 2012). In that vein, I focus on investigating the association between enforcement and accounting choices by both managers and auditors.

\subsection{Objectives and structure of the thesis}

As outlined in the previous section, the adoption of IFRS and the implementation of enforcement mechanisms in many countries around the world significantly changed the financial reporting environment. These developments are investigated in broad literature streams and, interestingly, most positive capital market effects associated with IFRS adoption are predominantly found in countries with strong legal enforcement or in conjunction with substantive changes in enforcement (e.g., Daske et al., 2008; H. B. Christensen et al., 2013). Hence, I focus on enforcement in this thesis and aim to supply more insights into this seemingly important supportive channel of IFRS adoption. I aim to investigate the direct effects of enforcement on stakeholders' decision making, as these might be the very effects that partly drive capital market effects. I believe that it is especially fruitful to examine the effects on the decision making of managers and auditors. These particular stakeholders prepare and audit financial statements and therefore have a direct impact on accounting quality. Specifically, the objectives of this thesis are to: (1) document the role of ongoing and concluded enforcement reviews in managerial decisions with respect to voluntary disclosure; (2) test whether auditors employ more conservative decision making when the likelihood of an enforcement review is high; and (3) test whether accounting, on average, becomes more conservative following substantive changes in enforcement regulation.

My thesis consists of three studies that use different methodological approaches to investigate the role of enforcement scrutiny in the decision making of financial statement preparers and auditors. The first study, "Firm Disclosures about Enforcement Reviews", examines managers' voluntary disclosures in their firms' annual reports about ongoing and concluded enforcement reviews in the German setting. The objective of this exploratory and mainly descriptive study is primarily to establish the existence of such managerial 
disclosures of enforcement reviews and to test whether the decision to voluntarily disclose enforcement reviews is driven by specific strategic considerations. Hence, the study specifically investigates the influence of enforcement on managerial decisions. The second study, "Auditor Conservatism in the Presence of Financial Reporting Enforcement”, uses an experimental design to test whether auditors employ more conservative decision making when the likelihood of being reviewed by an enforcement body is high. Finally, the third and last study, "The Role of Enforcement in Shaping Conservative Accounting Choices", utilises a broad cross-country setting with staggered changes in enforcement regulation in an archival empirical approach. The objective addressed in this study is to investigate whether accounting, on average, becomes more conservative after substantive changes in enforcement have occurred. This would indicate more conservative decision making by financial statement preparers. Figure 1.1 outlines the overall aim of my thesis, its specific objectives and how they are addressed in the included studies.

In conjunction, the three studies included in this thesis provide an overview of the role played by enforcement institutions in the decision making of managers and auditors. The second and the third study focus on the conservatism of auditors and managers, while the first study explores managers' voluntary disclosure about enforcement reviews. Such voluntary disclosure could serve as a potential substitute for conservatism (Gietzmann and Trombetta, 2003; Hui et al., 2009). The first study follows an exploratory and mainly descriptive approach in order to show what steps are openly taken by managers as a response to enforcement. The experimental approach of the second study then supplies internal validity to the thesis by investigating auditors' decisions in an audit case where only the likelihood of an enforcement review is manipulated. Finally, external validity of the thesis is achieved with the archival empirical approach taken in the third study where the association between enforcement and accounting conservatism is examined in a broad cross-country setting. 
Figure 1.1: Objectives and structure of the thesis

\begin{abstract}
Aim: The aim of this thesis is to investigate the role that enforcement plays in the decision making of financial statement preparers and auditors. Specifically, it aims to examine whether both managers and auditors would make more conservative decisions as a response to enforcement scrutiny.
\end{abstract}

\section{Objective 1:}

Document the role of ongoing and concluded enforcement reviews in managerial decisions with respect to voluntary disclosure

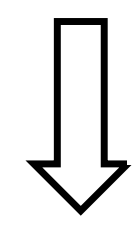

Descriptive approach

\section{Study 1:}

"Firm Disclosures about Enforcement Reviews" (Co-author: Jörg-Markus Hitz)

- Examines managers' voluntary disclosure of enforcement reviews in the German setting

- Finds weak evidence that voluntary disclosure is an efficient means to walk down market expectations

Forthcoming: Accounting in Europe

\section{Objective 2:}

Test whether auditors employ more conservative decision making when the likelihood of being reviewed by an enforcement institution is high

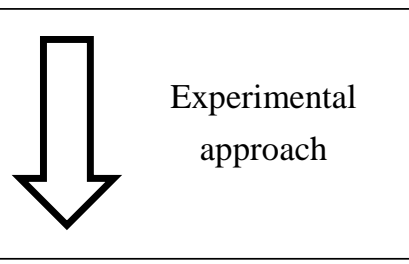

Study 2:

"Auditor Conservatism in the Presence of Financial Reporting Enforcement" (Coauthor: Andreas Hellmann)

- Regards auditors' conservatism in an experiment with 72 auditors

- Higher enforcement review likelihood is not associated with more conservative decision making by auditors

Revise \& Resubmit: The International Journal of Auditing

\section{Objective 3:}

Test whether accounting, on average, becomes more conservative after substantive changes in enforcement

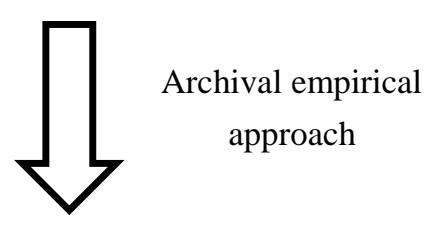

Study 3:

"The Role of Enforcement in Shaping Conservative Accounting Choices" (Singleauthor paper)

- Investigates a broad cross-country setting with staggered substantive enforcement changes

- Enforcement is associated with accounting conservatism

Working Paper 
In the following paragraphs, I elaborate on the three specific research objectives followed in this thesis and how they are addressed in the respective studies.

\section{Study 1: Firm Disclosures about Enforcement Reviews (Chapter 2)}

Voluntary disclosure is always associated with costs. These costs include direct costs of the preparation and publication of disclosure as well as indirect costs such as proprietary costs which occur when market participants, such as competitors, use the information contained in the disclosure for their advantage (Wagenhofer, 1990). Hence, managers will only engage in voluntary disclosure if its benefits outweigh these costs (e.g., Depoers, 2000). Intuitively, managers have incentives to voluntarily disclose good news. For instance, Lev and Penman (1990) find that managers make good news disclosures when their firms are doing well in order to distinguish themselves from poorly performing firms. Moreover, incentives also exist to voluntarily disclose bad news (Skinner, 1994). In some cases, it might be sensible for managers to pre-emptively disclose bad news to partly bring negative market reactions to the bad news forward by walking down market expectations.

Hitz et al. (2012) show that error announcements equal bad news to investors as they result in significant negative capital market effects. Error announcements represent mandatory disclosures imposed by enforcement institutions. As soon as a firm's financial statements are under review by an enforcement body, the managers will most likely be under increased pressure as the possibility of an error announcement becomes obvious. Thus, they will consider the costs and benefits of informing investors about the ongoing enforcement review through voluntary disclosure. Disclosure theory holds that managers have a number of potential incentives to disclose information about ongoing enforcement reviews. Consequently, the first study of this thesis aims to, firstly, establish the existence of such voluntary disclosures and, secondly, investigate in what manner and with what potential strategic reasoning managers carry out such disclosures. Thus, the study focuses on the role played by ongoing and concluded enforcement reviews in managerial decisions with respect to voluntary disclosure. 
Study 2: Auditor Conservatism in the Presence of Financial Reporting Enforcement (Chapter 3)

Auditors' decision-making behaviour, in general, and their conservatism, in particular, are influenced by a variety of external factors. As auditor conservatism has a direct impact on reporting choices in the financial statements under audit (Hackenbrack and Nelson, 1996), it is relevant to broaden the understanding of what drives auditor conservatism.

Mora and Walker (2015) define conservatism as "the inclusion of a degree of caution in the exercise of the judgements needed in making the estimates required under conditions of uncertainty". Prior literature provides several factors that seemingly increase auditors' willingness to include a higher degree of caution. To be specific, the most important factors that drive auditors' decision-making behaviour and that could potentially induce higher caution are accountability (e.g., Lord, 1992; Johnson and Kaplan, 1991); risk of client loss (e.g., Nelson and Kinney Jr, 1997); reputation risk (e.g., Rich et al., 1997; Skinner and Srinivasan, 2012); and litigation risk (e.g., Kida, 1980; Krishnan and Krishnan, 1997). As enforcement is connected to all of these factors, this could indicate that a high likelihood of being subject to an enforcement review will lead auditors to employ more conservatism. This research question is addressed in the second study of this thesis. Moreover, this experimental study examines whether past experiences with enforcement reviews will lead auditors to employ more conservatism and whether higher-rank auditors are more profoundly influenced in their decision making than lower-rank auditors.

Study 3: The Role of Enforcement in Shaping Conservative Accounting Choices (Chapter 4)

Regulation (EC) No. 1606/2002 required EU member states to impose IFRS adoption on firms listed in EU-regulated market segments as of 2005. Moreover, EU member states were required to implement enforcement institutions to enforce correct and consistent IFRS application. This is one of many examples of IFRS adoption and substantive changes in enforcement. Many other countries around the world enacted similar regulations and these events and their consequences have been extensively studied ever since. However, while a large amount of evidence is available with regard to capital market effects associated with IFRS adoption and substantive enforcement changes (Brüggemann et al., 2013), evidence of the influence on accounting properties, such as conservatism, is scarce and quite inconclusive (Leuz and Wysocki, 2016; Hitz et al., 2018). 
Conservatism theory (Watts, 2003a) as well as agency theory (Jensen and Meckling, 1976) in conjunction with prior literature hint at enforcement being a potential driver of accounting conservatism. Hence, substantive changes in enforcement should, in theory, increase accounting conservatism. This is important as conservatism "is critical to constraining manipulation and fraud" (Watts, 2003b). My third and final study aims to investigate this specific research question in a broad cross-country setting with staggered substantive changes in enforcement, and thereby add to the scarce and inconclusive literature stream on the effects of enforcement on managerial accounting choices which effectively translate into accounting properties.

\subsection{Summary of the thesis}

The thesis comprises three studies on the direct effects of enforcement on the decision making of financial statement preparers and auditors. The first study examines voluntary disclosures of firm managers about ongoing and concluded enforcement reviews (Chapter 2). The second study uses an experimental design to investigate whether auditors employ more conservative decision making when the likelihood of being subject to an enforcement review is high (Chapter 3). Finally, the third study of this thesis utilises a broad cross-country setting to investigate the role played by substantive changes in enforcement regulation in shaping conservative accounting choices (Chapter 4).

\section{Study 1: Firm Disclosures about Enforcement Reviews (Chapter 2)}

The first study examines the existence, determinants and potential strategic incentives of voluntary firm disclosures about ongoing and concluded enforcement reviews. In the German institutional environment, the two-tier enforcement mechanism is quite active and rather transparent, allowing for the desired analyses. It is mandated that firms disclose error announcements once the enforcement institutions establish that their financial statements contain material errors. Hence, mandatory disclosure of enforcement reviews only exists when enforcement bodies find erroneous accounting.

However, strategic incentives may exist for firm managers to inform investors about ongoing enforcement reviews for several reasons. Without taking into account the likelihood of an adverse outcome of the enforcement review, voluntary disclosure of the review could serve as an attempt to signal the managers' commitment to transparency and, consequently, their management quality (e.g., Hughes, 1986; Teoh and Hwang, 1991; Wang 
et al., 2008). As increased transparency reduces information risk, which is priced, investors may value such commitment (R. Lambert et al., 2007). Moreover, if managers think that it is unlikely that an enforcement institution will censure them, they may want to disclose information about the review to show their confidence and hence signal the high quality of their financial reporting (Trueman, 1986). Lastly and potentially most importantly, managers also have incentives to inform investors about ongoing enforcement reviews when they deem the risk of being censured to be high. For instance, this could serve as a means to manage and walk down market expectations (Skinner, 1994). By preparing the market for future adverse news, potentially the market impact of an error announcement could be softened. Additionally, managers could strategically time the disclosure of the ongoing review together with unrelated good news to minimise the market impact (Acharya et al., 2011; Beyer et al., 2010).

In an exploratory and mainly descriptive approach, this study conducts content analyses of all annual reports published by firms subject to the German enforcement mechanism from 2006 to 2016 in order to identify those firms that decided to opt for this as yet unexplored means of disclosure. Moreover, multivariate analyses are carried out to investigate determinants of the decision to undertake voluntary disclosure with regard to ongoing enforcement reviews. Using event study methodology, this study also examines whether pre-emptive disclosures on ongoing reviews that eventually resulted in error findings help to mitigate future negative market reactions to the error announcements.

The study finds that firms do, in fact, disclose information about enforcement reviews. While disclosures of ongoing enforcement reviews are a rather rare phenomenon (one out of 13 cases), disclosures of concluded reviews occur more frequently (one out of four cases). Content analyses provide evidence that the format of disclosures about ongoing enforcement reviews is potentially associated with the eventual outcome of the review, which is in line with managers using these disclosures in a strategic manner. The multivariate analyses support this notion as such disclosures appear to be more likely for contentious reviews. The study provides weak evidence that market reactions to error announcements are mitigated by pre-emptive voluntary disclosure of ongoing reviews. Taken together, the findings of this study show that managers deem enforcement reviews to be associated with certain risks and they believe it to be reasonable to inform investors 
about ongoing reviews that they expect to result in error findings. Hence, ongoing enforcement reviews have a direct effect on managers' decision making with respect to voluntary disclosure.

Study 2: Auditor Conservatism in the Presence of Financial Reporting Enforcement (Chapter 3)

The second study investigates how enforcement scrutiny influences auditors' decision making. More specifically, it examines whether auditors make more conservative decisions when the likelihood of being subject to an enforcement review is high. As enforcement bodies review firms' financial statements that have already been audited, enforcement scrutiny is likely to put pressure not only on firm managers but also on auditors.

Prior literature shows that firms are more likely to switch audit firms after error announcements have occurred (Brocard et al., 2018). This risk may lead auditors to employ more conservative decision making with respect to accounting choices. Consequently, the second study examines this research question by carrying out an experiment with 72 practising auditors. In the experiment, the auditors are confronted with an audit case on the recognition of provisions for possible litigation costs. Towards the end of the experiment, they must decide whether to require the fictitious client to recognise a provision for litigation costs (more conservative accounting choice) or to disclose a contingent liability in the notes (more aggressive accounting choice). Moreover, this study investigates whether auditors affected by enforcement reviews in the past are more likely to make conservative decisions and whether higher-rank auditors are more affected by the enforcement review likelihood than lower-rank auditors.

The study's findings suggest that auditors already employ fairly conservative decision making in the first place and are not significantly influenced by the likelihood of an enforcement review. However, those auditors affected by enforcement reviews in the past are more likely to opt for the conservative accounting choice irrespective of the current enforcement review likelihood. The study does not find evidence in support of higherrank auditors being more affected than lower-rank auditors by the enforcement review likelihood.

In conclusion, the increased likelihood of an enforcement review itself does not exert sufficient pressure on auditors for them to become more conservative. Once an auditor 
has actually been affected by an enforcement review in their professional career, they become more aware of the actual risks associated with enforcement and, in the future, are more likely to employ more conservative decision making. Hence, according to these results, enforcement significantly influences auditors' decisions only once they have been directly confronted with enforcement themselves.

Study 3: The Role of Enforcement in Shaping Conservative Accounting Choices (Chapter 4)

The third and final study investigates whether substantive changes in enforcement regulation lead to higher levels of accounting conservatism in a broad cross-country setting. This would indicate a direct effect of enforcement on the decision making of managers who prepare the financial statements and potentially also on the auditors involved. Both conservatism theory (Watts, 2003a) and agency theory (Jensen and Meckling, 1976) support the hypothesis of increasing conservatism following changes in enforcement regulation.

Using parts of H. B. Christensen et al.'s (2013) identification strategy allows this study to utilise a rich setting of staggered changes in enforcement in 56 IFRS-adopting and nonIFRS-adopting countries around the globe. Conservatism is measured by C_Score, a firmyear measure developed by Khan and Watts (2009) and based on Basu (1997). By carrying out multivariate analyses for a set of different country and control groups, this study supplies evidence on whether enforcement increases accounting conservatism. Furthermore, the study examines whether a firm's corporate governance strength has an influence on the effect enforcement may have on conditional conservatism.

The study, in fact, finds that substantive changes in enforcement regulation are associated with increasing levels of accounting conservatism. These findings, however, only hold for a sample of non-IFRS-adopting countries. Moreover, enforcement's effect on conservatism is predominant in firms with weak corporate governance.

In conclusion, these results represent and constitute direct effects of enforcement on the decision making of firm managers and potentially also on auditors with respect to the preparation of financial statements. Moreover, these findings can be understood in a potentially more meaningful way. García Lara et al. $(2011,2014,2016)$ show that conservatism supports efficient capital allocation, and reduces information asymmetry and the 
cost of capital. As enforcement seems to increase conservatism, it may well be a significant supportive channel for the achievement of the stated positive capital market effects. 


\title{
2 Firm Disclosures about Enforcement Reviews
}

Jörg-Markus Hitz and Henning Schnack ${ }^{1,2}$

Accounting in Europe (Forthcoming) ${ }^{3}$

\begin{abstract}
This paper provides descriptive evidence on voluntary firm disclosures related to enforcement reviews. Our analyses are set in the German institutional environment, where firms are mandated to disclose error announcements if enforcement institutions, after conclusion of the review, formally establish financial statements to contain material errors. We find that firms provide voluntary disclosures about ongoing enforcement reviews on rare occasions while they opt to disclose information about concluded reviews more frequently. Content analyses reveal that the format of disclosures about ongoing reviews is potentially associated with the eventual review outcome, which is consistent with firms deliberately using these disclosures. This interpretation is supported by additional multivariate analyses of disclosures relating to ongoing reviews, which turn out more likely for contentious reviews. Analysis of market reactions provides weak evidence that investors price these disclosures, as negative market responses to the disclosure of error findings are mitigated. Hence, our paper provides a novel angle on the growing literature on accounting enforcement and yields insights into firm-level incentives for strategic disclosures.
\end{abstract}

JEL Classification: C21, G34, M41

Keywords: enforcement, disclosure incentives, strategic disclosure

Acknowledgements: For helpful comments and suggestions, we thank an anonymous reviewer, the associate editor, Stephanie Müller-Bloch, participants at the 40th EAA Annual Congress in Valencia, Spain in May 2017 and at the Macquarie University Conference on Contemporary Accounting Research in Sydney, Australia, in March 2017. For valuable research assistance, we thank Anna Schlüter and Viktoria Schefer. All remaining errors are our own.

1 Georg-August Universität Göttingen, Faculty of Economic Sciences, Chair of Accounting and Auditing, Platz der Göttinger Sieben 3, 37073 Göttingen, Germany.

2 This study was conducted in cooperation with Jörg-Markus Hitz.

3 The Version of Record of this manuscript has been published and is available in Accounting in Europe 2018: https://www.tandfonline.com/doi/abs/10.1080/17449480.2018.1519320. 


\subsection{Introduction}

This paper presents exploratory empirical evidence on firms' disclosure choices pertaining to pending or concluded investigations by enforcement authorities. A growing body of literature provides evidence that "enforcement matters", that is, the introduction of enforcement bodies in charge of reviewing financial statements, for example, in member states of the European Union, has substantially altered the reporting environment and firm-level disclosure incentives. For example, H. B. Christensen et al. (2013) show that the introduction of IFRS for listed firms in the European Union coincided with significant positive capital market effects (increases in liquidity), particularly in those EU member states which had concurrently implemented the mandate to install enforcement institutions. The finding of positive capital market effects is consistent with increased transparency, or quality of disclosures, suggesting that incentives for managers to provide compliant, high quality financial statements may have increased under the auspices of enforcement institutions. Consistent with this, Hitz et al. (2012) find evidence that capital market participants, on average, react negatively to the disclosure of error findings established by enforcement institutions in Germany. This finding illustrates the potential effectiveness of the "name and shame" mechanism, which aims at providing capital market deterrence for managers to abstain from reporting misconduct. Taken together, this literature demonstrates that the activities of enforcement institutions are one out of many factors shaping reporting incentives by managers.

Interestingly, no paper has so far investigated firms' reporting choices with respect to enforcement activities as such. Given the documented relevance of enforcement for capital market and reporting outcomes, information on both ongoing enforcement activities and on past reviews may be of interest to market participants. This renders said information a potentially relevant object for firm disclosure choices. For example, firms may voluntarily decide to divulge information on an ongoing investigation in order to prepare markets for a potentially adverse outcome. Also, firms may regard an enforcement investigation that was concluded with no error finding as a signal of good accounting quality, which they may want to share with the investment public.

Given the void in the extant literature on enforcement, our paper provides exploratory evidence on enforcement disclosures. In our main analyses, we employ content analysis of one major disclosure outlet, the annual report, to take stock of firm disclosures about 
ongoing and concluded enforcement investigations, thereby shedding light on the pervasiveness or relevance of these disclosures, and their characteristics. In additional analyses, we focus on disclosures related to ongoing enforcement reviews and their underlying objectives. First, we use a determinants analysis to compare characteristics of disclosure firms with firms that exerted their "right to remain silent". Second, we include into our analyses the capital market perspective, to investigate whether disclosures about ongoing reviews potentially mitigate the market impact of an eventual error announcement.

We stage our analyses in the German setting, where enforcement institutions are both quite active and relatively transparent. Our first set of analyses is based on a keyword search of all annual reports published by firms that were subject to enforcement during the period 2006-2016, to identify firms that chose to disclose information about ongoing or concluded enforcement reviews. We find that voluntary enforcement disclosures do indeed occur. Firms decide to provide disclosures about ongoing enforcement reviews in about one out of 13 cases ( $7.5 \%$ ), while they opt to disclose information about concluded reviews more frequently, in roughly one out of four cases (24.0\%). These proportions are comparatively larger for firms that were eventually censured for erroneous reporting. Content analyses reveal that disclosures about ongoing reviews differ substantially with respect to volume, disclosure location and the board tier responsible for disclosure when conditioning on the outcome of the review (error finding, no error finding). Also, compared to reviews that are not covered in annual reports, enforcement reviews that are subject to disclosure are, on average, longer in duration, and do more often result in errors that were established by the securities regulator, which indicates particularly contentious reviews. These findings indicate that users of financial statements may glean relevant information about potential outcomes of ongoing reviews from analysing pertinent disclosures. Moreover, this evidence is broadly consistent with managers using enforcementrelated disclosures in a deliberate manner to convey information to market participants.

Our first set of additional analyses reveals that the probability for firms to opt for voluntary disclosure about an ongoing review increases when the review is relatively contentious (i.e., it was taken over by the securities regulator BaFin). In contrast, there is no evidence that the severity of the error is associated with the disclosure decision. This may hint at deliberate disclosures by the respective firms, potentially to reveal to the market their assessment of the likelihood of an error finding. Also, we do not find evidence that 
firms with positive earnings surprises systematically opt for or against enforcement-related disclosure. Hence, our findings provide no evidence that firms strategically attempt to "hide" bad news.

Our second set of additional analyses investigates market reactions to error announcements in order to further explore one particular disclosure motive: preparing the market for "bad news". We corroborate prior findings of average negative market reactions to disclosure of error findings established by enforcers. However, consistent with enforcement-related disclosures being priced, we find weak evidence that the market reactions are smaller when firms embraced their right "not to remain silent" while the review was under way, hence mitigating the impact of an eventual adverse review outcome.

While descriptive in nature, our findings are important as they identify a disclosure choice that a substantial number of firms deliberately embrace. Hence, we contribute to the literature on strategic disclosures. Also, we provide an additional angle on the literature on the enforcement of accounting standards. Finally, our results should be of interest to regulators and managers too, as they alert to motives and potential consequences of a disclosure choice that so far has received little attention.

The remainder of the paper is structured as follows. Sections 2.2 and 2.3 provide background information on the German enforcement setting and the theoretical background, respectively. Section 2.4 reports findings from the content analysis of enforcement-related disclosures, while Section 2.5 focuses on determinants and consequences of ex ante disclosures of ongoing enforcement reviews. Section 2.6 concludes.

\subsection{Background: Enforcement of IFRS in Germany}

The German enforcement system was legally established in 2004 and went into operation in June 2005. Establishing this mechanism was a direct response to the European Union's Regulation (EC) No. 1606/2002, widely known as the IAS Regulation, which requires firms listed on regulated stock markets of its member states to prepare financial statements under International Financial Reporting Standards (IFRS) as of January 1st 2005. Paragraph 16 of the IAS Regulation states that member states should create enforcement mechanisms that secure the correct application of IFRS. The German enforcement mechanism is organised in a two-tier structure, and consists of a private body called Deutsche Prüfstelle für Rechnungslegung e.V. (DPR), the Financial Reporting Enforcement Panel 
(FREP) on the first tier, and the federal securities regulator Bundesanstalt für Finanzdienstleistungsaufsicht (BaFin) on the second tier. Subject to enforcement oversight are all recent (individual and consolidated) annual financial statements and the management reports of firms publicly traded on an EU-regulated stock exchange. In 2007, Germany adopted legislation to incorporate the EU transparency directive. Ever since then, interim financial statements have also been subject to the enforcement mechanism's scrutiny, yet upon indication only.

On the first level of the two-tier structure of this enforcement system, the FREP conducts reviews of recently published financial statements either (a) reactively, that is, as a result of specific indications by third parties, or gleaned from the media, or upon request by the securities regulator BaFin, or (b) proactively, based on random / risk based sampling (Hitz et al., 2012). The FREP's mandate is to review financial statements and conclude whether they contain material errors. If the review follows third party indications, the FREP focuses on the specific treatment suspected to be erroneous. In contrast, random reviews typically have a broader scope and focus on firm-specific issues that hold a significant error risk. To that end, FREP releases on an annual basis a list of relevant accounting issues that their random-sampling investigations will focus on in the following year. This list also adopts the very fields that the European securities regulator ESMA identifies for enforcement scrutiny.

Firms under review are expected to provide any pertinent information requested by FREP, such as the long-form report and the summary of unadjusted audit differences (Berger, 2010). If the firm refuses to cooperate, the case will be directly referred to the second tier institution of the enforcement mechanism, the securities regulator BaFin. In cases where the FREP concludes that the financial reports contain one or more material errors, the firm may decide whether it agrees with the FREP's decision or not.

As the second tier institution of the German enforcement mechanism, the securities regulator BaFin carries out its own investigations in cases where firms do not cooperate with FREP, or, more importantly, in cases where firms contest an error finding established by FREP. For any error finding established by either FREP or by BaFin, the securities regulator enacts disclosure of error findings. To that end, BaFin orders firms to publish error findings via specific press releases on the electronic platform of the federal registry (Bundesanzeiger) and in at least two daily financial newspapers. This disclosure regime is at the heart of the German enforcement mechanism, which relies on adverse publicity to 
effect market based penalties such as negative stock price reactions ("name and shame", see Hitz et al., 2012).

One important feature of the German enforcement mechanism is that any reviews under way, either by the FREP or by BaFin, are conducted without notification of the public. Both institutions are legally bound to secrecy about any ongoing or concluded review. Hence, the only mandatory channel of disclosure of firm-level information on enforcement action is the mandatory disclosure of an error finding upon conclusion of a review.

In its annual activity report, the FREP periodically informs on review activities and outcomes. From these reports, it can be gleaned that since its introduction in 2005, the German enforcement mechanism has, on average, reviewed financial statements of more than a hundred firms per year, which represents a significant fraction of Germany's publicly traded firms. As of 2016, with the enforcement mechanism being in place for twelve years, these numbers add up to 1,239 concluded reviews, out of which roughly $90 \%$ $(1,111)$ are based on random reviews. Out of the total number of reviews performed, roughly one out of five resulted in the disclosure of an error finding (247, or 19.9\%), with a declining trend in recent years.

\subsection{Theoretical background: Voluntary disclosures about enforcement reviews}

As outlined in the previous section, the activities of the German enforcement institutions entail mandatory disclosures for firms that, upon conclusion of the review, have been found to have prepared erroneous financial statements. Hence, the disclosure framework does not mandate any disclosure of ongoing reviews, nor of reviews that have been concluded without an error finding. As a result, only a small fraction of enforcement activities is observable. Figure 1 illustrates how this disclosure environment creates two potential points or periods in time where firms may decide to voluntarily disclose information on enforcement activities: while the review is under way or after conclusion of the review. Distinguishing reviews which eventually resulted in observable enforcement action, as documented by the publication of an error finding, results in a total of four types of enforcement-related disclosures (Figure 1). Note that only after the conclusion of a review that resulted in an error finding are firms mandated to divulge the fact that they have been subject to an enforcement review (type III in Figure 1). Yet, even in those cases, managers may decide to voluntarily report supplementary information via disclosure channels other 
than the error announcement. For example, while the format of an error finding is mandated by the securities regulator, a firm may decide to report on the error finding, for instance, in the annual report, and provide supplemental information, such as how the error has been addressed, or whether the firm agrees with the error finding.

Figure 2.1: Taxonomy of enforcement-related disclosures

\begin{tabular}{|l|l|l|}
\hline & \multicolumn{1}{|c|}{ Ongoing review } & \multicolumn{1}{c|}{ Concluded review } \\
\hline Error finding & I: Voluntary disclosure & III: Mandatory disclosure \\
\hline No error finding & II: Voluntary disclosure & IV: Voluntary disclosure \\
\hline
\end{tabular}

This figure identifies four principal cases of voluntary disclosures about enforcement reviews, by (1) differentiating disclosures about ongoing reviews from disclosures about concluded reviews, and (2) differentiating reviews that resulted in an error finding from those that did not.

In the remainder of this section, we briefly discuss potential disclosure incentives for the various classes of voluntary disclosures about enforcement reviews, pointing out potential firm-level perspectives on the "right not to remain silent". First, we address incentives to divulge details on ongoing review activities (disclosure types I \& II, Figure 1). Naturally, firm managers are not only informed of the ongoing review. The review is conducted as a communication between the enforcer and the firm, based mostly on written correspondence, and managers involved will typically have an idea of the quality of their financial statements and any potential errors they contain. Hence, as the review proceeds, the managers will form their own assessment of the likelihood that enforcers will eventually establish errors. This is a piece of private information which is of potential relevance to firm outsiders such as investors, and managers may strategically decide whether and how to disclose it.

Disclosure theory suggests various incentives for firms to disclose or to withhold information about ongoing enforcement reviews. For one thing, managers may decide to inform the market of an ongoing enforcement review, in an attempt to signal their commitment to transparency and hence their management quality (e.g., Hughes, 1986; Teoh and Hwang, 1991; Wang et al., 2008). Investors may value such a commitment, as increased 
transparency reduces information risk, which is priced (R. Lambert et al., 2007). A related motive may be signalling (Trueman, 1986), that is, the attempt by managers to shape their disclosure in a way that credibly conveys their private assessment of a low risk of an adverse outcome of the enforcement review.

Managers may also have incentives to inform markets about ongoing enforcement reviews when the risk of getting censured by enforcement institutions is high. For one thing, managers may attempt to manage market expectations, that is, to prepare the market for a potential adverse outcome, in order to "soften" the market impact of an official error finding (Skinner, 1994). Also, managers may strategically time the disclosure of the pending review (Acharya et al., 2011; Beyer et al., 2010), to minimise market impact. For instance, if annual earnings turn out to exceed market expectations, managers may decide to factor into the earnings announcement or annual report information on the enforcement review with the expectation of investors being distracted by the earnings surprise, or putting more weight on the positive news (DeAngelo, 1988).

Once an enforcement investigation has been concluded without an adverse ruling, the firm also has the choice to divulge that information (disclosure type IV, Figure 1). As the majority of errors established by the German enforcement bodies pertain to financial statements with a qualified audit opinion, the information that an enforcement review has yielded no error findings potentially conveys additional information on the high quality of a firm's financial statements, and hence of its overall disclosures. Firms may hence decide to communicate that information in an attempt to reduce information asymmetry with investors.

Taken together, theoretical reasoning based on disclosure theory suggests that firms may decide to disclose information on ongoing enforcement reviews, or on a concluded investigation, based on firm-specific trade-offs of the potential costs and benefits of these disclosures. However, it is an open empirical question whether firms actually make such enforcement-related disclosures. We know of no prior literature investigating this question. Hence, in Section 2.4, we conduct an exploratory analysis using content analyses of annual reports to establish whether enforcement-related disclosures take place, to what extent, and in what shape. In additional analyses presented in Section 2.5, we then investigate whether observable enforcement-related disclosure choices vary in a systematic way that is consistent with some of the disclosure motives we have outlined. To that end, 
we first conduct a determinants analysis to infer characteristics of firms that opted to reveal details of an ongoing enforcement review, relative to firms that embraced their "right to silent" (Section 2.5.1). In a second set of analyses (Section 2.5.2), we then include the market perspective, using event study methodology to investigate whether disclosures related to ongoing enforcement reviews potentially mitigate market reactions to the eventual disclosure of error findings, consistent with the notion of walking down market expectations.

\subsection{Empirical evidence on enforcement-related disclosures}

Given the hitherto unexplored nature of enforcement-related disclosures, our first objective is to provide exploratory evidence whether disclosures about ongoing or concluded enforcement reviews take place, and, if so, investigate attributes of these disclosures. We focus our analysis on one important disclosure channel, the annual report, which includes both mandatory sections such as the annual financial statements and the management report, and voluntary sections containing, for example, the CEO's letter to shareholders, or additional financial and non-financial information.

\subsubsection{Sample selection and research design}

Panel A of Table 2.1 details the sample selection procedure for our content analysis of annual reports. We derive our sample of firms from the entire population of firms listed on EU-regulated stock market segments in Germany between 2006 and 2016 as these are the very firms whose financial statements are subject to enforcement scrutiny in the respective time frame. ${ }^{4}$ We identify sample firms based on coverage data which the securities regulator BaFin discloses on a yearly basis. This procedure yields a total of 9,613 firm year observations. We exclude firms domiciled outside Germany (1,672 observations) and firms that have listed debt securities only (676 observations). Also, 1,816 observations were eliminated because annual reports were not available, for instance, due to bankruptcies, or delistings. This procedure yields a final sample of 5,449 annual reports.

\footnotetext{
4 We exclude annual reports for the year 2005, as the enforcement mechanism went into operation only in
} the middle of the year, and only seven reviews were undertaken. 
Table 2.1: Sample selection

\begin{tabular}{|c|c|c|c|c|c|c|c|c|c|c|c|c|}
\hline \multicolumn{13}{|l|}{ Panel A: Sample for descriptive analyses } \\
\hline Year & 2006 & 2007 & 2008 & 2009 & 2010 & 2011 & 2012 & 2013 & 2014 & 2015 & 2016 & $\sum$ \\
\hline Based outside of Germany & 227 & 213 & 173 & 152 & 143 & 146 & 136 & 126 & 168 & 147 & 41 & 1672 \\
\hline No annual report (AR) available & 298 & 245 & 221 & 203 & 173 & 137 & 121 & 104 & 103 & 98 & 113 & 1816 \\
\hline Adjusted sample & 481 & 549 & 572 & 555 & 541 & 532 & 513 & 467 & 430 & 393 & 416 & 5449 \\
\hline \multicolumn{13}{|l|}{ Panel B: Sample for determinants analysis } \\
\hline Debt instruments & 0 & 1 & 2 & 2 & 0 & 1 & 3 & 0 & 1 & 0 & 0 & 10 \\
\hline Repetitive/corrective disclosure & 0 & 2 & 2 & 2 & 0 & 1 & 0 & 1 & 0 & 0 & 0 & 8 \\
\hline Respective AR not available & 2 & 9 & 5 & 6 & 2 & 4 & 4 & 0 & 0 & 3 & 0 & 35 \\
\hline Relevant error announcements & 19 & 21 & 25 & 8 & 27 & 19 & 9 & 9 & 11 & 9 & 15 & 172 \\
\hline Data missing for determinants analysis & 2 & 3 & 2 & 1 & 0 & 0 & 1 & 0 & 0 & 0 & 0 & 9 \\
\hline Relevant error announcements & 19 & 21 & 25 & 8 & 27 & 19 & 9 & 9 & 11 & 9 & 15 & 172 \\
\hline Data missing for event study & 5 & 5 & 8 & 5 & 1 & 1 & 1 & 2 & 1 & 2 & 0 & 33 \\
\hline Sample for event study & 14 & 16 & 17 & 3 & 26 & 18 & 8 & 7 & 10 & 7 & 15 & 139 \\
\hline Data missing for market based determinants model & 0 & 6 & 6 & 2 & 3 & 5 & 1 & 1 & 0 & 2 & 8 & 34 \\
\hline Sample for market based determinants model & 14 & 10 & 11 & 1 & 23 & 13 & 7 & 6 & 10 & 5 & 7 & 105 \\
\hline
\end{tabular}


Annual reports were collected from the websites of the respective firms. To identify enforcement-related disclosures, we conducted for each annual report an electronic keyword search using the following keywords related to enforcement investigations: "Enforcement", "review of financial statement" ("Bilanzkontrolle"), "Securities regulator" ("Bundesanstalt"), "BaFin", “review panel" ("Prüfstelle”), "FREP” (“DPR”), and "error" ("Fehler"). We then categorised enforcement-related disclosures according to the four categories outlined in Figure 1, that is, we established for each disclosure observation whether (1) it related to an ongoing review or a concluded review and whether (2) the review outcome was an error finding, or not. ${ }^{5}$ Hence, we also documented whether firms that were mandated to disclose error findings via error announcements (Type III firms, Figure 1) additionally chose to provide pertinent information or comments in their annual report.

\subsubsection{Frequency and types of enforcement-related disclosures}

Table 2.2 reports the findings on the (relative) frequency of enforcement-related disclosures. Panel A reveals that in 65 cases, firms chose to report about an enforcement review while it was still under way. In comparison, Panel B reports that in 207 cases, firms decided to include into their annual reports information about recently concluded enforcement reviews. In $28(16+12)$ out of these 207 cases, firms had previously provided disclosures about the review while it was still under way. This indicates that almost one out of two firms (28 out of 65) which decided to report about an ongoing review also provided disclosures upon conclusion of the review.

Compared to the number of 863 reviews conducted during the sample period, findings in Table 2.2 suggest that disclosures about concluded reviews do occur on a somewhat frequent basis (24.0\%), while disclosures on ongoing reviews represent more of a rare incident $(7.5 \%)$. While rare though, the descriptive findings suggest that disclosures about ongoing reviews to a comparatively high proportion relate to reviews that eventually result in enforcement actions documented by error findings, as the 26 observations represent $15.1 \%$ of all error reviews, while the 39 disclosure observations for non-error reviews represent only $5.6 \%$ of all non-error reviews.

5 Appendix A reports examples for each disclosure category. 
Table 2.2: Enforcement-related disclosures

\section{Panel A: Disclosures about ongoing reviews}

\begin{tabular}{|c|c|c|c|}
\hline & Disclosures & $\begin{array}{c}\text { Total } \\
\text { enforcement } \\
\text { reviews }\end{array}$ & Prop. \\
\hline Error finding & 26 & 172 & $15.1 \%$ \\
\hline No error finding & 39 & 691 & $5.6 \%$ \\
\hline Total & 65 & 863 & $7.5 \%$ \\
\hline \multicolumn{4}{|c|}{ Panel B: Disclosures about concluded reviews } \\
\hline & Disclosures & $\begin{array}{c}\text { Total } \\
\text { enforcement } \\
\text { reviews }\end{array}$ & Prop. \\
\hline Error finding & 98 & 172 & $57.0 \%$ \\
\hline $\begin{array}{l}\text { Out of which firms that already disclosed } \\
\text { about ongoing review }\end{array}$ & 16 & & \\
\hline No error finding & 109 & 691 & $15.8 \%$ \\
\hline $\begin{array}{l}\text { Out of which firms that already disclosed } \\
\text { about ongoing review }\end{array}$ & 12 & & \\
\hline Total & 207 & 863 & $24.0 \%$ \\
\hline \multicolumn{4}{|c|}{$\begin{array}{l}\text { This table displays the respective amounts of enforcement-related disclosures for the four disclosure cases } \\
\text { identified in Figure 1, and relates these amounts to the total number of enforcement reviews reported by } \\
\text { the German enforcer FREP. Panel A reports findings for disclosures about ongoing reviews, and Panel B } \\
\text { reports findings for disclosures about concluded reviews. Disclosure observations are gleaned from } \\
\text { content analysis of annual reports (see sample selection in Panel A of Table } 2.1 \text { ), and error announcements } \\
\text { are retrieved from the federal gazette (Panel B of Table 2.1). The number of } 691 \text { reviews with no error } \\
\text { finding represents an approximation which we make for reasons of comparability, as detailed data is not } \\
\text { available. We arrive at this number by taking the overall number of reviews with no error finding, which } \\
\text { FREP in its activity reports states at } 992 \text { for the period 2005-2016, and adjusting it to the number of error } \\
\text { announcements we use in our analyses (i.e., } 172 \text { out of } 247 \text {, or } 69.6 \% \text {, see Panel B of Table 2.1). }\end{array}$} \\
\hline
\end{tabular}

\subsubsection{Characteristics of enforcement-related disclosures}

In a second step, we perform several content analyses of the enforcement-related disclosures, and of the sub-sample of error announcements that relate to reviews on which disclosures were provided. Table 2.3 reports findings from analysing enforcement-related disclosures. With respect to the volume of these disclosures, Panel A reveals a substantial degree of variation in word count across all four disclosure categories. Disclosures by firms that were eventually censured are relatively larger on average, with a mean word count of 169 for disclosures on ongoing reviews (compared to 57 without an error finding), and a mean word count of 395 for disclosures about reviews concluded with an error finding (compared to 73 without an error finding). 
A detailed look at the respective narratives reveals that censured firms often repeat the detailed error findings as established by the enforcers, and how these findings were addressed, for example by restatements. On some occasions, firms also provide their own view on error findings, in particular when they feel the error finding was not substantiated. In contrast, non-censured firms in their disclosures do not have much scope for length, as their key message normally is confined to the very fact that a FREP / BaFin review took place without establishing errors, which as some firms note, speaks to the quality of the financial statements. For example, in its 2016 annual report, one firm, 4SC AG, notes: “The quality of 4SC's accounting is underpinned by a FREP review of fiscal year 2015 reports, which confirmed that the financial statements were correct". While purely anecdotal, this evidence supports the notion that one motive for disclosures about concluded enforcement action is to signal to the market the high quality of firms' financial reporting. 
Table 2.3: Content analyses: characteristics of voluntary enforcement disclosures

\section{Panel A: Volume (word count) of enforcement-related disclosures}

\begin{tabular}{|c|c|c|c|c|}
\hline & \multicolumn{2}{|c|}{ Ongoing review $(\mathrm{N}=65)$} & \multicolumn{2}{|c|}{$\begin{array}{c}\text { Concluded review } \\
(\mathbf{N}=207)\end{array}$} \\
\hline & $\begin{array}{c}\text { Average no. } \\
\text { of words }\end{array}$ & $\mathbf{N}$ & $\begin{array}{c}\text { Average no. } \\
\text { of words }\end{array}$ & $\mathbf{N}$ \\
\hline Error finding & 169 & 26 & 395 & 98 \\
\hline No error finding & 57 & 39 & 73 & 109 \\
\hline
\end{tabular}

\section{Panel B: Positioning of voluntary disclosure about enforcement reviews in the annual report}

\section{Ongoing review $(\mathrm{N}=65)$}

\section{Segment of annual report}

Mandatory disclosure

Report of the supervisory board

Management report

Notes

Corporate governance report

Voluntary disclosure

Foreword of the management board

Presentation of the firm

Total

\begin{tabular}{|c|c|}
\hline \multicolumn{2}{|c|}{ Error finding $(\mathrm{N}=26)$} \\
\hline Obs. & Prop. \\
\hline 36 & $100 \%$ \\
\hline 11 & $30.6 \%$ \\
\hline 13 & $36.1 \%$ \\
\hline 12 & $33.3 \%$ \\
\hline 0 & $0.0 \%$ \\
\hline 0 & $0.0 \%$ \\
\hline 0 & $0.0 \%$ \\
\hline 0 & $0.0 \%$ \\
\hline 36 & $100 \%$ \\
\hline
\end{tabular}

No error finding $(\mathrm{N}=39)$

Obs.

$\frac{\text { Obs. }}{42}$

Prop.

$100 \%$

$64.3 \%$

$19.0 \%$

$16.7 \%$

7

$\frac{0}{0}$

\begin{tabular}{l}
$0.0 \%$ \\
\hline $0.0 \%$ \\
\hline $0.0 \%$
\end{tabular}

$\begin{array}{ll}0 & 0.0 \% \\ 42 & 100 \%\end{array}$

\section{Concluded review $(\mathrm{N}=207)$}

\section{Error finding $(\mathrm{N}=98)$}

No error finding ( $N=109)$

\begin{tabular}{ccc}
\hline Obs. & & Prop. \\
\hline 158 & & $94.6 \%$ \\
\hline 37 & & $22.2 \%$ \\
52 & & $31.1 \%$ \\
68 & & $40.7 \%$
\end{tabular}

Obs. Prop.

$126 \quad 95.5 \%$

$33 \quad 25.0 \%$

$30 \quad 22.7 \%$

$1-0.6 \% \quad-\quad 7 \quad 5.3 \%$

$\frac{9}{8}-\frac{5.4 \%}{4.8 \%}-\frac{6}{6}-\frac{4.5 \%}{4.5 \%}$

\begin{tabular}{cccc}
1 & $0.6 \%$ & 0 & $0.0 \%$ \\
\hline 167 & $100 \%$ & 132 & $100 \%$ \\
\hline
\end{tabular}


Table 2.3 cont'd: Content analyses: characteristics of voluntary enforcement disclosures

\section{Panel C: Ex ante disclosure about enforcement reviews by board}

\begin{tabular}{|c|c|c|c|c|c|c|}
\hline & \multicolumn{6}{|c|}{ Ongoing reviews $(\mathrm{N}=65)$} \\
\hline & \multicolumn{3}{|c|}{ Error finding $(\mathrm{N}=26)$} & \multicolumn{3}{|c|}{ No error finding $(\mathrm{N}=39)$} \\
\hline & Obs. & Prop. & Average no. of words & Obs. & Prop. & Average no. of words \\
\hline Management board & 15 & $57.7 \%$ & 133 & 12 & $30.8 \%$ & 132 \\
\hline Supervisory board & 6 & $23.1 \%$ & 52 & 26 & $66.7 \%$ & 19 \\
\hline Both boards (MB/SB) & 5 & $19.2 \%$ & $364 / 58$ & 1 & $2.6 \%$ & $82 / 40$ \\
\hline \multirow[t]{4}{*}{ Total } & 26 & $100 \%$ & 169 & 39 & $100 \%$ & 57 \\
\hline & \multicolumn{6}{|c|}{ Concluded reviews $(\mathrm{N}=\mathbf{2 0 7})$} \\
\hline & \multicolumn{3}{|c|}{ Error finding $(\mathrm{N}=98)$} & \multicolumn{3}{|c|}{ No error finding $(\mathrm{N}=109)$} \\
\hline & Obs. & Prop. & Average no. of words & Obs. & Prop. & Average no. of words \\
\hline Management board & 61 & $62.2 \%$ & 380 & 53 & $48.6 \%$ & 89 \\
\hline Supervisory board & 11 & $11.2 \%$ & 60 & 45 & $41.3 \%$ & 38 \\
\hline Both boards (MB/SB) & 26 & $26.5 \%$ & $498 / 74$ & 11 & $10.1 \%$ & $106 / 26$ \\
\hline Total & 98 & $100 \%$ & 395 & 109 & $100 \%$ & 73 \\
\hline
\end{tabular}

This table reports findings from content analyses of annual reports and of the enforcement-related disclosures therein. Panel A reports average volume of enforcement-related disclosures, measured by the average number of words, for our four classes of disclosures. Panel B displays the positioning of the enforcement-related disclosures in the firms' annual reports. Note that the number of observations in Panel B exceeds the number of respective disclosures as reported in Table 2.2, as firms on several occasions provide disclosures on one particular enforcement review in more than one section of the annual report. Panel C breaks down enforcement-related disclosures to the originating management institution, the management board, the supervisory board, or both. 
Panel B of Table 2.3 provides a breakdown of enforcement-related disclosures to the subsections of the annual report. These findings essentially reflect managerial decisions where to locate the enforcement-related disclosures, in particular in terms of including these disclosures into mandatory or voluntary subsections or reports. From the findings in Panel B of Table 2.3 it can be gleaned that in the vast majority of cases, managers decided to include enforcement disclosures in the mandatory, audited sections of the annual report. Of a total of $377(36+42+167+132)$ disclosure observations, only $15(9+6)$, all of them relating to concluded reviews, were located in voluntary sections of the annual report. Also, the report of the supervisory board turns out to be an important disclosure channel to that end, in particular for firms that decided to inform on ongoing investigations that were eventually concluded without an error finding.

Panel C of Table 2.3 breaks down the disclosure observations according to the board tier that effected disclosure, management board, supervisory board, or both. In the German two-tier board system, executive board members are in charge of disclosure decisions and are responsible for preparing compliant financial statements. However, supervisory board members, who act as agents to shareholders and stakeholders, may also choose to divulge pertinent information, in the report of the supervisory board which has to be made publically available according to German disclosure regulation. We argue that it is important and potentially insightful to distinguish these two disclosure sources, as the disclosure incentives of the supervisory board may deviate from those of the executives, given that it is the task of the supervisory board to monitor executives and financial reports.

Findings in Panel C of Table 2.3 show that disclosure sources and content appear to vary substantially for the two groups of censured and uncensured firms. For disclosures about ongoing reviews, the findings suggest that the review outcome is somewhat correlated with the disclosure source. For disclosures about reviews that eventually result in unfavourable outcomes (i.e., error findings); it is the management board who will in the majority of cases decide to reveal this private information (15 out of 26 cases). In contrast, for firms that are subject to an ongoing review, but where managers appear to see little risk of an error finding, the executive board is more likely to stick to its "right to be silent" (in two out of three cases), while the supervisory board opts to briefly report on the ongoing review in 26 out of 39 cases observed.

Panel C of Table 2.3 also reveals some differences in the disclosure sources for concluded reviews, depending on the outcome. Unfavourable outcomes will in the majority of cases 
be solely reported by the management board (61 out of 98 observations), while disclosure sources are more balanced for reviews with no error finding, with 53 disclosures effected by the management board alone, 45 by the supervisory board, and 11 jointly.

\subsubsection{Characteristics of enforcement reviews subject to disclosure}

Table 2.4 reports results from analysing the content of error findings pertaining to enforcement reviews that were covered by firm disclosures, 26 of which related to ongoing reviews, and 98 related to concluded reviews. ${ }^{6}$ Panel A of Table 2.4 documents that the time lag between the release of the erroneous financial statement and the publication date of the error announcement is quite substantial for censured firms, with some indication that potentially, those reviews that firms decided to disclose to the market while they were still under way were particularly contentious, taking 677 days on average, compared to 566 days for reviews that were subject to firm disclosures only after the conclusion of the review, and 508 days for reviews that firms did not cover in their annual reports.

Table 2.4: Content analyses: characteristics of enforcement reviews subject to disclosure

\begin{tabular}{|c|c|c|c|}
\hline \multicolumn{4}{|c|}{ Panel A: Average length of review (in days) } \\
\hline & $\begin{array}{c}\text { Ongoing review } \\
\quad(\mathbf{N}=26)\end{array}$ & $\begin{array}{c}\text { Concluded review } \\
(\mathbf{N}=98)\end{array}$ & $\begin{array}{l}\text { Non-disclosure review } \\
(\mathrm{N}=48)\end{array}$ \\
\hline Error finding & 677 & 566 & 508 \\
\hline
\end{tabular}

\section{Panel B: Institution establishing error finding}

\section{Enforcement-related disclosures}

\begin{tabular}{|c|c|c|c|c|c|c|}
\hline & \multicolumn{2}{|c|}{$\begin{array}{c}\text { Ongoing review } \\
(\mathrm{N}=26)\end{array}$} & \multicolumn{2}{|c|}{$\begin{array}{c}\text { Concluded review } \\
(\mathrm{N}=98)\end{array}$} & \multicolumn{2}{|c|}{ findings $(\mathrm{N}=172)$} \\
\hline & Obs. & Prop. & Obs. & Prop. & Obs. & Prop. \\
\hline FREP & 14 & $53.8 \%$ & 78 & $79.6 \%$ & 130 & $75.6 \%$ \\
\hline BaFin & 12 & $46.2 \%$ & 20 & $20.4 \%$ & 42 & $24.4 \%$ \\
\hline Total & 26 & $100.0 \%$ & 98 & $100.0 \%$ & 172 & $100.0 \%$ \\
\hline
\end{tabular}

This table reports findings from content analyses of error findings that were established for reviews that firms decided to report about while the review was on the way, or after the conclusion of the review (disclosure classes I and III in Figure 1). Panel A displays the average length (in days) of the respective reviews, and Panel B reports which institution established the error finding, the enforcement panel FREP (first tier), or the securities regulator BaFin (second tier).

6 Note that out of the 26 error announcements related to ongoing reviews, 16 error announcements are also included into the sample of 98 error announcements that relate to disclosures about concluded reviews (see Panel B of Table 2.2). 
Panel B of Table 2.4 breaks down disclosures about enforcement reviews that resulted in an error finding according to the institution which established the finding, the FREP (first tier) or BaFin (second tier). As noted in Section 2.2, BaFin will typically undertake a review if a firm did not agree with an error finding by the FREP in the first place. Hence, errors established by BaFin are reflective of relatively contentious reviews. It can be gleaned from Panel B that for the entirety of error findings, only one out of four (42 out of 172 , or $24.4 \%$ ) was established by BaFin. In contrast, almost one out of two firms (12 out of 26 , or $46.2 \%$ ) that opted to report on ongoing reviews were eventually censured by BaFin, that is, they contested the initial findings of the FREP.

Taken together, our exploratory findings document that enforcement-related disclosures indeed take place, indicating that this not a solitary phenomenon confined to only a few firms. At the same time, we observe that informing about ongoing reviews is a relatively rare disclosure strategy. However, where firms decide to divulge information about ongoing reviews, the review outcome is more often contentious. Also, we find disclosures about ongoing reviews to differ substantially with respect to size and disclosure location, when conditioning on the outcome of the review (error finding, no error finding). This indicates that users of financial statements may glean relevant information about potential outcomes of ongoing reviews from analysing pertinent disclosures. Also, this evidence is broadly consistent with managers using enforcement-related disclosures in a deliberate manner to convey information to market participants. This notion is further explored in the following Section 2.5.

\subsection{Additional analyses of motives for disclosures about ongoing reviews}

In this section, we shed more light on the characteristics and potential motives of firms that choose to adopt the disclosure strategy of revealing to the market information about ongoing enforcement reviews, and investigate the market recognition of those disclosures. We conduct two sets of analyses: In Section 2.5.1, we conduct a determinants analysis to identify characteristics associated with disclosure decisions relating to ongoing enforcement reviews. In Section 2.5.2, we report and discuss findings from an event study analysis aiming to infer whether investors price prior enforcement-related disclosures upon announcements of erroneous financial statements. 
2.5.1 Factors associated with disclosure decisions about ongoing enforcement reviews

\subsubsection{Research design}

Our determinants analysis is motivated by the theoretical background in Section 2.3, as we attempt to investigate in the cross-section various characteristics that we expect to be associated with certain disclosure motives. We confine our analyses to the sample of disclosures about ongoing reviews because as outlined in Section 2.3, there are various potential costs and benefits, and hence motives associated with these disclosures. Also, given the observability of enforcement-related disclosures and of firms that were eventually censured for erroneous accounting, we are able to conduct more revealing empirical analyses. $^{7}$

We analyse the determinants of firms' disclosure decisions by estimating a logit regression model. Effectively, we determine whether and how certain firm and error characteristics are associated with the likelihood for a firm to disclose information about an ongoing enforcement review. Hence, this analysis compares the characteristics of type I firms in Figure 1 to those firms that were ultimately censured for erroneous accounting, but chose not to report about the review, that is, chose to "remain silent" while the review was under way. Panel B of Table 2.1 details how we arrive at the final sample of 163 error announcements (firm observations), which comprises 22 disclosure firms, and 141 non-disclosure firms. For this sample, we estimate versions of model (1):

$$
\begin{gathered}
\text { Disclosure }_{i t}=\text { Big }_{i t}+\text { BaFin }_{i t}+\text { Error Severity }_{i t}+ \\
{\text { Time } \text { Lag }_{i t}+\text { Earnings Surprise }_{i t}+}{\text { S } \text { Controls }_{i t}+\varepsilon}^{+}
\end{gathered}
$$

The dependent variable Disclosure equals one if a firm in a given year voluntarily discloses information about an ongoing enforcement review, and zero otherwise. We include

7 The principal obstacle to empirical analyses of enforcement actions or, in this case, enforcement disclosures, is the very fact that, unless firms decide to divulge details on a voluntary basis, markets only learn that a review has been conducted if it results in an error finding. Hence, the comparable group of firms that were subject to an enforcement review, yet decided not to reveal this to the public, is not observable. 
five test variables, Big 4, BaFin, Error Severity, Time Lag, and Earnings Surprise, and a vector of four control variables, Controls.

The binary variable Big 4 indicates whether a firm was audited by a Big 4 auditor in the year of voluntary enforcement disclosure. As we deem Big 4 auditors to be potentially more aware of the potential risk accompanying an enforcement review, their clients may be more likely to disclose information about the ongoing enforcement review.

The binary variable BaFin equals one if the error was established by the German securities regulator. It captures the notion that the perceived likelihood of being publicly censured for erroneous accounting potentially increases once FREP on the first tier establishes errors, but the firm chooses to contest this error finding, which results in the case being referred to BaFin for investigation on the second tier. Given this increased likelihood of enforcement action, managers may be more inclined to divulge details about ongoing enforcement reviews to prepare the market for upcoming bad news. Also, managers under those circumstances may use disclosure to explain their own view and announce their disagreement with the steps undertaken by the enforcement institutions.

We include the variable Error Severity, which is a compound variable including the amount of errors published in the respective error announcement and the errors' impact on return on equity and leverage in the erroneous financial statements. If a financial statement contains a high amount of errors or more severe errors, managers are more likely aware of at least some of these errors and thus know of the higher probability of an adverse outcome to the enforcement review under way. Hence, managers may be more likely to disclose information about the ongoing reviews if Error Severity is comparably high.

Time Lag represents the number of days between the release of the erroneous financial statement and the error announcement. If this time span is relatively large, enforcement reviews might have taken longer than expected. Such delay, for instance, could result from a lack of cooperation by managers, indicating that these managers do not agree with the enforcement institutions on a specific accounting matter and therefore use ex ante disclosure in order to explain their own view as well as prepare the market for upcoming negative information. Consequently, we propose that managers may be more likely to disclose information about ongoing enforcement investigations that eventually result in error findings if Time Lag is high. 
Our last variable of interest is Earnings Surprise, which takes the value of one for firm year observations where earnings exceeded prior year's earnings, and zero otherwise. This variable captures positive earnings surprises and hence "good news", in the spirit of Ball and Brown (1968). ${ }^{8}$ In line with Section 2.3, we conjecture that firms may seize this opportunity of good news to divulge to the market information of a potential error finding as a result of an ongoing review.

Finally, we include four control variables in our regressions. Size equals the natural logarithm of total assets at the beginning of the year in question. Return on assets (ROA) is computed by dividing earnings before interest and taxes (EBIT) by the average of total assets at the beginning of the year. Moreover, we incorporate Free Float in \% and Leverage as total assets minus common equity divided by total assets at the beginning of the year of ex ante disclosure.

Panel A of Table 2.5 summarises the definitions of all variables used in our determinants model. We collect the data for our variables from annual reports, error announcements and Thomson Reuters Datastream.

8 Given that the majority of firms is relatively small and not covered by analysts, we are unable to calculate a more sophisticated measure of Earnings Surprise, for example, analyst forecast error. 
Table 2.5: Variables measurement

\begin{tabular}{|c|c|}
\hline \multicolumn{2}{|c|}{ Panel A: Determinants model (Section 2.5.1) } \\
\hline Variable name & Definition \\
\hline Disclosure & $\begin{array}{l}\text { Dummy variable indicating that a firm voluntarily discloses } \\
\text { information relating to an ongoing enforcement review in the } \\
\text { respective year, which eventually results in an error finding }\end{array}$ \\
\hline Big 4 & $\begin{array}{l}\text { Dummy variable indicating that the firm was audited by a Big } 4 \text { auditor } \\
\text { in the year of the ex ante disclosure }\end{array}$ \\
\hline BaFin & $\begin{array}{l}\text { Dummy variable indicating that the enforcement investigation was } \\
\text { handed over to BaFin, who established the error finding. }\end{array}$ \\
\hline Error Severity* & $\begin{array}{l}\text { Compound variable including the number of errors established in the } \\
\text { respective error announcement and the errors' impact on return on } \\
\text { equity and leverage in the respective financial statements }\end{array}$ \\
\hline Time Lag* & $\begin{array}{l}\text { Number of days between the release of the erroneous financial } \\
\text { statement and the error announcement }\end{array}$ \\
\hline Earnings Surprise & $\begin{array}{l}\text { Dummy variable indicating that a firm reported annual earnings in } \\
\text { excess of prior year earnings }\end{array}$ \\
\hline Size* & $\begin{array}{l}\text { Natural logarithm of total assets at the beginning of the year of ex ante } \\
\text { disclosure }\end{array}$ \\
\hline$R O A^{*}$ & $\begin{array}{l}\text { Return on assets (EBIT divided by average total assets) at the } \\
\text { beginning of the year of ex ante disclosure }\end{array}$ \\
\hline Ownership & $\begin{array}{l}\text { Percentage of free float at the beginning of the year of ex ante } \\
\text { disclosure }\end{array}$ \\
\hline Leverage* & $\begin{array}{l}\text { Total assets minus common equity divided by total assets at the } \\
\text { beginning of the year of ex ante disclosure }\end{array}$ \\
\hline
\end{tabular}

\begin{tabular}{|c|c|}
\hline \multicolumn{2}{|c|}{ Panel B: Market tests (Section 2.5.2) } \\
\hline Variable name & Definition \\
\hline CAR & $\begin{array}{l}\text { Ranked cumulative abnormal returns (Corrado, 1989) in the } \\
{[-2 ; 2] \text { event window around the error announcement }}\end{array}$ \\
\hline Legal & $\begin{array}{l}\text { Dummy variable indicating that the error announcement pertains to } \\
\text { legal-entity accounts }\end{array}$ \\
\hline Opportunism* & $\begin{array}{l}\text { Compound variable including governance quality, earnings } \\
\text { management and the incentives of management to inflate earnings }\end{array}$ \\
\hline Resources* & $\begin{array}{l}\text { Compound variable including firm growth, number of years the firm } \\
\text { has been listed and firm complexity }\end{array}$ \\
\hline Change & $\begin{array}{l}\text { Dummy variable indicating whether a firm changed its auditor and/or } \\
\text { restructured its top management between the balance sheet date of the } \\
\text { erroneous financial statement and the error announcement }\end{array}$ \\
\hline additional va & $\begin{array}{l}\text { variables used in the determinants analyses (Table 2.7) in Panel A, and the } \\
\text { the market tests (Table 2.8) in Panel B. } \\
\text { Size, ROA, Leverage, Opportunism and Resources are winsorised at the } 1 \% \\
\text { e impact of outliers. }\end{array}$ \\
\hline
\end{tabular}




\subsubsection{Empirical findings}

Table 2.6 reports descriptive statistics (Panel A) and correlations for our variables (Panel B). Panel A shows that, on average, firms that choose to provide ex ante disclosures on ongoing enforcement investigations are more often investigated by BaFin (1\% significance level) and that Time Lag is higher (5\% significance level) for these firms. Not surprisingly, Panel B reveals a high positive correlation between Size and Big $4(0.483)$ and a high positive correlation between BaFin and Time Lag (0.500). 
Table 2.6: Descriptives (determinants model)

\begin{tabular}{|c|c|c|c|c|c|c|}
\hline Panel A: Descript & & & & & & \\
\hline & Disclos & mple & Non-c & sample & Difference & t-value \\
\hline Big 4 & 0.500 & 22 & 0.461 & 141 & -0.039 & $(-0.34)$ \\
\hline Error Severity & -0.116 & 22 & -0.038 & 141 & 0.078 & $(0.65)$ \\
\hline Time Lag & 660.682 & 22 & 525.475 & 141 & -135.207 & $(-2.60)^{* *}$ \\
\hline Earnings Surprise & 0.500 & 22 & 0.567 & 141 & 0.067 & $(0.59)$ \\
\hline Free Float & 0.520 & 22 & 0.535 & 141 & 0.014 & $(0.20)$ \\
\hline Leverage & 0.646 & 22 & 0.634 & 141 & -0.123 & $(-0.22)$ \\
\hline
\end{tabular}

\section{Panel B: Correlations}

\begin{tabular}{|c|c|c|c|c|c|c|c|c|c|c|c|}
\hline Variable & & (1) & (2) & (3) & (4) & (5) & (6) & (7) & (8) & (9) & (10) \\
\hline Disclosure & (1) & 1 & & & & & & & & & \\
\hline Big 4 & (2) & 0.063 & 1 & & & & & & & & \\
\hline BaFin & (3) & 0.205 & 0.035 & 1 & & & & & & & \\
\hline Error Severity & (4) & -0.029 & -0.163 & -0.054 & 1 & & & & & & \\
\hline Time Lag & (5) & 0.200 & 0.116 & 0.500 & -0.009 & 1 & & & & & \\
\hline Earnings Surprise & (6) & -0.081 & -0.258 & 0.092 & 0.085 & 0.062 & 1 & & & & \\
\hline Size & (7) & 0.005 & 0.483 & 0.174 & -0.297 & 0.216 & -0.050 & 1 & & & \\
\hline$R O A$ & (8) & -0.161 & 0.043 & -0.003 & -0.280 & -0.071 & -0.091 & 0.282 & 1 & & \\
\hline Free Float & (9) & 0.002 & 0.088 & 0.078 & -0.064 & 0.072 & 0.019 & 0.091 & 0.054 & 1 & \\
\hline Leverage & (10) & 0.121 & 0.076 & -0.023 & 0.021 & 0.140 & 0.008 & 0.154 & -0.182 & 0.022 & 1 \\
\hline
\end{tabular}

This table displays the descriptives for the variables used in the determinants model in Table 2.7. Definitions of variables are reported in Table 2.5. In Panel B, bold letters indicate significance at the 10\% level. The disclosure sample comprises all firms that voluntarily disclosed on an ongoing enforcement review that eventually resulted in an error announcement $(\mathrm{n}=26$ in Table 2.2$)$. Due to missing data we lose four observations and, thus, arrive at a sample size of 22 . The non-disclosure sample comprises all firms that did not voluntarily disclose on an ongoing enforcement review that eventually led to an error announcement $(\mathrm{n}=172-26=146$ in Table 2.4 ). Due to missing data we lose five observations, arriving at a sample of 141 non-disclosure firms. 
The results of estimating our regression model (1) are presented in Table 2.7. We estimate one separate model for each of the five variables of interest plus controls and a full model (column 6) including all variables. In untabulated analyses, we re-estimate the model including year and industry fixed effects to control for unobserved heterogeneity over time and industries, which yields very similar results.

Results in Table 2.7 indicate that managers are more likely to disclose information about ongoing enforcement reviews if these investigations are carried out by BaFin. In model (2) as well as in the full model specification (6), the coefficient for the BaFin variable turns out significant on the $1 \%$ and $5 \%$ level, respectively. This suggests that managers are more likely to notify markets of ongoing enforcement reviews in their annual reports if the FREP forwards the investigation to BaFin. We propose two non-exclusive explanations for this finding. First, managers will probably expect the likelihood of an error announcement to increase once BaFin takes over the investigation because the FREP already established an error. In this case, managers may use the voluntary disclosure as a means of preparing the stock market for imminent negative information. Second, and somewhat related, managers may decide to disclose information on the ongoing review in order to state their own view on the matter at hand, that is, to openly disagree with error findings established by the FREP. For example, in its 2006 annual report, Intertainment AG states that "the FREP informed us that the indemnification claims from litigation are overstated in the 2005 financial statements. The management does not agree with nor accept this finding as the FREP's outlined reasons do not necessarily require a writedown from the management's point of view". 
Table 2.7: Ex ante disclosure determinants

\begin{tabular}{|c|c|c|c|c|c|c|}
\hline Variable & (1) & (2) & (3) & (4) & (5) & (6) \\
\hline Big 4 & $\begin{array}{l}0.1849 \\
(0.33)\end{array}$ & & & & & $\begin{array}{c}0.1473 \\
(0.22)\end{array}$ \\
\hline BaFin & & $\begin{array}{c}1.4732 * * * \\
(2.84)\end{array}$ & & & & $\begin{array}{c}1.2203 * * \\
(2.14)\end{array}$ \\
\hline Error Severity & & & $\begin{array}{c}-0.5547 \\
(-0.87)\end{array}$ & & & $\begin{array}{c}-0.6131 \\
(-1.14)\end{array}$ \\
\hline Time Lag & & & & $\begin{array}{c}0.0024 * * \\
(2.39)\end{array}$ & & $\begin{array}{c}0.0014 \\
(1.43)\end{array}$ \\
\hline $\begin{array}{l}\text { Earnings } \\
\text { Surprise }\end{array}$ & & & & & $\begin{array}{l}-0.3479 \\
(-0.70)\end{array}$ & $\begin{array}{c}-0.5881 \\
(-1.06)\end{array}$ \\
\hline Size & $\begin{array}{l}0.014 \\
(0.10)\end{array}$ & $\begin{array}{c}-0.0277 \\
(-0.20)\end{array}$ & $\begin{array}{l}0.0089 \\
(0.07)\end{array}$ & $\begin{array}{c}-0.0247 \\
(-0.15)\end{array}$ & $\begin{array}{c}0.0352 \\
(0.28)\end{array}$ & $\begin{array}{l}-0.105 \\
(-0.58)\end{array}$ \\
\hline$R O A$ & $\begin{array}{c}-2.1556 \\
(-1.35)\end{array}$ & $\begin{array}{c}-2.0469 \\
(-1.17)\end{array}$ & $\begin{array}{c}-2.5579 \\
(-1.60)\end{array}$ & $\begin{array}{c}-1.9305 \\
(-1.03)\end{array}$ & $\begin{array}{c}-2.3576 \\
(-1.49)\end{array}$ & $\begin{array}{c}-2.3621 \\
(-1.19)\end{array}$ \\
\hline Free Float & $\begin{array}{l}-0.142 \\
(-0.18)\end{array}$ & $\begin{array}{c}-0.2646 \\
(-0.33)\end{array}$ & $\begin{array}{c}-0.1342 \\
(-0.17)\end{array}$ & $\begin{array}{l}-0.184 \\
(-0.23)\end{array}$ & $\begin{array}{c}-0.1055 \\
(-0.13)\end{array}$ & $\begin{array}{c}-0.3016 \\
(-0.37)\end{array}$ \\
\hline Leverage & $\begin{array}{c}-0.1394 \\
(-0.13)\end{array}$ & $\begin{array}{c}-0.0504 \\
(-0.05)\end{array}$ & $\begin{array}{c}-0.1973 \\
(-0.19)\end{array}$ & $\begin{array}{c}-0.4552 \\
(-0.40)\end{array}$ & $\begin{array}{c}-0.1812 \\
(-0.17)\end{array}$ & $\begin{array}{c}-0.2473 \\
(-0.24)\end{array}$ \\
\hline Constant & $\begin{array}{c}-1.9804 \\
(-1.20) \\
\end{array}$ & $\begin{array}{c}-1.8201 \\
(-1.11) \\
\end{array}$ & $\begin{array}{c}-1.8444 \\
(-1.13) \\
\end{array}$ & $\begin{array}{c}-2.6397 \\
(-1.51) \\
\end{array}$ & $\begin{array}{c}-1.9574 \\
(-1.28) \\
\end{array}$ & $\begin{array}{c}-1.3336 \\
(-0.71) \\
\end{array}$ \\
\hline Pseudo $\mathrm{R}^{2}$ & 0.0187 & 0.0814 & 0.0272 & 0.0645 & 0.0221 & 0.1129 \\
\hline $\mathrm{N}$ & 163 & 163 & 163 & 163 & 163 & 163 \\
\hline $\begin{array}{l}\text { Clustered } \\
\text { standard errors }\end{array}$ & Firm & Firm & Firm & Firm & Firm & Firm \\
\hline \multicolumn{7}{|c|}{$\begin{array}{l}\text { This table displays coefficient estimates and t-statistics from estimating logit model (1) (Section 2.5.1). } \\
\text { The regression model is based on all firms that were censured by the German enforcement mechanism } \\
\text { between } 2006 \text { and } 2016(\mathrm{n}=172 \text { in Table } 2.1) \text {. Due to missing data we lose nine observations and arrive } \\
\text { at a sample size of } \mathrm{n}=163 \text {. The dependent variable is a binary variable indicating disclosure about an } \\
\text { ongoing enforcement review in the annual report. Definitions of variables are reported in Table } 2.5 \text {. t- } \\
\text { values are reported in parentheses. ***, **, and * indicate significance at the } 1 \%, 5 \% \text {, and } 10 \% \text { levels, } \\
\text { respectively. Standard errors are clustered by firm. }\end{array}$} \\
\hline
\end{tabular}

The coefficient on Time Lag is positive and, in model (4), statistically significant at the $5 \%$ level. This finding may reflect disagreement on specific accounting issues between the respective management and the FREP, or BaFin, indicating a highly contested review process. Similar to our interpretation of the role of BaFin reviews, even a contentious review procedure on the FREP level will alter management's perception of error likelihood, and hence create disclosure incentives.

Our other three variables proxying for a Big 4 auditor, error severity, and earnings surprise do not load in a meaningful way. This evidence speaks against Big 4 auditing firms specifically shaping or endorsing enforcement-related disclosures with their clients. Also, 
the nature and, in particular, the severity of looming error findings appears not to be a driver of the decision to report about an ongoing review. Lastly, we find no evidence supporting the notion of managers strategically reporting about potentially bad news (an ongoing enforcement review) upon revelation of good news (a positive earnings surprise).

\subsubsection{Market reactions to error announcements}

\subsubsection{Research design}

Our final analysis further explores one particular motive for disclosures about ongoing reviews: attempting to mitigate the market impact of a potential error finding by intentionally disclosing information on an ongoing review. We conduct an event study and cross-sectional analyses of market reactions to the disclosure of error findings. Prior literature demonstrates that markets react negatively on average, consistent with error findings conveying new, negative information. We build on that literature and explore market reactions for two sub-samples of error firms, those that did and those that did not provide ex ante disclosures. Effectively, we test whether prior disclosures about ongoing enforcement reviews are factored into market expectations and hence effectively confound disclosures of error findings.

Panel C of Table 2.1 details how we arrive at the sample of 139 error announcements for our univariate tests, and the sample of 105 announcements for the determinants model. We estimate short-window market reactions around the error announcement date following the methodology suggested by Hitz et al. (2012) based on MacKinlay (1997), Bamber (1987) and Dechow et al. (1996). We confine our analyses to one return-based measure of market reactions, cumulative abnormal returns (CARs), which we calculate for three different event windows around the date of the publication of error findings: one day window [0], three days window $[-1 ; 1]$ and five days window $[-2 ; 2]$. In addition to conventional t-statistics, we compute event-study-specific t-statistics introduced by Brown and Warner (1985) and Corrado (1989). These tests also take into account information from the estimation window and thus deliver a more informative assessment of the market reactions' significance.

\subsubsection{Empirical findings}

Panel A of Table 2.8 reports market reactions for the whole sample of error announcements. Mean CARs are negative for all three event windows, with significance levels 
varying depending on the test statistic. All in all, these findings are consistent with negative average market reactions to the publication of error announcements, as documented by Hitz et al. (2012).

Table 2.8: Short-window market reactions

\begin{tabular}{lcccc}
\hline Panel A: Full sample of error announcements & \multicolumn{4}{c}{ Cumulative abnormal returns } \\
\cline { 2 - 5 } & \multicolumn{3}{c}{ (in \%) } \\
\cline { 2 - 5 } Event window & {$[0]$} & {$[-1 ; 1]$} & {$[-2 ; 2]$} \\
Mean & -0.292 & -0.709 & -0.831 \\
(t-statistic) & $-0.87)$ & $(-1.37)^{*}$ & $(-1.45)^{*}$ \\
N & 139 & 125 & 118 \\
Statistic following Brown and Warner (1985) & $(-1.57)^{*}$ & $(-2.37)^{* * *}$ & $(-1.37)^{*}$ \\
Statistic following Corrado (1989) & $(-1.21)$ & $(-2.34)^{* *}$ & $(-1.71)^{* *}$ \\
\hline
\end{tabular}

Panel B: Sub-samples of error announcements with and without ex-ante disclosure

\begin{tabular}{llccc}
\hline & & \multicolumn{3}{c}{ Cumulative abnormal returns } \\
\cline { 3 - 5 } Disclosure & Event window & {$[0]$} & {$[-1 ; 1]$} & {$[-2 ; 2]$} \\
& $\mathrm{N}$ & 21 & 20 & 19 \\
& Mean & -0.245 & -1.131 & 1.494 \\
& (t-statistic) & $(-0.33)$ & $(-1.62)^{*}$ & $(0.82)$ \\
& Statistic following Brown and Warner (1985) & $(-0.54)$ & $(-0.92)$ & $(0.43)$ \\
& Statistic following Corrado (1989) & $(-0.60)$ & $(-1.11)$ & $(0.16)$ \\
\cline { 2 - 5 } No disclosure & $\mathrm{N}$ & 118 & 105 & 99 \\
& Mean & -0.300 & -0.629 & -1.277 \\
& (t-statistic) & $(-0.81)$ & $(-1.04)$ & $(-2.20)^{* *}$ \\
& Statistic following Brown and Warner (1985) & $(-1.47)^{*}$ & $(-2.18)^{* *}$ & $(-1.68)^{* *}$ \\
Mean difference & Statistic following Corrado (1989) & $(-1.10)$ & $(-2.15)^{* *}$ & $(-1.94)^{* *}$ \\
(t-statistic) & & -0.055 & 0.502 & -2.771 \\
\hline & & $(-0.06)$ & $(0.62)$ & $(-4.05)^{* * *}$ \\
\hline
\end{tabular}

Panel C: Determinants of short-term market reactions to error announcements

\begin{tabular}{|c|c|c|}
\hline Variable & (1) & (2) \\
\hline Disclosure & 0.444 & 2.184 \\
\hline
\end{tabular}

Variables of interest (Hitz et al., 2012)

Yes -10.40

\begin{tabular}{llccc} 
Controls & Yes & & No \\
\cline { 1 - 1 } & & 0.026 & & 0.027 \\
$\mathrm{~N}$ & 105 & & 105
\end{tabular}

This table displays market reactions pertaining to error announcements $(n=139$ in Table 2.1) for three short-term event windows. Sample sizes differ in these three event windows due to elimination of confounding events. Panel A reports market reactions for the entire sample of relevant error announcements, and Panel B reports market reactions separately for both sub-samples with and without ex-ante disclosure. Markets reactions are measured using cumulative abnormal returns. *, ** and *** indicate one-tailed significance at the $10 \%, 5 \%$ and $1 \%$ levels, respectively. Panel C displays coefficient estimates and t-statistics from estimating the determinants model described in Section 2.5.2. Appendix B displays descriptive statistics and correlations of the variables used in these market based tests. 
In Panel B of Table 2.8, we split the initial sample into two sub-samples: firms that adopted disclosures about ongoing enforcement investigations, and those that chose to "remain silent". We do this to test whether prior disclosures about ongoing reviews are factored into market prices. If this is the case, investors price the market value implications of the expected error finding, multiplied with the positive likelihood of such an error finding which the disclosure communicates. Findings in Panel B of Table 2.8 indicate that the average market reaction turns out significantly negative for the sample of nondisclosure firms only. This result is in line with the expectation that investors price disclosures about ongoing reviews, and that these disclosures mitigate the market impact of an eventual error announcement.

In our final analysis, we employ a multivariate test to shed further light on the potential mitigating role of disclosures about ongoing reviews on the market reaction to the eventual publication of an error finding. To that end, we estimate a determinants model for market reactions to error announcements. This determinants model estimates the association of several firm variables with ranked cumulative abnormal returns (following Corrado, 1989) in the $[-2 ; 2]$ event window around error announcements. We include into the model as independent variables all the variables used by Hitz et al. (2012) ${ }^{9}$, which are defined in Panels A and B of Table 2.6. As our main variable of interest, we include as an additional explanatory variable Disclosure, which is a dummy variable indicating that a firm voluntarily disclosed information about the ongoing enforcement review that eventually resulted in an error finding. To support the notion of smaller market reactions due to confounding disclosures, we expect Disclosure to have a positive and significant effect on ranked cumulative abnormal returns.

Panel C of Table 2.8 reports coefficient estimates for Disclosure. For both specifications of our determinants model, with and without control variables, we find a positive coefficient. However, these results are not significant at conventional levels. Taken together, our findings on market reactions provide weak evidence at best that disclosures on ongoing enforcement reviews result in comparatively weaker market reactions compared to firms that embraced their "right to remain silent". There are at least two explanations why these disclosures appear not to mitigate the market impact of error announcements in a

\footnotetext{
9 We include the main test variables used by Hitz et al. (2012): Error Severity, Legal and BaFin. Moreover, we include the same control variables as in Hitz et al. (2012): Opportunism, Resources, Change, Time Lag, Size, Leverage, Liquidity and Ownership.
} 
meaningful way. For one thing, market participants may not regard this information as useful. If enforcement-related disclosures are not priced, then they present no effective means of influencing market valuation.

Our second explanation relates to the non-disclosure firms and proposes that these firms did, in fact, disclose information on ongoing reviews too, or that such information was leaked via other channels. To test that explanation, we conducted an analysis of press coverage for all error announcements. We did so employing a keyword search ("FREP", "review panel"), using the LexisNexis Database and the electronic archive of one major financial newspaper in Germany, the Handelsblatt. We find press coverage of an enforcement review under way for only one out of the 26 disclosure firms. In comparison, out of the 146 non-disclosure firms, eight received press coverage about the review under way. While these findings are anecdotal at best, they suggest that information about ongoing reviews, at least in some cases, is leaked or intentionally communicated via means other than the annual report. This finding provides an additional explanation for the weak results of our market tests. More importantly, it hints at other disclosure channels for enforcement-related information which future research may investigate.

\subsection{Conclusion}

This paper presents exploratory evidence for a disclosure phenomenon that so far has not received attention in the literature: firm disclosures about enforcement reviews. We exploit the German institutional environment, where enforcement institutions are not only quite active but also relatively transparent, and where firms are mandated to systematically report errors established by enforcers to effect "adverse disclosure".

Our analyses reveal that enforcement-related disclosures take place on a rather regular basis, at least for concluded reviews, while disclosures about ongoing reviews only occur in one out of 13 cases on average. Detailed analyses of those firms that choose not to be silent and reveal to the market information on an ongoing enforcement review suggest that managers may deliberately adopt such a disclosure strategy and, in a related vein, that the format of the disclosure and its location in the annual report potentially convey information on the likely outcome of the review. Consistent with this, we find weak market based evidence to support the notion that executives deliberately use disclosures on ongoing reviews to prepare markets for an adverse outcome. 
Our analyses are subject to several limitations. First, for the most part, our analyses are exploratory in nature and do not shed light on any causal relations, for example, between (unobservable) managerial disclosure incentives and observable disclosure choices. Also, our findings are based on relatively small samples and thus do not lend themselves to general insights. That said, our results shed light on an interesting disclosure phenomenon and its variation on the firm-level. Given the nature of our findings, we are confident that future research into the area of enforcement disclosure promises interesting insights not only to researchers but to regulators and practitioners alike. One obvious path to take here is to shed further light on the motives and potential effects of disclosures about concluded enforcement reviews, in particular for firms which unveil that enforcement institutions established the high quality of financial statements. Another path is to further investigate how firms use channels other than the annual report to communicate enforcement-related information to the market, and the role of information intermediaries in this dissemination process. 


\subsection{Appendix}

Appendix A: Examples for different disclosure sub-samples from the annual reports (English translation by the authors)

(1) Ongoing review with no error finding: Maschinenfabrik Berthold Hermle AG, 2008

In addition, audit fees of $20 \mathrm{k}$ Euro (prior year: $0 \mathrm{k}$ Euro) accrued due to a review of the 2007 consolidated financial statements by the Financial Reporting Enforcement Panel. (p. 60)

(2) Ongoing review with error finding: FRoSTA AG, 2008

The FREP (Financial Reporting Enforcement Panel) began conducting an indicationbased investigation of our financial statements, because we did not provide a segment report.

As in prior years, the omission of the segment report resulted in a qualified audit opinion. We choose not to prepare a segment report as this would negatively affect our competitive position. An indication-based investigation has been initiated by the Financial Reporting Enforcement Panel because of the omitted segment report. This ongoing investigation has been subject to supervisory board discussions. (p. 29)

(3) Concluded review with no error finding: Wilex AG, 2010

Moreover, the audit committee oversaw the investigation of our 2009 financial statements by the Financial Reporting Enforcement Panel, which did not result in an error finding. (p. 18)

(4) Concluded review with error finding: PARK \& Bellheimer AG, 2010

The Financial Reporting Enforcement Panel established that the consolidated management report of PARK \& Bellheimer AG's financial year 2009 was erroneous as the expected development of the group respectively the firm, including its material opportunities and risks, was not comprehensively forecasted for the following two years. The management report, in particular, did not include any remarks on the strained liquidity and profit situation of the group nor on the planned restructuring. (p. 41) 
Last year's financial statement was corrected because of FREP's error finding. Originally, the debt waiver of a former affiliate had been recognised as a profit. Now, this transaction is directly recognised in equity due to the former affiliation of the firms. Thus, the prior year financial statement was restated with respect to several line items such as other operating income and bottom-line profit. (p. 31) 
Appendix B: Descriptives of the market reaction determinants model

Table 2.9: Descriptives of market reaction determinants

\section{Panel A: Descriptive statistics}

\begin{tabular}{|c|c|c|c|c|c|c|}
\hline Variable & Mean & $\begin{array}{l}\text { Standard } \\
\text { deviation }\end{array}$ & Median & Min. & Max. & $\mathbf{N}$ \\
\hline Disclosure & 0.162 & 0.370 & 0 & 0.000 & 1.000 & 105 \\
\hline \multicolumn{7}{|c|}{ Components of Error Severity } \\
\hline Error Amount & 3.771 & 3.696 & 2 & 1 & 22 & 105 \\
\hline Impact ROE & -0.081 & 0.208 & 0.000 & -0.880 & 0.030 & 105 \\
\hline Impact Leverage & 0.020 & 0.058 & 0.000 & -0.010 & 0.260 & 105 \\
\hline Legal & 0.286 & 0.454 & 0 & 0 & 1 & 105 \\
\hline BaFin & 0.210 & 0.409 & 0 & 0 & 1 & 105 \\
\hline \multicolumn{7}{|c|}{ Components of Opportunism } \\
\hline Violations & 0.590 & 0.494 & 1 & 0 & 1 & 105 \\
\hline Remuneration & 0.228 & 0.218 & 0.200 & 0.000 & 0.810 & 105 \\
\hline Discretionary Accruals & -0.003 & 0.175 & 0.003 & -0.562 & 0.671 & 105 \\
\hline \multicolumn{7}{|l|}{ Components of Resources } \\
\hline Firm Growth & 0.228 & 0.608 & 0.060 & -0.380 & 3.090 & 105 \\
\hline Years Listed & 14.381 & 8.443 & 13 & 1 & 42 & 105 \\
\hline Complexity & -0.102 & 1.770 & -0.069 & -3.584 & 4.961 & 105 \\
\hline Change & 0.619 & 0.488 & 1 & 0 & 1 & 105 \\
\hline Time Lag & 516.067 & 209.810 & 468 & 222 & 1057 & 105 \\
\hline Size & 12.283 & 2.445 & 12.110 & 8.410 & 16.600 & 105 \\
\hline Leverage & 0.661 & 0.286 & 0.640 & 0.180 & 1.410 & 105 \\
\hline Liquidity & 0.820 & 0.208 & 0.900 & 0.162 & 1.000 & 105 \\
\hline Ownership & 0.540 & 0.314 & 0.530 & 0.000 & 1.000 & 105 \\
\hline
\end{tabular}


Table 2.9 cont'd: Descriptives of market reaction determinants

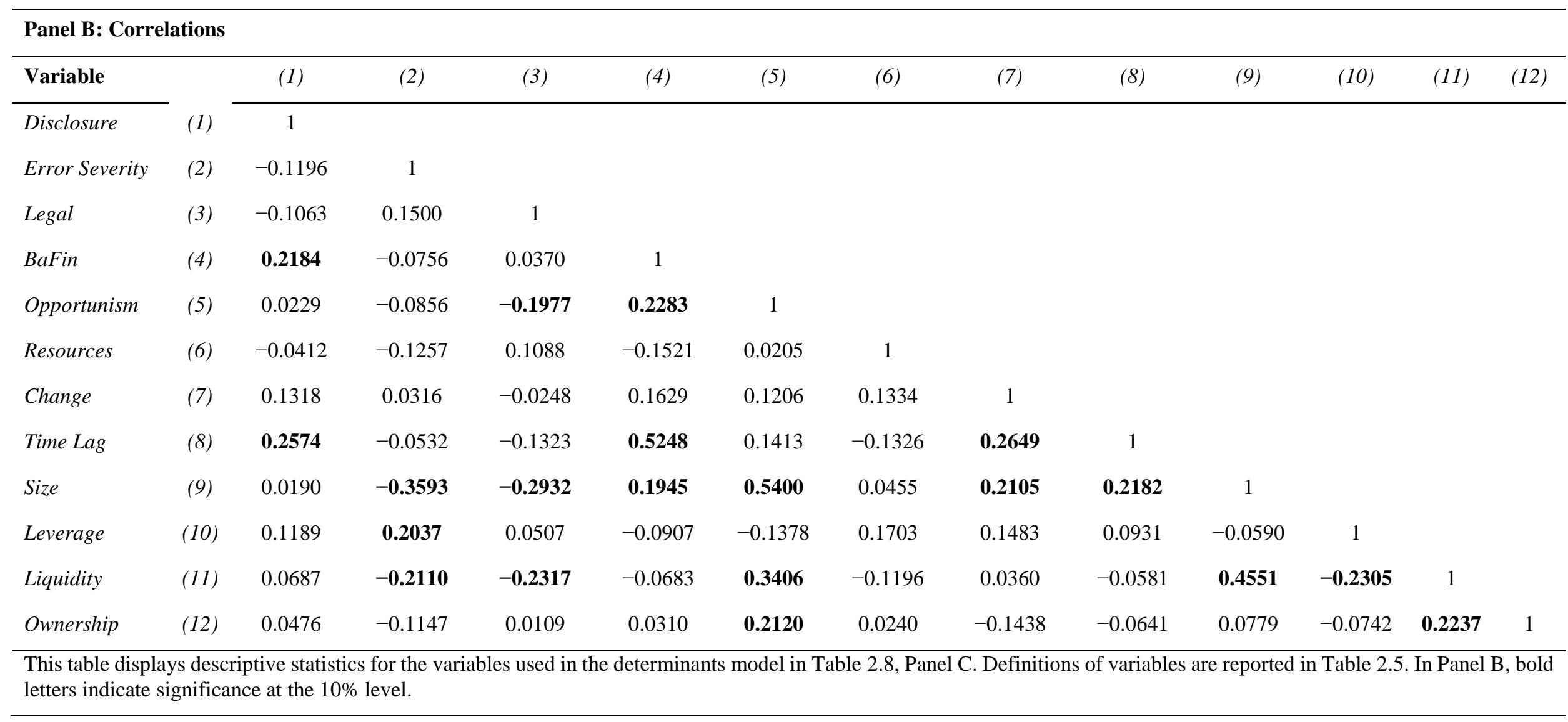




\section{Auditor Conservatism in the Presence of Financial Reporting Enforcement}

Henning Schnack and Andreas Hellmann ${ }^{10,11}$

Working Paper (Revise and resubmit at The International Journal of Auditing) ${ }^{12}$

Abstract: This paper provides evidence on the influence of potential enforcement reviews of the client's financial statements by financial reporting enforcement institutions on auditors' decision making. Specifically, we examine whether the likelihood of an enforcement review would influence auditors' decisions to require more conservative accounting choices from their clients. Moreover, we test if past experiences with such enforcement reviews lead auditors to be more conservative. Lastly, we examine whether higher-rank auditors, due to their higher responsibility and liability, are more likely to be influenced than lower-rank auditors. The results of an experiment with 72 auditors indicate that the higher likelihood of an enforcement review is not associated with more conservative decision making by auditors. However, auditors who were affected by enforcement reviews in the past tend to make more conservative accounting choices. Our findings do not suggest that higher-rank auditors employ higher levels of conservatism as compared to lower-rank auditors.

JEL Classification: C91, M41, M42

Keywords: enforcement, auditing, conservatism, experiment, regulation, decision making

Acknowledgements: We thank Jörg-Markus Hitz, Maroš Servátka, Medhat Endrawes, Elizabeth Sheedy, Chris Patel, Dominic Soh and Nonna Martinov-Bennie for their comments and support. We also thank the participants of the 2nd Macquarie University Conference on Contemporary Accounting Research for their helfpul feedback. All potentially remaining errors are our own. Henning Schnack gratefully acknowledges financial support from Macquarie University (iMQRES grant number 2016283).

10 Macquarie University Sydney, Faculty of Business and Economics, Department of Accounting and Corporate Governance, 4 Eastern Road, NSW 2109, Australia.

11 This study was conducted in cooperation with Andreas Hellmann.

12 This working paper is currently in the revise and resubmit process of The International Journal of Auditing (as of January 2019). 


\subsection{Introduction}

This study examines the impact reviews of the client's financial statements by enforcement bodies have on the decision making of auditors, more specifically on their conservatism. Enforcement bodies are governmental or private agencies that have the authority to review audited financial statements of listed corporations. Enforcement, in general, describes the supervision of listed firms by such agencies with the objective of ensuring that accounting standards are complied with.

Enforcement is largely a national matter and in some countries enforcement has a long tradition. In the United States (U.S.), for example, the Securities and Exchange Commission (SEC) has been carrying out enforcement of accounting rules since 1937 (Feroz et al., 1991). In many member states of the European Union, on the other hand, enforcement is a relatively new phenomenon. The implementation of enforcement mechanisms in the EU was mandated in 2005 concurrently with the adoption of International Financial Reporting Standards (IFRS). While the United Kingdom (U.K.) and some other EU member states already had enforcement institutions set up, Germany and other countries did not have enforcement institutions prior to 2005 (H. B. Christensen et al., 2013).

However, enforcement bodies vary across countries in terms of structure, procedures and competencies. For example, enforcement is carried out by a stock exchange regulator in the United States, Australia, China and Japan and by a private-sector review panel in the United Kingdom. The SEC conducts reactive investigations, proactive surveillance, and issues advance clearance, whereas the Financial Reporting Review Panel in the United Kingdom does not have the authority to provide advance clearance.

Despite differences in structure, procedures and competencies, enforcement bodies serve two main functions. Firstly, the preventive function is deemed to prevent financial statement preparers from engaging in incorrect, or even fraudulent, accounting behaviour in the first place. Secondly, the sanctioning function punishes firms for errors made in their financial statements. For this purpose, enforcement bodies can utilise at least two sanction mechanisms: monetary penalties and the publication of error findings. As error announcements constitute adverse publicity for the respective firm, they are a means of the "name and shame" mechanism which is a prominent tool of enforcement's sanctioning function (Hitz et al., 2012).

The extant enforcement literature focuses largely on the sanctioning function and, specifically, on the capital market effects of enforcement's sanctioning actions (e.g., Ebner et 
al., 2015; Hitz et al., 2012) and of the presence of enforcement institutions (Barth and Israeli, 2013; H. B. Christensen et al., 2013; Ernstberger et al., 2012). Hitz et al. (2012), for instance, find that the publication of error announcements as a direct result of enforcement reviews leads to negative market reactions. H. B. Christensen et al. (2013) show that the introduction of IFRS for listed firms in the EU coincided with significant positive capital market effects (increases in liquidity), particularly in those EU member states that had concurrently implemented the mandate to install enforcement institutions. Moreover, prior research shows that error announcements established by enforcers lead to enhanced turnover of members of the board of directors (Johnstone et al., 2011); audit committee members (Carver, 2014; Srinivasan, 2005); top management (Arthaud-Day et al., 2006; Collins et al., 2009; Desai et al., 2006; Land, 2010; Wang and Chou, 2011); and audit teams (Brocard et al., 2018). However, uncertainty persists as to what fully drives capital market effects that are associated with the presence of enforcement. It is important to understand the influence of enforcement institutions on the behaviour of individuals, such as financial statement preparers and auditors, as this might help regulators in evaluating the outcome of their efforts.

While most studies focus largely on the sanctioning function, research on the preventive function is scarce. For this reason, we examine the direct effects of the presence of an enforcement body, that is, the likelihood of an enforcement review of the client's financial statements, on the decision making of auditors. We focus our analyses on auditors as they potentially have the power to make their clients change financial reporting choices before financial statements are released. Thus, auditors may play a crucial role in supporting and underpinning the preventive function of enforcement mechanisms. As enforcement's "name and shame" mechanism holds reputational risks for auditors, it is very likely that auditors are very much aware of its presence and take its potential harm into consideration when conducting an audit. Thus, the presence of an enforcement mechanism may exert increased pressure on auditors, possibly, in turn, leading them to be more conservative with clients and allowing less aggressive accounting practices.

In this context, we define conservatism as "the inclusion of a degree of caution in the exercise of the judgements needed in making the estimates required under conditions of uncertainty" (Mora and Walker, 2015). This conservative behaviour may eventually lead to less erroneous financial statements and, thus, a positive outcome of the preventive function. This is important as these direct effects on auditors' decision making may further support the efficacy of enforcement mechanisms. Thus, the potential of an overall 
improvement in audit and accounting quality in the presence of an enforcement mechanism, in fact, may originate from more rigorous decision making by the auditor. This would be a significant achievement of enforcement's preventive function, with auditors directly influencing their clients' financial statements if they feel that their accounting choices are too aggressive (Hackenbrack and Nelson, 1996). It is important to investigate this matter as the impact of enforcement on individual behaviour might help in understanding and explaining already established capital market effects.

The aim of this paper is to examine enforcement's preventive function via the influence enforcement reviews of client's financial statements may have on auditors' conservatism. Specifically, we examine whether the likelihood of an enforcement review of the client's financial statements may influence auditors to require more conservative accounting choices from their clients. Moreover, we test whether auditors who were affected by enforcement reviews in the past tend to make more conservative accounting choices. In addition, we examine whether the efficacy of the preventive function may be influenced by the hierarchical level of auditors. Specifically, we examine whether higher-rank auditors, due to their higher reputation, responsibility and liability, are more likely to be influenced in their decision making by the likelihood of enforcement reviews of the client's financial statements than lower-rank auditors. This is important as higher-rank auditors are the ones making more significant decisions and reviewing lower-rank auditors' work (Nelson and Tan, 2005).

To test our hypotheses, we carry out an experiment with 72 auditors. The experiment employs a between-subjects design where the participants have to choose between a conservative or an aggressive accounting choice after reading an audit case. The case material describes a client in the pharmaceutical industry who faces a lawsuit with an uncertain verdict. All information is kept equal across the two groups of participants except for the likelihood that the client's financial statements will be subjected to an enforcement review. This represents our manipulated independent variable and is described as being either high or low depending on which group the participants are randomly assigned to. After reading the audit case, the participants are asked to state whether they would require the client to recognise a provision for litigation costs or to disclose a contingent liability in the notes. Recognition of the provision represents the more conservative choice in this scenario and disclosure of a contingent liability is the more aggressive accounting choice. The collected data is analysed with logit regression models. 
Our results suggest that the likelihood of an enforcement review alone does not have a significant effect on auditors' behaviour. Auditors do not require more conservative accounting choices from their clients when the likelihood of being subject to an enforcement review is high. Moreover, we cannot find significant evidence suggesting that higher-rank auditors would employ more conservative decision making than lower-rank auditors. However, auditors who were affected by enforcement reviews in the past do employ more conservative decision making. Hence, in order to strengthen enforcement's preventive function, it may be necessary to increase the frequency of such reviews.

Our study contributes to prior literature in two ways. Firstly, we contribute to the broad literature stream on enforcement of accounting standards (e.g., Brocard et al., 2018; H. B. Christensen et al., 2013; Hitz et al., 2012). Most prior studies implement empirical research designs and many regard post-error announcement effects on either real management decisions or capital market reactions. These studies focus on the sanctioning function of enforcement mechanisms. However, prior literature on whether enforcement directly influences accounting choices made by managers or auditors is scarce. In order to examine the efficacy of enforcement's preventive function, we provide a pre-error announcement perspective that experimentally investigates the impact of enforcement reviews on auditors' decision making. Secondly, we contribute to the conservatism literature and, more specifically, to the stream of conservatism literature that deems regulation to be a driving force of conservatism (Watts, 2003a) as enforcement represents an outcome or an integral part of regulation. Watts (2003b) expressed a need for more research in regulation-driven conservatism. We aim to answer this call by providing an experimental approach that explores the impact of regulation on the behaviour of auditors as opposed to other conservatism research that investigates archival time-series or crosssectional data and conservatism measures such as the asymmetric timeliness measure (Basu, 1997). ${ }^{13}$

The remainder of the paper is structured as follows. Section 3.2 provides a review of prior literature on auditors' decision making and develops our hypotheses. Section 3.3 outlines the research design. In Section 3.4, we present and discuss our experimental findings. Section 3.5 concludes the paper.

13 Basu (1997) interprets conservatism "as resulting in earnings reflecting 'bad news' more quickly than 'good news"'. Thus, he constructs a regression equation that estimates how strongly earnings reflect good news and bad news, respectively, measured by stock returns. The higher the reflection of bad news in earnings, the more conservative the underlying accounting. 


\subsection{Literature review and hypotheses development}

\subsubsection{Influence of enforcement reviews of clients' financial statements on auditor conservatism}

Our aim is to examine enforcement's preventive function via the influence enforcement reviews of client's financial statements may have on auditors' conservatism. This is important as conservative auditor behaviour has a direct impact on the reporting choices in the financial statements under audit (Hackenbrack and Nelson, 1996). Thus, we expect it to be a determining factor of accounting quality on which enforcement may have an effect. Accordingly, auditor conservatism is an important construct to examine in evaluating the efficacy of enforcement's preventive function.

An important factor that may influence auditors' conservatism is accountability, in the sense of being responsible for the outcome of the audit and potentially having to explain decisions to clients, colleagues, superiors or oversight bodies such as enforcement agencies. This accountability is inherent in auditing through the hierarchical review process (Messier Jr et al., 1992). As auditors are subject to codes of conduct and ethics, they are well aware of the presence of accountability in their daily work environment (Emby and Gibbins, 1987; Gibbins and Emby, 1984; Peecher et al., 2013). Hence, accountability may inflict pressure on individuals as the consequences of not following codes of conduct or ethics may include disciplinary proceedings such as expulsion (Preston et al., 1995; Velayutham, 2003). Experimental evidence shows that, when accountable for their decisions, auditors are less likely to give unqualified audit opinions (Lord, 1992) and will process information more thoroughly and carefully before coming to a decision (Johnson and Kaplan, 1991). This shows that accountability may have an impact on auditors' decisions to require financial statement adjustments from clients. In addition, prior research shows that such adjustment decisions can be affected by other variables such as misstatement size, size of the client, subjectivity, impact on current-year income and precision (Nelson et al., 2005; A. Wright and S. Wright, 1997).

However, auditors take several risks into account when deciding about the necessity of financial statement adjustments, namely, the risk of client loss, reputation risk (Rich et al., 1997; Skinner and Srinivasan, 2012) and litigation risk (Kida, 1980; Krishnan and Krishnan, 1997). Managers' accounting choices are not random, and it is likely that certain accounting choices have a specific purpose for the firm or the manager, such as managing earnings upwards to meet earnings targets or to increase one's own performance- 
related remuneration (Healy and Wahlen, 1999). Therefore, clients will not be content with auditors suggesting a multitude of adjustments and might consider hiring a different auditor in the future (Hatfield et al., 2011; A. Wright and S. Wright, 1997). Thus, the apparent client pressure on auditors could potentially encourage them to refrain from requiring financial statement adjustments. Prior literature on auditor independence, in fact, shows that auditors in high client pressure situations are more likely to insist only on small adjustments in clients' financial statements as opposed to auditors in low client pressure situations who are shown to insist on a higher level of adjustments (Hatfield et al., 2011). Moreover, Nelson and Kinney Jr (1997) show in an experimental study that the risk of client loss appears to make auditors deal with ambiguous loss probabilities less conservatively. Their findings suggest that auditors are more likely than clients to avoid references to contingent losses in order not to harm their relationship in case these references are shown to have been unnecessary in hindsight. ${ }^{14}$ Clients might also try to influence auditors' judgments through ingratiation and, as suggested in prior research, may be successful in doing so (Robertson, 2010).

However, closely related to the risk of client loss is the reputational risk to which auditors are exposed, as clients will be interested in hiring an auditor with a reputation for conducting high-quality audits. For instance, if an audit firm was involved in auditing a firm's financial statements which eventually were censured by an enforcement institution, this would have a negative impact on the audit firm's reputation and potentially drive other clients to end their relationship with that audit firm. Studies by Weber et al. (2008), Cahan et al. (2009) and Kläs and Werner (2014) suggest that such spill-over effects exist with regard to auditor reputation. In fact, managers state that reputation is one of the main factors they take into consideration when deciding which auditor to hire; especially, firms that stand out due to significant visibility on capital markets, that is, firms with high analyst following, press coverage and institutional ownership, value auditors with prime reputations (Barton, 2005). Therefore, auditor reputation should not only be of concern for clients but also for the auditors themselves, possibly leading them to produce high-quality audits and therefore potentially outweighing the risk of client loss.

14 Nelson and Kinney Jr (1997) did not look at contingent losses from the perspective of being a less conservative decision option among others. Their research design required participants to choose whether or not to disclose contingent losses. 
Momentous declines in reputation can result from litigation. A significant stream of literature explores the effects of litigation or fraud risk (Brazel et al., 2014) on auditor decisions. Results indicate that auditors will engage in more conservative behaviour if they expect litigation or client risk to be high. In prior studies, this conservatism was represented either by the decision to choose the more conservative of two accounting choices in a setting where client risk was high (Hackenbrack and Nelson, 1996) or by decreases in abnormal accruals when litigation risk was deemed to be high (Cahan and Zhang, 2006). The probability of requiring clients to carry out financial statement adjustments is even more pronounced when litigation risk is high while, at the same time, the risk of client loss is low (Farmer et al., 1987), supporting the idea of the extent of the deep connection between the different risk components. Similarly, in settings with only small litigation risk, auditors might still prefer conservative accounting choices to avoid harming their reputation. Research shows that, in the Japanese setting with basically no litigation risk for the auditor, a client's accounting fraud still holds great reputational damage for the auditor (Skinner and Srinivasan, 2012). Furthermore, reputation loss can result from government inspections at an auditor's client which, in turn, can also provoke economic losses (Firth, 1990).

Auditors influence their clients by applying more conservative accounting choices in cases of high client litigation risk, especially if the client's financial performance is poor (Chung et al., 2003). Importantly, auditors are more conservative after audit failure has occurred (Fafatas, 2010; Sun et al., 2016) and while they are under investigation by a supervisory enforcement agency for potential audit failure at a different client (Bannister and Wiest, 2001). This represents a post-effect or a simultaneous effect of enforcement investigations. Moreover, DeFond et al. (2018) find that Big 4 offices tend to issue more going-concern reports to clients in distress if they are located in close proximity to SEC regional offices. DeFond et al. (2018) indicate that this close proximity makes the audit offices more aware of SEC enforcement, which may induce a conservative bias.

As outlined above, there are many risk factors (i.e., risk of client loss, reputation risk and litigation risk) that may influence auditors' decision making and potentially put significant pressure on them. Hence, these factors may lead auditors to employ conservative decision making. Importantly, prior literature shows that these risk factors are connected to enforcement actions. Brocard et al. (2018) find that firms that were censured by an enforcement agency have an increased probability of changing auditors, indicating that 
enforcement influences the risk of client loss. Moreover, prior studies show that enforcement actions may result in reputation loss (Rollins and Bremser, 1997) and increased litigation risk (Bonner et al., 1998). Consequently, the likelihood of a client's financial statements being reviewed by an enforcement agency may affect an auditor's perception of his or her exposure to the described risk factors. Therefore, we expect that enforcement reviews of client's financial statements influence auditors' conservatism and formulate the following hypothesis.

H1: Auditors are more likely to require conservative accounting choices from their clients when the probability of an enforcement review of the client's financial statements is high.

\subsubsection{Influence of past enforcement reviews of clients' financial statements on audi- tor conservatism}

H1 is concerned with auditors' expectations of potentially upcoming enforcement reviews of client's financial statements and the associated risks. Furthermore, auditors' prior experiences with such reviews may also have an impact on auditor conservatism. That is because auditors who were involved in prior reviews of client's financial statements may have experienced potential consequences firsthand. Prior literature has shown that, once enforcement reviews have been conducted and sanctions have been imposed on firms or auditors, capital market effects (e.g., Hitz et al., 2012) as well as real effects on both firm managers (e.g., Arthaud-Day et al., 2006; Collins et al., 2009; Desai et al., 2006) and auditors occur. Brocard et al. (2018) propose that error announcements by the German enforcement agencies reveal information about the auditor and cause harm to the auditor's reputation. Their findings show that this loss of reputation and trust of the client in the auditor's work results in an increased probability of subsequent auditor changes by censured firms. In a similar vein, Mande and Son (2012) investigate the comparable case of financial restatements in the U.S. American setting. They also find subsequent auditor changes after firms had to announce restatements. These findings indicate that auditors potentially face severe consequences from error announcements. Hence, it is likely that auditors employ more caution once they have been affected by an enforcement review and consequently require more conservative accounting choices from their clients in order not to be harmed by possible future enforcement reviews. Therefore, we formulate our second hypothesis as follows. 
H2: Auditors who were affected by enforcement reviews of client's financial statements in the past require more conservative accounting choices from their clients.

\subsubsection{Joint influence of enforcement reviews and hierarchical level on auditor con- servatism}

Prior research has identified a variety of individual factors that may influence auditors' decision making. An important dimension that may influence the quality of an audit is the hierarchical level of the auditor (e.g., Abdolmohammadi and Wright, 1987; Ramsay, 1994). Auditors at higher hierarchical levels are likely to differ from auditors at lower hierarchical levels in several ways, for example, the experience, responsibility and personal traits that allowed them to move up the hierarchy in the first place, and thus may have different decision-making processes.

Prior research suggests that auditors with a higher level of experience apply more conservatism in planning audit efforts and the allocation of man-hours (S. Wright and A. Wright, 1997) than less experienced auditors. Even though experience and hierarchical level are separate constructs, generally, they are closely related. Therefore, these findings may indicate that higher-rank auditors, in general, may utilise more conservative decision making compared to lower-rank auditors. We aim to explore whether this expectation also holds when regarding single accounting choices and not only when planning audit efforts in general. This finding and those outlined above might stem from a higher reputational risk, especially for audit partners, and a higher level of responsibility relating partly to maintaining client relationships and potentially to being personally liable, indicating a higher level of responsiveness to the risk factors previously outlined in the development of H1. Therefore, we expect higher-rank auditors to make more conservative accounting choices than lower-rank auditors. They are likely to be more affected by the existence of an enforcement mechanism and show a higher preference for conservative accounting behaviour when the likelihood of an enforcement review is high compared to lower-rank auditors. Hackenbrack and Nelson (1996) already hint at the potentially higher sensitivity to client pressure of auditors on a higher hierarchical level. They state that "audit partners may be (...) more sensitive to litigation exposure" than individuals on lower hierarchical levels. Consequently, we expect them also to be more sensitive to pressure inflicted by an enforcement regime than auditors on lower hierarchical levels. 
Thus, we expect the hierarchical level of auditors within the firm to be an important factor influencing their behaviour towards enforcement and, hence, it may have an increasing effect on auditor conservatism. We expect this due to the increased responsibility and liability faced by auditors on higher hierarchical levels and therefore the potentially higher responsiveness to enforcement risk. It is important to investigate this effect as it would indicate a strong efficacy of enforcement's preventive function. This stems from an enforcement effect being more meaningful if it influences higher-rank auditors more strongly than lower-rank auditors. They are the ones making more significant decisions and, therefore, they might be more likely to promote conservatism and, accordingly, enforcement's preventive function. We formulate our last hypothesis as follows.

H3: The effect of the likelihood of enforcement reviews on auditors' conservatism is stronger for higher-rank auditors than for lower-rank auditors.

\subsection{Research method}

\subsubsection{Overview and design}

To test our hypotheses, we conducted an experiment with 72 auditors. The experiment employed a between-subjects design which is related to the work of Hackenbrack and Nelson (1996) who investigate the effect of engagement risk on auditor conservatism. The participants were supplied with an audit case (see Appendix) and, after carefully reading the case material, were expected to choose between a conservative and an aggressive accounting choice. The accounting choices are generally the same as used in Hackenbrack and Nelson (1996), however, the underlying accounting matter is different. All case information was kept equal between subjects, except for the likelihood of being subject to an enforcement review, which is our manipulated variable of interest. The probability of being reviewed was described as either high or low. Based on the audit case at hand, participants had to decide whether to recognise a provision for litigation costs or to disclose a contingent liability in the notes. In this case, recognition is regarded as the more conservative choice, while disclosure in the notes is the more aggressive choice as in Hackenbrack and Nelson (1996). The participants were informed that the client decided to choose the more aggressive reporting method. 


\subsubsection{Subjects}

After pilot testing our experiment with five practitioners ${ }^{15}$, we undertook the experiment with 72 auditors who worked in Australia. All participants were sourced from Qualtrics, LLC. Prior studies in auditing that have used Qualtrics LLC's services for data collection include B. E. Christensen et al. (2014), B. E. Christensen et al. (2016) and T. A. Lambert et al. (2017). Holt and Loraas (2018) test and support the suitability of auditors sourced from Qualtrics for experimental studies. It was important to the credibility and validity of our results to use practising auditors as subjects in our experiment. Recruiting auditors as participants leads to smaller samples due to their lower availability than, for instance, when recruiting students. Importantly, students would most likely not fully grasp the implications that enforcement reviews have on an auditor. To be able to test our second hypothesis, auditors on all hierarchical levels were approached. Participants were randomly assigned to the different scenarios with the likelihood of being reviewed by an enforcement agency as either high or low.

\subsubsection{Procedure and stimulus}

Data was collected between September 2017 and November 2018. The participants were provided with an online questionnaire which was sent by email. It comprised three parts. In the first part, participants were introduced to the stimulus, including introductory remarks on the broad research topic, audit case materials and excerpts of the relevant international accounting standard (IAS) 37. In the questionnaire's second part, participants were asked to decide, based on the given case information, which accounting treatment they would require from the fictitious client and to justify their decision. The third part of the questionnaire considered manipulation checks and sought information on gender, educational background, and work experience.

We chose a fictitious firm for our stimulus to mitigate familiarity biases in participants. The client was described as a manufacturer and distributor of pharmaceutical products

15 Prior to the administration of the experiment, a pilot test of the experimental stimulus and questionnaire was conducted to ensure that they were understandable, logically articulated, readable and appropriate in layout. The pilot study was trialed on five auditing practitioners. One practitioner was a partner of a Big 4 audit firm. Four auditing practitioners (Junior Auditors and Senior Auditors) also held casual academic positions at our university. All participants were approached by one of the authors and asked to complete the research instrument. Following this, the participants provided extensive face-to-face feedback to one of the authors. The five practitioners did not participate in the main experiment. Amendments made to the experimental stimulus and questionnaire after the pilot test included rephrasing and shortening some sentences that were perceived as too complex and/or vague, and swapping the order of certain questions to improve their logical flow. 
that faced a lawsuit after a substantial number of customers fell ill after consuming one of its products. The case material revealed that the lawsuit had two potential outcomes (Lewis, 1980). The client either had to settle and pay $\$ 5,000,000$ or would have no liability at all. However, uncertainty persisted about the probabilities of these potential outcomes. The stakeholders involved were not able to quantify these probabilities and expressed their uncertainty, allowing for subjective decision making by the participants who were then charged with the audit of provisions for litigation costs. They were informed that the annual report might be subject to review by an enforcement agency. The probability of such a review was either high or low, depending on the group to which the participants were randomly assigned. After the review, the enforcement agency was authorised to establish errors and enforce their disclosure.

The participants were next provided with excerpts of IAS 37 "Provisions, Contingent Liabilities and Contingent Assets", which is the relevant standard in this case. In IAS 37.14 , the cases in which provisions shall be recognised are explained. The information provided on the audit case made it relatively clear that under IAS 37 a provision would have to be recognised if it was "more likely than not that a present obligation exists at the end of the reporting period". The evidence, however, was unclear about this likelihood, leaving room for the participants' subjectivity.

Finally, the participants learned that the client decided not to recognise a provision for litigation costs to avoid violating restrictive debt covenants. A contingent liability should be disclosed instead. After receiving all this information, each participant was asked to decide whether to require the client to recognise a provision for litigation costs or to disclose a contingent liability in the notes instead, as suggested by the client.

We employed three manipulation checks to ensure that the participants were aware of the presence of the enforcement agency and the likelihood of being reviewed. Moreover, it was crucial to our design that the participants had the same impression of which reporting method was the more conservative one. Therefore, we used the questionnaire to specifically ask the participants which accounting choice they thought was more conservative, whether an enforcement agency was present and how high the likelihood of an enforcement review was. We employed these questions after the participants already decided for an accounting choice in order not to influence their decision by being able to guess the 
research question at hand. The final sample included only participants who successfully passed all our manipulation checks. ${ }^{16}$

\subsubsection{Data analysis}

\subsubsection{Sample characteristics}

Table 3.1 depicts details on the characteristics of our sample and their distribution across the two experimental conditions. Importantly, the entire sample $(\mathrm{N}=72)$ consists of professionally certified auditors who work in Australia. 90\% of the participants have lived in Australia for more than five years. The distribution across the two experimental conditions is balanced for most characteristics, except for the distribution of male and female auditors. Moreover, slightly more men than women participated in our experiment - 41 men versus 31 women. This is consistent with empirical data by Ittonen and Peni (2012) who show that the profession has more male than female auditors. Of the 72 participants included in the final sample, 30 had been affected by enforcement reviews in their professional life in the past, indicating that enforcement is not only perceived by auditors but they may also have experienced its personal work-related effects. $45.8 \%$ of our participants hold a Master's degree or higher and, on average, are very experienced in auditing (44.4\% of our participants have been working in the audit industry for more than five years). The auditors' high level of education and experience substantiates the validity of the results presented in this paper. These auditors can be expected to fully understand the audit case at hand, to be familiar with the accounting issue and to analyse all relevant information in their decision process, including, most importantly, the likelihood of an enforcement review. Finally, information on the current positions held by the participants in their respective firms shows that our sample is very diverse in that aspect, thus allowing us to test our second hypothesis.

16 In total, 198 participants took part in the study. 126 participants did not pass all three manipulation checks and were screened out. This rather stringent condition is consistent with previous studies such as Lambert et al. (2017). As a result, the final sample included 72 participants who successfully passed all manipulation checks. 
Table 3.1: Distributions of sample characteristics across the two experimental conditions

\begin{tabular}{|c|c|c|c|}
\hline & \multirow[b]{2}{*}{ Full sample $(N=40)$} & \multicolumn{2}{|c|}{ Experimental conditions } \\
\hline & & $\begin{array}{c}\text { Low review } \\
\text { likelihood }\end{array}$ & $\begin{array}{c}\text { High review } \\
\text { likelihood }\end{array}$ \\
\hline \multicolumn{4}{|l|}{ Professional certification } \\
\hline \multicolumn{4}{|l|}{ Country of residence } \\
\hline Australia & 72 & 36 & 36 \\
\hline \multicolumn{4}{|c|}{ Years lived in country of residence } \\
\hline Entire life & 36 & 17 & 19 \\
\hline 20 years or more & 13 & 6 & 7 \\
\hline $15-19$ years & 4 & 1 & 3 \\
\hline $10-14$ years & 5 & 3 & 2 \\
\hline $5-9$ years & 7 & 3 & 4 \\
\hline less than 5 years & 7 & 6 & 1 \\
\hline \multicolumn{4}{|l|}{ Gender } \\
\hline Male & 41 & 23 & 18 \\
\hline Female & 31 & 13 & 18 \\
\hline \multicolumn{4}{|c|}{ Affected by enforcement review in the past } \\
\hline Yes & 30 & 13 & 17 \\
\hline No & 42 & 23 & 19 \\
\hline \multicolumn{4}{|c|}{ Highest academic qualification } \\
\hline Bachelor's degree & 39 & 19 & 20 \\
\hline Master's degree & 29 & 15 & 14 \\
\hline Doctorate & 4 & 2 & 2 \\
\hline \multicolumn{4}{|c|}{ Work experience in auditing } \\
\hline $0-2$ years & 16 & 8 & 8 \\
\hline $3-5$ years & 24 & 10 & 14 \\
\hline 6-9 years & 14 & 9 & 5 \\
\hline More than 10 years & 18 & 9 & 9 \\
\hline \multicolumn{4}{|c|}{ Current position at respective firm } \\
\hline Junior auditor & 26 & 12 & 14 \\
\hline Senior auditor & 25 & 13 & 12 \\
\hline Audit manager & 18 & 10 & 8 \\
\hline Audit partner & 3 & 1 & 2 \\
\hline
\end{tabular}

This table displays sample characteristics and their distribution across the two experimental conditions of our subjects, including professional certification, country of residence, years lived in the country of residence, gender, being affected by an enforcement review in the past, academic qualifications, work experience and hierarchical level. This data was collected with the online questionnaire. 


\subsubsection{Questionnaire data analysis}

In order to test our hypotheses, we conduct a logit regression analysis. We control for certain personality characteristics of auditors and investigate whether our results are influenced by these characteristics. Table 3.2 summarises the variables used in the logit regression models. Our basic model is depicted below. Depending on the hypothesis we are testing, certain independent variables are added to the model.

$$
\text { Conservatism }_{i}=\text { Enforcement }_{i}+\sum \text { Controls }_{i}+\varepsilon_{i}
$$

Conservatism is the dependent dummy variable which indicates whether or not a participant decided to require the client to make the conservative accounting choice. It takes the value " 1 " if conservative accounting behaviour was required and " 0 " if not. ${ }^{17}$ Our main test variable is Enforcement. It is a dummy variable indicating the likelihood of being subject to an enforcement review ("1" = enforcement review likelihood is high; "0" = enforcement review likelihood is low).

To test H1, we estimate the basic logit regression model from above including only our main test variable Enforcement and the controls (model (1)). Moreover, to test H2 we specify model (2) where we implement the variable Affected in addition to Enforcement. Affected is a dummy variable indicating that a participant has been affected by an enforcement review in the past. We expect auditors who were affected by enforcement reviews in the past to employ more conservative decision making. Finally, to test H3 we estimate model (3), where Hierarchy and the interaction term Hierarchy*Enforcement are added to the basic logit model. Hierarchy is a dummy variable indicating that a participant is an audit manager or higher in his/her firm. ${ }^{18} \mathrm{We}$ expect auditors on higher hierarchical levels to be more conservative and to be more affected by the likelihood of an enforcement review as described in $\mathrm{H} 3$.

The control variables are defined as follows. Settlement Probability represents the probability of a settlement needing to be paid by the client as estimated by the participants.

17 Measuring Conservatism with a binary variable is in line with Hackenbrack and Nelson's (1996) research design and appears more appropriate than using a continuous variable, e.g., a required amount of a provision for litigation costs. In order to employ a continuous variable, the audit case material would need to be much more detailed. A longer and more complex audit case could undermine the understandability of the case and, hence, jeopardise the experiment's results.

18 We also carried out our analyses with different scales of Hierarchy. For instance, we rescaled Hierarchy so it indicates that a participant is a senior auditor or higher. The results do not change when measuring this variable differently. Moreover, replacing Hierarchy with variables dependent on being the lead auditor at a current or a past mandate does not change the results either. 
We include this control variable as we deem it crucial to our experimental design that the participants estimate the likelihood of such a settlement to be roughly around $50 \%$. Strongly diverging estimations could influence the accounting choice and, thus, we need to control for this factor. Next, we include the control variable Task Experience that accounts for how familiar a participant is with the audit task at hand and how frequently he/she works on such accounting issues. We arrive at Task Experience by merging the two variables Familiarity and Frequency. Familiarity measures the degree to which a participant is familiar with the audit task at hand - provisions for litigation costs - while Frequency measures the degree to which the participant works on such audit tasks on a regular basis. Both variables are measured using a seven-point Likert scale ranging from "not at all familiar"/"not at all frequent" to "highly familiar"/"highly frequent". Furthermore, we include Work Experience, which is a binary variable indicating that a participant has been working in the auditing profession for at least two years. ${ }^{19}$ Education is a dummy variable indicating that the participant holds a Master's Degree or higher. Gender is a binary variable that has the value "1" if the participant is male. Finally, we include two control variables that represent specific character traits of the participants. Agreeableness and Conscientiousness are both based on the Mini-International Personality Item PoolFive-Factor (IPIP) Scales of personality (Donnellan et al., 2006). We arrive at these measures by asking the participants to indicate the accuracy with which certain statements describe them on a five-point Likert scale from "Very Inaccurate" to "Very Accurate". Agreeableness represents the degree to which a participant is likely to agree with someone else to keep a harmonious relationship. In our setting, we expect participants with higher Agreeableness to be more likely to concur with the client's accounting choice and, therefore, that they will not require conservative accounting from the client. Conscientiousness generally describes how likely someone is to follow their inner sense of what is right. Therefore, we expect participants with high Conscientiousness to be more likely to require conservative accounting choices from the client.

19 We also carried out our analyses with different scales of Work Experience. For instance, we rescaled Work Experience so it indicates that a participant has been working in the auditing profession for at least five years. The results do not change when measuring this variable differently. 
Table 3.2: Variables measurement - determinants of conservative disclosure choices

\begin{tabular}{|c|c|}
\hline Variable name & Definition \\
\hline Conservatism & $\begin{array}{l}\text { Dummy variable indicating that a participant decided to require } \\
\text { the client to make a conservative disclosure choice }\end{array}$ \\
\hline Enforcement & $\begin{array}{l}\text { Dummy variable indicating the likelihood of being subject to an } \\
\text { enforcement review ("1" = high; "0" = low) }\end{array}$ \\
\hline Hierarchy & $\begin{array}{l}\text { Dummy variable indicating that a participant is an audit } \\
\text { manager or higher in his/her firm }\end{array}$ \\
\hline Affected & $\begin{array}{l}\text { Dummy variable indicating that a participant has been affected } \\
\text { by an enforcement review in the past }\end{array}$ \\
\hline Settlement Probability & $\begin{array}{l}\text { Probability of a settlement needed to be paid to clients as } \\
\text { estimated by participant }\end{array}$ \\
\hline Familiarity & $\begin{array}{l}\text { Degree to which the participant is familiar with the audit task at } \\
\text { hand }\end{array}$ \\
\hline Frequency & $\begin{array}{l}\text { Degree to which the participant works on comparable audit tasks } \\
\text { on a regular basis }\end{array}$ \\
\hline Work Experience & $\begin{array}{l}\text { Dummy variable indicating that a participant has been working } \\
\text { in the auditing profession for at least two years }\end{array}$ \\
\hline Education & $\begin{array}{l}\text { Dummy variable indicating that a participant holds a Master's } \\
\text { Degree or higher }\end{array}$ \\
\hline Gender & $\begin{array}{l}\text { Dummy variable indicating the gender of a participant ("1" = } \\
\text { male; "0" = female) }\end{array}$ \\
\hline Agreeableness & $\begin{array}{l}\text { Degree to which the participant is likely to agree to someone } \\
\text { else; this variable is based on the Mini-IPIP Scales of personality } \\
\text { developed by Donnellan et al. (2006) }\end{array}$ \\
\hline Conscientiousness & $\begin{array}{l}\text { Degree of a participant's conscientiousness or sense of duty; this } \\
\text { variable is based on the Mini-IPIP Scales of personality } \\
\text { developed by Donnellan et al. (2006) }\end{array}$ \\
\hline
\end{tabular}

\subsection{Results and discussion}

\subsubsection{Descriptive statistics and correlations}

Table 3.3 displays the descriptive statistics of the variables used in our logit regression models. It is worth noting, for instance, that our participants are relatively experienced, with $76 \%$ of the participants having worked in the audit industry for two years or more and $29 \%$ being audit managers or higher in their respective firms. More importantly, the mean estimated Settlement Probability is $45.96 \%$ and the median is 50\%. This shows that our experimental design was successful in creating an ambiguous scenario in which the auditors estimate the probability of the requirement of a settlement to be approximately $50 \%$. This is important to our study as we need an ambiguous case where the "correct" accounting choice is not distinctly identifiable. Correlations of the variables at hand are 
displayed in Table 3.4. For instance, we find a significant positive correlation between Task Experience and Work Experience (0.3162).

Table 3.3: Descriptive statistics of conservative disclosure choices

\begin{tabular}{lcccccr}
\hline Variable & Mean & $\begin{array}{c}\text { Standard } \\
\text { deviation }\end{array}$ & Median & Min. & Max. & N \\
\hline Conservatism & 0.63 & 0.49 & 1.00 & 0.00 & 1 & 72 \\
Enforcement & 0.50 & 0.50 & 0.50 & 0.00 & 1 & 72 \\
Hierarchy & 0.29 & 0.46 & 0.00 & 0.00 & 1 & 72 \\
Affected & 0.42 & 0.50 & 0.00 & 0.00 & 1 & 72 \\
Settlement & 45.96 & 22.84 & 50.00 & 1.00 & 100 & 72 \\
Probability & 7.85 & 3.48 & 8.00 & 2.00 & 14 & 72 \\
Task Experience & 0.76 & 0.43 & 1.00 & 0.00 & 1 & 72 \\
Work Experience & 0.46 & 0.50 & 0.00 & 0.00 & 1 & 72 \\
Education & 0.58 & 0.50 & 1.00 & 0.00 & 1 & 72 \\
Gender & 13.40 & 2.86 & 13.00 & 8.00 & 20 & 72 \\
Agreeableness & 13.61 & 2.95 & 13.00 & 7.00 & 20 & 72 \\
Conscientiousness & This table displays the descriptives for the variables used in the determinants model in Table 3.6. \\
Definitions of variables are reported in Table 3.2.
\end{tabular}


Table 3.4: Correlations of conservative disclosure choices.

\begin{tabular}{|c|c|c|c|c|c|c|c|c|c|c|c|c|}
\hline Variable & & (1) & $(2)$ & (3) & (4) & $(5)$ & $(6)$ & $(7)$ & $(8)$ & (9) & $(10)$ & (11) \\
\hline Conservatism & (1) & 1 & & & & & & & & & & \\
\hline Hierarchy & (3) & -0.0710 & -0.0306 & 1 & & & & & & & & \\
\hline Settlement Probability & (5) & 0.0429 & -0.1598 & -0.0918 & -0.0320 & 1 & & & & & & \\
\hline Task Experience & (6) & 0.2315 & -0.0040 & 0.2407 & 0.2657 & -0.0079 & 1 & & & & & \\
\hline Work Experience & (7) & 0.1773 & 0.0327 & 0.2129 & 0.3372 & 0.0019 & 0.3162 & 1 & & & & \\
\hline Agreeableness & (10) & -0.1628 & -0.0049 & 0.0058 & -0.3677 & 0.0632 & -0.1692 & -0.2089 & 0.0168 & -0.0686 & 1 & \\
\hline Conscientiousness & (11) & -0.1715 & -0.1613 & 0.0435 & -0.3015 & 0.0640 & -0.1528 & 0.0937 & 0.1793 & -0.0064 & 0.3995 & 1 \\
\hline
\end{tabular}




\subsubsection{Testing the influence of enforcement on auditor conservatism (H1)}

Table 3.5 reports participants' accounting choices depending on what likelihood of an enforcement review they are randomly assigned to. The data in Table 3.5 shows that, when the enforcement review likelihood was low, 23 of the 36 auditors (63.88\%) decided to require the client to recognise a provision. When the enforcement review likelihood was high, a similar amount of auditors (22 of the 36 auditors; $61.11 \%$ ) required this conservative accounting behaviour from their clients. Given that the number of auditors making conservative decisions is almost the same in both groups, this already hints at our first hypothesis not being supported.

Table 3.5: $\quad$ Selected disclosure choices

\begin{tabular}{|c|c|c|c|}
\hline \multicolumn{4}{|c|}{ Likelihood of enforcement review } \\
\hline \multicolumn{2}{|c|}{ Low } & \multicolumn{2}{|c|}{ High } \\
\hline Provision & Contingent liability & Provision & Contingent liability \\
\hline 23 & 13 & 22 & 14 \\
\hline
\end{tabular}

As depicted in Table 3.6 and described in 3.3.4.2, we estimate a total of three different logit regression models with Conservatism being the dependent variable and Enforcement, Affected and Hierarchy*Enforcement being the independent variables of interest. Firstly, we test H1 in model (1) and in contrast to our expectation as well as indicated by the descriptive results in Table 3.5, we find no significant relationship between Conservatism and Enforcement. Even after controlling for a variety of variables, the higher likelihood of an enforcement review appears not to be related to conservative auditing behaviour. Hence, we do not find evidence in support of H1. 
Table 3.6: Determinants of conservative disclosure choices

\begin{tabular}{|c|c|c|c|}
\hline Variable & $(1)$ & $(2)$ & (3) \\
\hline \multirow[t]{2}{*}{ Enforcement } & -0.2773 & -0.5797 & -0.4805 \\
\hline & $(-0.51)$ & $(-0.95)$ & $(-0.71)$ \\
\hline \multirow[t]{2}{*}{ Affected } & & $2.6824 * * *$ & \\
\hline & & (3.19) & \\
\hline \multirow[t]{2}{*}{ Hierarchy } & & & -1.3832 \\
\hline & & & $(-1.55)$ \\
\hline \multirow[t]{2}{*}{ Hierarchy*Enforcement } & & & 0.4149 \\
\hline & & & $(0.34)$ \\
\hline \multirow[t]{2}{*}{ Settlement Probability } & 0.0050 & 0.0086 & 0.0036 \\
\hline & $(0.39)$ & $(0.58)$ & $(0.27)$ \\
\hline \multirow[t]{2}{*}{ Task Experience } & 0.1009 & 0.0893 & 0.1333 \\
\hline & $(1.19)$ & $(0.89)$ & $(1.48)$ \\
\hline \multirow[t]{2}{*}{ Work Experience } & 0.5904 & -0.2175 & 0.8166 \\
\hline & $(0.89)$ & $(-0.29)$ & $(1.15)$ \\
\hline \multirow[t]{2}{*}{ Education } & $0.9821 *$ & $1.1144^{*}$ & $1.3199 * *$ \\
\hline & $(1.78)$ & $(1.72)$ & $(2.15)$ \\
\hline \multirow[t]{2}{*}{ Gender } & 0.2204 & 0.4362 & 0.2319 \\
\hline & $(0.40)$ & $(0.72)$ & $(0.42)$ \\
\hline \multirow[t]{2}{*}{ Agreeableness } & -0.0320 & 0.0651 & -0.0295 \\
\hline & $(-0.31)$ & $(0.56)$ & $(-0.27)$ \\
\hline \multirow[t]{2}{*}{ Conscientiousness } & -0.1523 & -0.0848 & -0.1606 \\
\hline & $(-1.45)$ & $(-0.71)$ & $(1.48)$ \\
\hline \multirow[t]{2}{*}{ Constant } & 1.1719 & -1.3991 & 1.2169 \\
\hline & $(0.61)$ & $(-0.60)$ & $(0.60)$ \\
\hline Pseudo $\mathrm{R}^{2}$ & 0.11 & 0.26 & 0.15 \\
\hline $\mathrm{N}$ & 72 & 72 & 72 \\
\hline
\end{tabular}

This table displays coefficient estimates and t-statistics from a logit model. The regression model is based on the responses of 72 auditors to our online questionnaire. The dependent variable is a binary variable indicating that a participant decided to require the client to make a conservative accounting choice. Definitions of variables are reported in Table 3.2. t-values are reported in parentheses. ***, **, and * indicate significance at the $1 \%, 5 \%$, and $10 \%$ levels, respectively.

Our results show that, on average, auditors already employ conservative behaviour regardless of the enforcement risk. The risk factors outlined earlier that drive auditors' conservatism (e.g., reputation risk and litigation risk) are possibly already strong enough to promote a certain level of conservatism that cannot be increased by enforcement scrutiny. Moreover, auditors might be influenced by their firm's internal training, which could promote conservatism as well as professional codes of conduct and ethics. The latter explanation is supported by $\mathrm{Ng}$ and Tan's (2003) findings that auditors are more likely to opt for the conservative accounting choice in the presence of authoritative guidance in this 
direction. Moreover, those who choose to become auditors, in general, might be more conservative in nature. Hence, enforcement supervision and the likelihood of being subject to an enforcement review alone seemingly are not a potential means to increase auditor conservatism nor eventually accounting quality.

\subsubsection{Testing the influence of being affected by enforcement reviews in the past on auditor conservatism (H2)}

Table 3.7 shows the number of participants per disclosure choice based on whether they were affected by an enforcement review in the past. Interestingly, 27 of the 30 participants who were directly affected by an enforcement review in the past decided to require the client to recognise a provision for litigation costs (i.e., the more conservative choice). On the other hand, participants who had not been affected by an enforcement review before show a more balanced distribution of disclosure choices. In this group, 18 participants required the recognition of a provision, whereas 24 participants approved the disclosure in the notes. This suggests that past experiences with enforcement reviews may be associated with more conservative decision making by the auditors.

Importantly, the number of participants who had experiences with enforcement in the past is quite similar in both treatment conditions. Hence, the suggested association between past experiences with enforcement and conservative decision making is not likely to be attributed to the allocation of participants. In the group with participants who were affected by enforcement reviews in the past, 17 participants were exposed to the high likelihood of an enforcement review (approximately 47\%). Of those participants who have never been affected by an enforcement review in the past, 19 participants were exposed to the high likelihood of an enforcement review (approximately 53\%).

Table 3.7: Selected disclosure choices depending on past enforcement experiences

\begin{tabular}{|c|c|c|c|}
\hline \multicolumn{4}{|c|}{ Affected by enforcement review in the past } \\
\hline \multicolumn{2}{|c|}{ Yes } & \multicolumn{2}{|c|}{ No } \\
\hline Provision & Contingent liability & Provision & Contingent liability \\
\hline 27 & 3 & 18 & 24 \\
\hline
\end{tabular}


In model (2) of Table 3.6, we include the variable Affected, indicating that a participant was affected by an enforcement review in the past. We find a significant positive association at the $1 \%$ level between Affected and Conservatism. This indicates that auditors who were subject to an enforcement review in the past employ more conservative decision making. Thus, we find supportive evidence for $\mathrm{H} 2$. In conjunction with our findings with regard to $\mathrm{H} 1$, this suggests that the presence of an enforcement agency and more specifically the likelihood of an enforcement review of the client's financial statements does not lead to more auditor conservatism, however, once reviews are conducted and auditors are directly confronted with the risks associated with enforcement reviews this may promote conservatism. Hence, our findings suggest that past experiences with enforcement reviews do increase auditor conservatism, while the sheer expectations of what might be associated with such a review do not. As such, to strengthen enforcement's preventive function, it may be necessary to enhance the frequency of enforcement reviews.

\subsubsection{Testing the joint influence of enforcement and hierarchical level on auditor conservatism (H3)}

We test our third and final hypothesis by estimating model (3) as depicted in Table 3.6, which includes the variable Hierarchy and the interaction term Hierarchy*Enforcement. We find a positive coefficent for the interaction term, indicating that for higher-rank auditors conservatism increases stronger with enforcement review likelihood than for lowerrank auditors. However, these results are not significant and, therefore, we do not find supportive evidence for our third hypothesis (H3). Thus, higher-rank auditors and their decision making are not significantly more influenced by the likelihood of an enforcement review than their lower-rank peers.

\subsection{Conclusion}

In this experimental study, we investigate enforcement's preventive function via the influence enforcement reviews of client's financial statements may have on auditor's decisions. More precisely, we examine whether the likelihood that the client's financial statements are being subjected to an enforcement review has an impact on conservatism in auditors' decision making. To test this, we carry out an experiment with 72 auditors who had to choose between a conservative or an aggressive accounting choice after reading an audit case outlining that the client's financial statements may be subjected to an enforcement review. 
We find that a higher likelihood of enforcement reviews of client's financial statements is not related to auditors employing more conservative accounting decisions. Our descriptive results, in fact, show that auditors already employ conservative decision making regardless of how high the likelihood of an enforcement review is. Potentially, professional codes of conduct and ethics as well as the risk factors auditors are exposed to (i.e., litigation risk, risk of client loss and reputation risk) already condition auditors in their decision making. Firms' internal training might further promote conservatism, thus employing sufficient pressure on auditors. Moreover, those who choose to become auditors, in general, might be more conservative in nature. Therefore, we conclude that the indirect effects of enforcement on accounting quality via auditors are potentially fairly weak in the context of enforcement reviews of the client's financial statements. Enforcement effects on accounting quality, hence, appear to stem more from the direct effects on firm managers who prepare the accounts.

Interestingly, however, our findings show that auditors who were affected by enforcement reviews of a client's financial statements in the past employ more conservative decision making than those who have never had to deal with enforcement reviews in their careers. Apparently, enforcement supervision does not have a significant effect on auditors' conservatism until an auditor was directly confronted with a review of a client's financial statements and has experienced the associated consequences firsthand. This indicates that the preventive function of enforcement starts becoming effective once auditors directly experienced the risks associated with an enforcement review of the client's financial statements, which hints at the possibility of promoting conservatism through increasing the frequency of enforcement reviews. Finally, we do not find significant differences between higher-rank auditors' conservatism and lower-rank auditors' conservatism.

The results of this study should be viewed in light of certain limitations. First, our audit case described an accounting issue in the context of the pharmaceutical industry, so generalisation to other industries may be limited. Second, we were only able to procure 72 auditors, which may have impacted our observations when implementing an interaction term to test the third hypothesis. We encourage future research that employs larger sample sizes, where possible. Third, we did not distinguish between auditors who are working for larger or smaller firms. As it is possible that workplace culture is influencing auditors' judgments, we encourage future research to examine how workplace culture may influence auditors' conservatism in the context of our study. Finally, our sample consists of auditors working in Australia, so generalisations to other countries may be limited. Future 
research may examine whether cultural differences will impact auditors' judgments in the context of our study. 


\subsection{Appendix}

\section{Appendix A: Research instrument}

The following shows the audit case and questionnaire the participants of the experiment were presented with.

\section{Introduction}

The purpose of this study is to understand the relationship between firms, auditors and enforcement bodies in the preparation and publication of financial statements. After being presented with an audit case and the relevant accounting standard, you will be asked to make an accounting choice and answer several related questions. Please answer all questions as close to practice as possible by checking the most applicable box or filling in the blanks. All participation is voluntary and anonymous and the data will be handled strictly confidential. By continuing this survey, you give your consent for participation. 


\section{Audit case \& accounting issue}

You are conducting the audit of Pharma Ltd (client), which is a major and well-diversified manufacturer and distributor of pharmaceutical products. Pharma Ltd. has been in the market for 20 years and maintains a financial position near the industry average. The client is listed on a regulated stock exchange, has to report under International Financial Reporting Standards (IFRS) and its audited financial statements are subject to the surveillance of a supervisory enforcement body.

The client currently faces a lawsuit as a substantial number of customers fell ill after consuming "Artogin", which is one of Pharma's products designed to lower blood pressure. Through the solicitors' representation letters, you are informed that the product liability suit has two potential outcomes. The client would either have to settle and pay $\$ 5,000,000$ or would have no liability at all. There have been comparable cases in the past where the client was forced to settle. However, in just as many cases the charges were dropped. Thus, the client agrees that it is very difficult to predict the likelihood of either outcome. To eliminate any danger of biased assessments, your auditing firm retained its own highly regarded counsel Jennifer Hardman to provide advice on the two possible outcomes. In her analyses, Jennifer specifically focused on competitors' lawsuits within the same industry and concludes that with the information at hand it is not possible to narrow down the probabilities.

With the audit report due to be signed and released in five days' time, the audit of provisions for litigation costs needs to be finalised. The annual report might be subject to review by the enforcement agency. The likelihood of such a review is expected to be low/high (depending on what group the participant was randomly assigned to) this year. 


\section{Applicable accounting standard \& potential reporting methods}

In this specific case, IAS 37 "Provisions, Contingent Liabilities and Contingent Assets" is the relevant standard. Below you will find extracts of the standard. Do not take any other potentially relevant accounting standards into account in this matter.

IAS 37.14 explains in which cases provisions shall be recognised. It states: "A provision shall be recognized when:

(a) An entity has a present obligation (legal or constructive) as a result of a past event;

(b) it is probable that an outflow of resources embodying economic benefits will be required to settle the obligation; and

(c) a reliable estimate can be made of the amount of the obligation.

If these conditions are not met, no provision shall be recognized".

IAS 37.16 states: "In rare cases, for example in a lawsuit, it may be disputed either whether certain events have occurred or whether those events result in a present obligation. In such a case, an entity determines whether a present obligation exists at the end of the reporting period by taking account of all available evidence, including, for example, the opinion of experts. The evidence considered includes any additional evidence provided by events after the reporting period. On the basis of such evidence:

(a) where it is more likely than not that a present obligation exists at the end of the reporting period, the entity recognizes a provision (if the recognition criteria are met); and

(b) where it is more likely that no present obligation exists at the end of the reporting period, the entity discloses a contingent liability, unless the possibility of an outflow of resources embodying economic benefits is remote (see paragraph 86)". 


\section{The client's accounting choice}

The client's CFO Patrick Pierce informs you that the firm's restrictive debt covenants require the firm to stay below a 2:1 debt-to-equity ratio. Currently, the client has almost reached this threshold of 2:1 and recognising a provision would lead to a violation of the debt covenants. The client decided not to recognise a provision for litigation costs. A contingent liability is being disclosed instead. Patrick argues that this treatment is justified as it cannot be clearly decided whether it is more likely than not that a present obligation exists at the end of the accounting period. Patrick is confident that the firm will not have to settle in the respective case.

You now have to decide whether you agree with the client's reporting method or require the firm to recognise a provision for litigation costs. 


\section{Additional information}

- There have been numerous discussions between members of the audit team and all appropriate client staff to evaluate the probability that a present obligation exists at the end of the accounting period. No additional insights resulted from these discussions.

- The client's management was very outspoken and straightforward throughout the entire audit. Thus, there is no additional information available beyond that already supplied in the case. 
1. Which accounting choice would you require from the client?

\section{(Select only one.)}

$\square$ Recognise a provision for litigation costs

$\square$ Disclosure of a contingent liability in the notes

2. Please justify your choice.

3. With the given information, how high do you estimate the probability of a settlement to be? Please provide a percentage value. 
4. Which accounting choice did you think was more conservative?

(Select only one.)

$\square$ Recognise a provision for litigation costs

$\square$ Disclosure of a contingent liability in the notes

5. Did an enforcement regime exist that potentially reviews audited financial statements?

(Select only one.)

$\square$ Yes

$\square$ No

$\square$ Not sure

6. How high is the likelihood of an enforcement review expected to be in the given year?

(Select only one.)

$\square$ Low

$\square$ High

$\square$ Other

7. Have you ever been personally affected by an enforcement investigation in your professional life?

(Select only one.)

$\square$ Yes

$\square$ No

8. Have you ever been personally involved in enforcement-related consulting in your professional life?

(Select only one.)

$\square$ Yes

$\square$ No

9. How familiar are you with the audit task in the case - provisions for litigation costs?

Not at all

Highly

familiar

familiar

$\begin{array}{lllllll}1 & 2 & 3 & 4 & 5 & 6 & 7\end{array}$

10. How frequently have you worked on such audit tasks before-provisions for litigation costs?

Not at all

frequent
Highly

frequent

$\begin{array}{lllllll}1 & 2 & 3 & 4 & 5 & 6 & 7\end{array}$




\section{Your Gender}

(Select only one.)

$\square$ Female

$\square$ Male

12. In which country were you born?

13. In which country do you work?

14. Which culture do you most identify with?

(Select only one.)
$\square$ Aboriginal and Torres Strait Islander
$\square$ Anglo/European
$\square$ Chinese and North Asian
$\square$ South East Asian
$\square$ South Asian
$\square$ South American
$\square$ African
$\square$ Middle Eastern
$\square$ Other

15. How long have you lived in the country, in which you currently work?

(Select only one.)
$\square$ All my life
$\square 20$ years or more
$\square 15-19$ years
$\square 10-14$ years
$\square 5-9$ years
$\square$ less than 5 years

16. Your Highest Academic Qualification

\section{(Select only one.)}
$\square$ Bachelor's Degree
$\square$ Master's Degree
Doctorate

17. In which country did you receive most of your education? 
18. Your Work Experience as an Auditor

(How many years have you been working in accounting respectively auditing?)

$\square 0-2$

$\square 3-5$

$\square 6-9$

$\square$ More than 10 years

19. Which of the following best describes your current position in your firm?

(Select only one.)

$\square$ Junior Auditor

$\square$ Senior Auditor

$\square$ Audit Manager

$\square$ Audit Partner

20. Are you a Chartered Accountant (CA), Certified Public Accountant (CPA) or equivalent?

(Select only one.)

$\square$ Yes

$\square$ No

$\square$ Other

21. Are you currently the auditor in charge for an audit engagement of your firm?

(Select only one.)

$\square$ Yes

$\square$ No

22. Have you ever been the auditor in charge for an audit engagement in the past?

(Select only one.)

$\square$ Yes

$\square \mathrm{No}$ 
23. For each of the following statements, please indicate the likelihood that you would engage in the described activity or behaviour if you were to find yourself in that situation. Provide a rating from extremely unlikely to extremely likely using the following scale.

\begin{tabular}{|c|c|c|c|c|c|c|c|}
\hline & $\begin{array}{l}\text { Ex- } \\
\text { tremely } \\
\text { unlikely }\end{array}$ & $\begin{array}{l}\text { Moder- } \\
\text { ately } \\
\text { unlikely }\end{array}$ & $\begin{array}{c}\text { Some- } \\
\text { what } \\
\text { unlikely }\end{array}$ & $\begin{array}{c}\text { Neither } \\
\text { unlikely } \\
\text { nor } \\
\text { likely } \\
\end{array}$ & $\begin{array}{l}\text { Some- } \\
\text { what } \\
\text { likely }\end{array}$ & $\begin{array}{l}\text { Moder- } \\
\text { ately } \\
\text { likely }\end{array}$ & $\begin{array}{l}\text { Ex- } \\
\text { tremely } \\
\text { likely }\end{array}$ \\
\hline $\begin{array}{l}\text { Admitting that } \\
\text { your tastes are } \\
\text { different from } \\
\text { those of a } \\
\text { friend. }\end{array}$ & $\mathrm{O}$ & $\mathrm{O}$ & $\mathrm{O}$ & $\mathrm{O}$ & $\mathrm{O}$ & $\mathrm{O}$ & $\mathrm{O}$ \\
\hline $\begin{array}{l}\text { Disagreeing } \\
\text { with an } \\
\text { authority figure } \\
\text { on a major } \\
\text { issue. }\end{array}$ & $\mathrm{O}$ & $\mathrm{O}$ & $\mathrm{O}$ & $\mathrm{O}$ & $\mathrm{O}$ & $\mathrm{O}$ & $\mathrm{O}$ \\
\hline $\begin{array}{l}\text { Choosing a } \\
\text { career that you } \\
\text { truly enjoy over } \\
\text { a more secure } \\
\text { one. }\end{array}$ & $\mathrm{O}$ & $\mathrm{O}$ & $\mathrm{O}$ & $\mathrm{O}$ & $\mathrm{O}$ & $\mathrm{O}$ & $\mathrm{O}$ \\
\hline $\begin{array}{l}\text { Speaking your } \\
\text { mind about an } \\
\text { unpopular issue } \\
\text { in a meeting at } \\
\text { work. }\end{array}$ & $\mathrm{O}$ & $\mathrm{O}$ & $\mathrm{O}$ & $\mathrm{O}$ & $\mathrm{O}$ & $\mathrm{O}$ & $\mathrm{O}$ \\
\hline $\begin{array}{l}\text { Moving to a } \\
\text { city far away } \\
\text { from your } \\
\text { extended } \\
\text { family. }\end{array}$ & $\mathrm{O}$ & $\mathrm{O}$ & $\mathrm{O}$ & $\mathrm{O}$ & $\mathrm{O}$ & $\mathrm{O}$ & $\mathrm{O}$ \\
\hline $\begin{array}{l}\text { Starting a new } \\
\text { career in your } \\
\text { mid-thirties. }\end{array}$ & $\mathrm{O}$ & $\mathrm{O}$ & $\mathrm{O}$ & $\mathrm{O}$ & $\mathrm{O}$ & $\mathrm{O}$ & $\mathrm{O}$ \\
\hline
\end{tabular}


24. For each of the following statements please indicate the accuracy with which they describe you. Provide a rating from very inaccurate to very accurate using the following scale.

\begin{tabular}{|c|c|c|c|c|c|}
\hline & $\begin{array}{c}\text { Very } \\
\text { inaccurate }\end{array}$ & $\begin{array}{c}\text { Moderately } \\
\text { inaccurate }\end{array}$ & $\begin{array}{c}\text { Neither } \\
\text { inaccurate } \\
\text { nor accurate }\end{array}$ & $\begin{array}{l}\text { Moderately } \\
\text { accurate }\end{array}$ & $\begin{array}{l}\text { Very } \\
\text { accurate }\end{array}$ \\
\hline $\begin{array}{l}\text { I sympathise } \\
\text { with others' } \\
\text { feelings. }\end{array}$ & $\mathrm{O}$ & $\mathrm{O}$ & $\mathrm{O}$ & $\mathrm{O}$ & $\mathrm{O}$ \\
\hline $\begin{array}{l}\text { I get chores } \\
\text { done right away. }\end{array}$ & $\mathrm{O}$ & $\mathrm{O}$ & $\mathrm{O}$ & $\mathrm{O}$ & $\mathrm{O}$ \\
\hline $\begin{array}{l}\text { I feel others' } \\
\text { emotions. }\end{array}$ & $\mathrm{O}$ & $\mathrm{O}$ & $\mathrm{O}$ & $\mathrm{O}$ & $\mathrm{O}$ \\
\hline I like order. & & & & & \\
\hline & $\mathrm{O}$ & $\mathrm{O}$ & $\mathrm{O}$ & $\mathrm{O}$ & $\mathrm{O}$ \\
\hline $\begin{array}{l}\text { I am not } \\
\text { interested in } \\
\text { other people's } \\
\text { problems. }\end{array}$ & $\mathrm{O}$ & $\mathrm{O}$ & $\mathrm{O}$ & $\mathrm{O}$ & $\mathrm{O}$ \\
\hline $\begin{array}{l}\text { I often forget to } \\
\text { put things back } \\
\text { in their proper } \\
\text { place. }\end{array}$ & $\mathrm{O}$ & $\mathrm{O}$ & $\mathrm{O}$ & $\mathrm{O}$ & $\mathrm{O}$ \\
\hline $\begin{array}{l}\text { I am not really } \\
\text { interested in } \\
\text { others. }\end{array}$ & $\mathrm{O}$ & $\mathrm{O}$ & $\mathrm{O}$ & $\mathrm{O}$ & $\mathrm{O}$ \\
\hline $\begin{array}{l}\text { I make a mess } \\
\text { of things. }\end{array}$ & $\mathrm{O}$ & $\mathrm{O}$ & $\mathrm{O}$ & $\mathrm{O}$ & $\mathrm{O}$ \\
\hline
\end{tabular}




\section{The Role of Enforcement in Shaping Conservative Accounting Choices}

Henning Schnack ${ }^{20}$

Working Paper, Georg-August-Universität Göttingen and Macquarie University, Sydney $^{21}$

Abstract: In this paper, I investigate the association of substantive changes in enforcement with accounting conservatism, using a broad cross-country setting with staggered enforcement changes. I find for a sample of non-IFRS-adopting countries that substantive enforcement changes are significantly and positively associated with accounting conservatism. Examining a sample of IFRS countries does not lead to significant results. Moreover, I find weak evidence that firms with weak corporate governance are more profoundly affected by enforcement changes in their conservative accounting choices than firms with strong corporate governance. I interpret these findings as an indicator of the efficacy of enforcement's preventive function.

JEL Classification: M41, M48

Keywords: enforcement, regulation, conservatism, conditional conservatism, corporate governance, IFRS

Acknowledgements: I thank Joerg-Markus Hitz, Andreas Hellmann, Nico Lehmann, Florian Moritz and Ann-Kristin Großkopf for their helpful comments and suggestions.

${ }^{20}$ Georg-August Universität Göttingen, Faculty of Economic Sciences, Chair of Accounting and Auditing, Platz der Göttinger Sieben 3, 37073 Göttingen, Germany \& Macquarie University Sydney, Faculty of Business and Economics, Department of Accounting and Corporate Governance, 4 Eastern Road, NSW 2109, Australia.

21 First version of the working paper: July 2018. This version: September 2018. 


\subsection{Introduction}

In this paper, I investigate the association between substantive changes in accounting enforcement and conditional accounting conservatism. A broad stream of literature corroborates the importance of enforcement bodies and their actions which mainly involve reviewing audited financial statements and imposing sanctions such as enforcing the publication of error findings. This importance mainly constitutes itself in capital market effects but also in direct effects on the decision making of involved stakeholders. For instance, H. B. Christensen et al. (2013) ${ }^{22}$ find that the introduction of International Financial Reporting Standards (IFRS) for listed firms in the European Union (EU) coincided with significant increases in liquidity, mainly in those countries which had concurrently carried out substantive changes in their enforcement regulation by either installing new enforcement bodies or increasing the power of those already in existence. Moreover, several studies explore the consequences of enforcement actions (e.g., Brocard et al., 2018; Hitz et al., 2012) which represents an investigation of enforcement's sanctioning function. Hitz et al. (2012), for instance, find negative market reactions following error announcements established by enforcers in the German setting.

While a large amount of evidence shows that IFRS adoption and substantive changes in enforcement regulation are associated with capital market effects, evidence is scarce and inconclusive on the effects on accounting properties, such as conservatism, or on the comparability of accounting across jurisdictions, which might drive the observed capital market effects. Prior studies do not unanimously support the notion that financial reporting and disclosure regulation lead to more transparency and comparability nor that positive economic consequences will follow (Brüggemann et al., 2013; Leuz and Wysocki, 2016).

Given the lack of consistent findings on enforcement's effects on accounting properties, this paper examines the role of enforcement in shaping accounting conservatism. Conservatism is regarded as the most influential principle of valuation in accounting (Sterling, 1970) and it is estimated to have influenced accounting practice for at least five centuries (Basu, 1997). Basu (1997) defines conservatism in accounting as "the accountant's tendency to require a higher degree of verification to recognize good news as gains than to recognize bad news as losses". Thus, the greater the difference in the degree of verifica-

22 Below, I refer to the H. B. Christensen et al. (2013) study as CHL (2013). 
tion required for gains versus losses, the greater the conservatism. It is likely that enforcement institutions particularly target discretionary accounting choices, such as the recognition of provisions or intangibles, leading to more conservative accounting behaviour. Hence, this would be associated with less aggressive accounting choices and less erroneous and fraudulent financial reporting. For instance, Watts (2003b) points out that conservatism "is critical to constraining manipulation and fraud" as it decreases the leeway for manipulation of accounting numbers. More conservative accounting choices, as a response to enforcement, would thus also indicate the efficacy of enforcement's preventive function as this function aims to decrease fraudulent and erroneous accounting in the first place. Conservatism theory developed by Watts (2003a) hints at enforcement potentially being a source of conservative accounting behaviour. I aim to investigate this relationship and expect that a strengthening of accounting enforcement is associated with an increase in conservatism.

I expect a positive association between the strengthening of enforcement and conservative accounting choices based on two explanations for accounting conservatism brought forward by Watts (2003a): regulation and contracting. Firstly, Watts (2003a) elaborates that regulators are more likely to be criticised if firms overstate net assets than if they understate them. For instance, Enron and similar accounting scandals placed significant pressure on regulators as it is argued quite often that their loose regulation leads firms to exploit loopholes or vague standards. Thus, regulators may seek to impose more conservative accounting rules in order to prevent such criticism. The implementation of enforcement bodies can be regarded as an increase in regulation in the financial reporting environment, and thus it is likely that accounting conservatism increases as a result of such regulation. Consequently, regulation will influence managers' decision making and accounting choices. With enforcement bodies reviewing already audited financial statements, firm managers will most likely be influenced in their decision making towards a higher level of conservatism. As shown by Hitz et al. (2012), enforcement releases are associated with significant negative market reactions for the respective firms. Thus, managers have a direct incentive to prevent such error announcements and therefore employ more conservatism in their accounting decisions. In a way, conservatism acts as an insurance against adverse publicity and penalties associated with enforcement releases.

Secondly, in line with Watts' (2003a) contracting explanation for conservatism and agency theory (Jensen and Meckling, 1976), enforcement bodies represent monitoring 
mechanisms that aim to reduce agency costs. This stems from enforcement reviews serving as "secondary audits". Audits, in turn, are seen as typical monitoring devices which increase conservatism by reducing managers' leeway and incentives to manipulate accounting numbers or to report in an overly aggressive manner. Therefore, enforcement should reduce agency conflicts and incentivise managers to report more conservatively. In conclusion, the theories presented herein suggest that substantive changes in enforcement regulation are associated with increasing accounting conservatism, which represents my first hypothesis.

If such an enhancement of conservatism represents increasing accounting quality, this could explain positive capital market effects around substantive enforcement changes. Moreover, García Lara et al. $(2011,2014,2016)$ find that accounting conservatism leads to a higher efficiency of the allocation of capital and reduced levels of information asymmetry and cost of capital. ${ }^{23}$ As these were some of the main objectives of the EU's IAS Regulation (Regulation (EC) No. 1606/2002), which mandated the adoption of IFRS as well as the introduction of enforcement institutions, increased conservatism due to substantive enforcement changes would indicate that enforcement serves as a significant channel in achieving the regulator's objectives. Findings would therefore not only be relevant to managers and auditors but especially to regulators in order to evaluate the achievement of the goals they set for themselves when mandating both IFRS adoption and the implementation of enforcement mechanisms.

Enforcement agencies also represent external corporate governance mechanisms. Amongst others, Ahmed and Duellman (2007) and Badia et al. (2017) provide evidence that governance mechanisms, in their cases namely boards of directors, institutional ownership, and audit environment, have an influence on conservatism. I aim to build on this evidence by testing my second hypothesis. As enforcement does not only represent an outcome of regulation but also a corporate governance mechanism, it likely influences accounting conservatism in yet another manner. In line with prior literature, firms with

23 Their findings suggest that conservatism improves investment efficiency in both settings prone to overinvestment and settings prone to underinvestment (Bushman et al., 2011; Francis and Martin, 2010; García Lara et al., 2016). Thus, conservatism improves the efficient allocation of capital. Furthermore, García Lara et al. (2014) find that conservatism leads to decreases in information asymmetries between firm insiders and outside equity investors. One of the channels through which conservatism decreases information asymmetries may be limiting earnings management as proposed by García Lara et al. (2014). Related to this, Ernstberger et al. (2012) show that the introduction of an enforcement institution in Germany led to decreasing levels of earnings management. Hence, it is likely that enforcement improves the information environment by increasing accounting conservatism. Moreover, García Lara et al. (2011) show that conservatism is associated with lower cost of capital. 
strong corporate governance should employ more conservative accounting. Therefore, firms with weak corporate governance may still have more leeway to increase conservatism once reasons for doing so substantiate themselves. They could consequently show a stronger treatment effect from substantive changes in enforcement. On the other hand, firms with weak corporate governance may also not be that aware of enforcement or have other more pressing issues to worry about. Hence, with this cross-sectional hypothesis I test the rather open question whether firms with weaker/stronger corporate governance are affected more intensely by enforcement changes than firms with stronger/weaker corporate governance and thus employ more conservative accounting choices. This could imply that strong enforcement institutions may atone for other corporate governance mechanisms' shortcomings.

My research design builds on the identification approach of CHL (2013) who construct a data set containing whether and when substantive enforcement changes occurred in 56 IFRS (e.g., Germany and Australia) and non-IFRS adoption countries (e.g., Japan and the United States) from 2001 to 2009. CHL (2013) exploit the staggered implementation of enforcement regimes across countries, which is plausibly exogenous and creates natural control groups to separate IFRS and enforcement effects as best as possible. I use and extend parts of this identification strategy and replicate the data set with yearly data to carry out my analyses. For instance, to include events that are more recent my data set also covers the substantive change in enforcement regulation in Austria in 2013. In a difference-in-differences design, I estimate multivariate regressions for different country samples, where the influence of Enforcement, a binary variable indicating all firm-years following substantive changes in enforcement, on Conservatism is examined. Conservatism is measured by C_Score, a firm-year measure of accounting conservatism introduced by Khan and Watts (2009) ${ }^{24}$ that is based on Basu's (1997) conservatism measure. ${ }^{25}$ C_Score measures the incremental timeliness of bad news over good news and as Khan

24 This measure has been widely accepted and used in the literature as well (more than 1000 citations as of January 2019). Ettredge et al. (2012) provide evidence that supports the validity of C_Score as a measure of earnings conservatism.

25 As of January 2019, this paper was cited more than 4500 times. Ryan (2006) calls it "easily one of the most influential papers in accounting research in the past decade". There are a few papers that criticise Basu's measure. Dietrich et al. (2007) as an extreme example state that since earnings cause returns, and not the other way around, return-based measures of asymmetric timeliness are biased. However, for instance Ball et al.'s (2013) and Ettredge et al.'s (2012) results support the validity of the Basu measure and Ball et al. (2013) show that Dietrich et al.'s (2007) claims are based on misconceptions of the model. Taken together, the Basu (1997) measure is certainly widely accepted and used in accounting research (e.g., Zhang, 2008; LaFond and Watts, 2008; LaFond and Roychowdhury, 2008; Huijgen and Lubberink, 2005). 
and Watts (2009) show is a linear function of the firm variables Size, Market to Book Ratio and Leverage allowing for the estimation of firm-year values.

Moreover, I source data on corporate governance ratings from Aggarwal et al.'s (2011) data set. For the sub-sample of firms with corporate governance ratings at hand, I run the same regression as described above and examine whether the influence of enforcement on accounting conservatism is different for firms with weak corporate governance than for firms with strong corporate governance.

Findings indicate that, in fact, substantive changes in enforcement lead firms to employ more conservative accounting choices. I find this only for a sample of non-IFRS countries though. For the IFRS sample I do not find a significant association between substantive changes in enforcement and conditional conservatism. This may suggest that firms reporting under IFRS have less leeway to make more conservative accounting choices as a response to enforcement changes. Moreover, I find weak evidence suggesting that enforcement's effect on conservatism is more pronounced for firms with weak corporate governance than for firms with strong corporate governance.

This study contributes to the literature on consequences of enforcement on accounting behaviour and accounting properties as well as the literature on accounting conservatism and its determinants as it is the first study to distinctly regard the influence of enforcement on accounting conservatism. It is closely related to André et al.'s (2015) study, which investigates the impact of mandatory IFRS adoption on conditional conservatism and already hints at enforcement playing a moderating role in this relationship without, however, explicitly regarding enforcement as a potential driver of accounting conservatism. I advance their work by focusing primarily and directly on the role enforcement plays in potentially increasing accounting conservatism in a difference-in-differences design with two different treatment and control groups and staggered changes in enforcement. These changes in enforcement are indicated by a binary variable as opposed to their broad measurement of enforcement strength using the Brown et al. (2014) index which also covers the strength of the audit environment. Their study, furthermore, has several research design issues that result in a lack of construct and internal validity, which makes it difficult to empirically isolate the effects of IFRS reporting and enforcement on accounting conservatism.

More specifically, my study contributes to the literature that focuses on regulation being one of the driving forces of conservatism in accounting. Watts (2003b) pronounced a need 
for more research especially in the field of regulation-driven conservatism and I follow this call. I also add to the literature on enforcement's preventive function. The preventive function, which aims to prevent erroneous accounting, deserves to receive attention as in an ideal scenario accounting errors or even fraud should be prevented in the first place.

The remainder of the paper is structured as follows. In Section 4.2, I provide a review of prior literature on enforcement and its effects both on capital markets and the decision making of involved stakeholders and subsequently develop my hypotheses. Section 4.3 outlines the research design, while Section 4.4 presents and discusses my empirical findings. Section 4.5 concludes the paper.

\subsection{Literature review and hypotheses development}

\subsubsection{Literature review}

When regarding the impact enforcement bodies and their actions have on firms, I differentiate between capital market effects and what I call direct effects. The latter effects regard the decision making of different stakeholders such as managers, supervisory boards and auditors. Firstly, I review the literature on capital market effects of enforcement, which may at least partly be driven by effects on decision making.

The implementation or strengthening of enforcement agencies has positive capital market effects according to the literature. For instance, CHL (2013) find that the introduction of IFRS for listed firms in the European Union coincided with significant increases in liquidity, particularly in those EU member states which had concurrently implemented the mandate to install enforcement institutions. Moreover, Ernstberger et al. (2012) supply evidence that in the case of Germany the introduction of the new two-tier enforcement regime in 2005 resulted in significant increases in stock liquidity and market valuation for the firms that fall under the enforcement bodies' scrutiny. These positive capital market effects appear to be associated with the presence of enforcement institutions.

Once enforcement bodies start investigating firms' financial statements and publish error findings, which is one of the potential sanctioning mechanisms of enforcement, this will result in negative market reactions for the respective firms, thus achieving the aim of enforcement's sanctioning function. Hitz et al. (2012) examine in an event study design the effect such error announcements have on returns, liquidity and bid-ask spreads of censured German firms. They find consistent significant negative market reactions with regard to all three of these measures. In other words, managers have incentives to avoid 
being censured by enforcement bodies as this would harm the firm's position on the capital market as well as the firm's and the managers' reputation and wealth.

With regard to direct effects, a broad stream of literature shows that enforcement actions hold more than just negative capital market reactions for the decision makers involved. Several studies suggest that enforcement actions lead to an increased turnover in top management at the censured firms (e.g., Desai et al., 2006; Collins et al., 2009; Land, 2010; Wang and Chou, 2011). Arthaud-Day et al. (2006), for instance, find that CEOs and CFOs of firms that had to file material financial restatements ${ }^{26}$ are more than twice as likely to leave their firms as their counterparts in a matched sample of firms. Moreover, Johnstone et al. (2011) show that increased turnover of members of the board of directors and audit committee members can be associated with enforcement reviews. Carver (2014) and Srinivasan (2005) also find increased audit committee member turnover after accounting restatements. Lastly, auditors can be affected too by what in this sense should rather be called second order effects than direct effects. Brocard et al. (2018) and Mande and Son (2012) find that firms tend to change audit firms after being censured by an enforcement body.

Prior literature hence shows that enforcement has both capital market and direct effects for firms and other involved parties and points out why they should try to avoid being censured by enforcement bodies. It is worthwhile to investigate whether this results in more conservative accounting choices by managers, which would be an effect on decision making André et al. (2015) already hint at by suggesting that a decrease in conservatism associated with IFRS adoption is smaller for countries with strong enforcement regimes. More conservative accounting could stem from both managers' accounting decisions in the first place and from auditors requiring more conservative accounting choices from their clients. Either way, such findings would support the efficacy of enforcement's preventive function in line with previous studies (Ernstberger et al., 2012; Schmidt, 2005).

\footnotetext{
${ }^{26}$ In this context, it is important to point out that financial restatements, even though they are closely linked to enforcement reviews and error announcements, might have more severe consequences than error announcements and hence the findings described above need to be compared with caution. However, the related findings presented herein are relevant to the research question at hand because in many countries error announcements published by enforcers go hand in hand with restating the erroneous accounts in the following financial statements.
} 


\subsubsection{Hypotheses development}

Watts (2003a) developed a theory on the explanations for accounting conservatism. According to his theory, the four explanations for the existence of accounting conservatism are: contracting, taxation, litigation and regulation. In my setting, the contracting and the regulation explanations appear most relevant. ${ }^{27}$ The regulation explanation states that as regulators potentially run into "more criticism if firms overstate net assets than if they understate net assets" (Watts, 2003a), they favour conservative behaviour and thus impose regulation that leads to conservative accounting. The implementation of enforcement bodies can be regarded as an increase in regulation in the financial reporting environment, and thus it is likely that accounting conservatism increases as a result of such regulation. As enforcement bodies review already audited financial statements, most likely firm managers will be influenced in their decision making towards a higher level of conservatism. This might stem from managers employing more conservative accounting choices as an insurance against adverse publicity and penalties in connection with error announcements. If an enforcement mechanism preferred more conservative financial statements, it would be rational for firms to make more conservative accounting choices in an attempt to reduce the likelihood of enforcement intervention.

Several studies already supply evidence on the connection between regulation and conservatism (e.g., García Lara et al., 2009b). For instance, Bushman and Piotroski (2006) find that firms in countries with higher levels of regulation, in their setting represented by strong investor protection and high quality judicial systems, employ more conservative financial reporting. Moreover, Ball et al. (2000) examine the levels of conservative accounting in different common law countries (Australia, Canada, the U.K. and the U.S.). They find that accounting in the U.K., which has less regulation ${ }^{28}$ than the other sample countries, is significantly less conservative.

27 I present the remaining explanations here. Links between taxation and financial reporting generate incentives for conservative accounting as the asymmetric recognition of gains versus losses allows managers to reduce taxes' present value and thus increase firm value. Shareholder litigation can also be viewed as a source of conservatism as the overstatement of net assets increases potential litigation costs. Under conservatism net assets are regularly understated, which results in lower expected litigation costs. In certain legal environments with high risk of shareholder litigation, this might already hint at the potential influence of enforcement bodies on accounting conservatism as enforcement reviews and error releases increase litigation risk in such environments (e.g., the U.S.).

28 Ball et al. (2000) state that U.K. financial markets are "primarily self-regulating". For instance, the United Kingdom does not have a "regulatory body comparable to the SEC in the US". 
In a similar vein as the studies from above, Watts' (2003a) regulation explanation already hints at enforcement potentially promoting more conservative accounting. However, as eventually it is a manager's and not a regulator's decision whether or not to prepare more conservative accounts, it is also necessary to build on the contracting explanation. This explanation points at conservatism being a means of mitigating agency conflicts and opportunistic managerial behaviour. Agency theory, as developed, in particular, by Jensen and Meckling (1976), suggests that the separation of ownership and control in public corporations leads to agency costs due to information asymmetries between the manager (agent) and the shareholders (principals) of the firm. Adverse selection as well as moral hazard issues arise from such information asymmetries. Importantly, a manager might use her advantageous position of superior information to maximise her own self-interests at the principals' expense. Hence, a principal or an investor in the firm has a demand for both bonding and monitoring activities in order to reduce information asymmetries and the resulting agency costs.

Bonding activities aim at aligning an agent's interests with those of the principal for instance by linking remuneration contracts with firm performance. In my setting, however, monitoring activities are of more interest. Beaver (1998) states "that the less informed investor would have a demand for information that would monitor the behaviour of the more informed manager". He further suggests that audits are one form of such information. An audit essentially controls the manager's behaviour at least with regard to the correct application of accounting standards. Moreover, it aims at uncovering fraud or the manipulation of accounting numbers and thus helps to prevent such behaviour in the first place and thereby also promotes conservatism. I argue that enforcement represents a "secondary audit" as enforcement bodies conduct reviews of already audited financial statements. Therefore, enforcement can also be defined as a monitoring mechanism that aims at controlling managers' behaviour with the interest of investors in mind. Thus, substantive changes in enforcement should increase accounting conservatism.

Closely related to my research is the study by André et al. (2015), which investigates whether IFRS adoption in the EU had an influence on accounting conservatism. Their results suggest that the adoption of IFRS in the EU led to a decrease in conservatism. The authors also find that the decrease in conservatism due to IFRS adoption was higher in countries with low quality audit environments and weak enforcement of compliance with 
accounting standards. Even though their research design does not allow for the exact conclusion $^{29}$, a possible takeaway from their study might be that strong enforcement may increase accounting conservatism and the implementation of enforcement bodies itself may lead to an increase in conservatism. This notion goes along with the conservatism and agency theory described above and my research aim. Thus, I investigate the following hypothesis:

\section{H1: Substantive changes in enforcement regulation are associated with more} conservative accounting choices.

In a similar vein, enforcement agencies represent external corporate governance mechanisms, which according to prior literature also promote conservatism in financial reporting (e.g., García Lara et al., 2007; Jayaraman, 2012; García Lara et al., 2009a; Ramalingegowda and Yu, 2012; Vyas, 2011). For instance, both Ahmed and Duellman (2007) and Beekes et al. (2004) establish that more independent boards of directors, proxying stronger corporate governance mechanisms, result in more conservative accounting by the respective firms. Moreover, Badia et al. (2017) find that corporate governance mechanisms, namely institutional ownership and audit environment, have a significant positive effect on conservatism. In a more general approach, García Lara et al. (2007), taking both internal and external corporate governance characteristics into account, show that firms with stronger corporate governance employ more accounting conservatism than firms with weaker corporate governance. They base their expectations and findings on the notion that "adequate corporate governance results in better monitoring of the management", which in line with the development of my first hypothesis would be associated with more conservatism.

29 André et al. (2015) do not explicitly regard enforcement as a potential driver of accounting conservatism. They expect it to be more of a mitigating variable that softens the IFRS effect on conservatism. In their design, it is not possible to look at the impact of enforcement by itself as they use the Brown et al. (2014) index which does not only measure the strength of an enforcement regime but also the quality of the audit environment. This index rather covers the strength of the general regulatory environment on financial reporting. I, on the other hand, explicitly regard the implementation or strengthening of enforcement institutions represented by a dummy variable. The study of André et al. (2015) furthermore has several research design issues that result in a lack of construct and internal validity. They compare accounting conservatism in the European Union before and after the mandatory adoption of IFRS without an appropriate control group. Thus, they are potentially looking at a sheer time series effect or an effect that might be driven by concurrent regulatory changes within the EU. It is not possible to empirically isolate the effects of IFRS reporting and enforcement in their design. 
Based on this stream of literature, however, it remains an open question how the accounting conservatism of firms with different corporate governance strength is affected by substantive changes in enforcement. Possibly, firms with strong corporate governance already employ fairly conservative accounting and, therefore, have little leeway to be even more conservative when an enforcement change occurs. Firms with weak corporate governance, on the other hand, potentially still have the possibility to increase accounting conservatism. Taken together, this would suggest that firms with weak corporate governance increase their accounting conservatism more once substantive enforcement changes occur. However, firms with weak corporate governance may not be that aware of enforcement to be affected by increased regulation. Hence, I formulate my cross-sectional second hypothesis in an open way:

H2: The influence of substantive changes in enforcement on accounting conservatism depends on a firm's corporate governance strength.

\subsection{Research design}

\subsubsection{Identification strategy}

I use and extend the work of CHL (2013) to identify countries where substantive enforcement changes occurred irrespective of IFRS adoption in order to separate IFRS and enforcement effects as best as possible. CHL (2013) construct a data set containing whether and when substantive enforcement changes occurred in 56 IFRS and non-IFRS adoption countries from 2001 to 2009 . The extensive data set displays the staggered introduction or strengthening of enforcement institutions for a global sample and also contains a large control sample without changes in enforcement. The given variation in IFRS adoption as well as enforcement changes and a set of fixed effects help CHL (2013) to overcome many of the typical issues of IFRS and enforcement research. For instance, the clustering in calendar time of IFRS adoption and enforcement changes mostly being directly tied to IFRS adoption make it difficult to empirically isolate their effects. Moreover, the effects of IFRS adoption and substantive changes in enforcement could mutually reinforce each other.

I arrive at two different treatment groups to investigate. Treatment group (I) consists of all the countries in CHL's (2013) data set that have substantive enforcement changes several years after IFRS adoption plus Austria, which implemented an enforcement mechanism in 2013, and thus is not included in CHL's (2013) data set. This treatment group's potential enforcement effects might be dependent on prior IFRS adoption. However, as 
the enforcement changes occurred several years after and not bundled with IFRS adoption, IFRS and enforcement effects are expected to be separated for the most part. In order to take prior IFRS adoption out of the equation, I introduce Treatment group (II). This group consists of non-IFRS-adopting countries with substantive enforcement changes.

Each of these treatment groups needs to be compared to a different set of control countries. Treatment group (I) is compared to Control group (I), which consists of IFRS-adopting countries that did not have substantive enforcement changes within the time frame under investigation. Together, Treatment group (I) and Control group (I) form the IFRS sample. Treatment group (II) is compared to countries that did not adopt IFRS nor carry out substantive enforcement changes in the defined time frame (Control group (II)). Treatment group (II) and Control group (II) constitute the Non-IFRS sample.

I establish these control groups by matching potential countries from CHL's (2013) selection based on the Kaufmann et al. (2009) index for regulatory quality measured as of 2003. ${ }^{30}$ Table 4.1 displays the composition of Treatment groups (I) and (II) and the respective control groups. Based on the work of CHL (2013), I know the exact quarter in which the enforcement changes occurred. This allows me to include another level of variation into my analyses. This is the variation in the publication of the first annual report by firms in a given country under the new enforcement regime as depicted in Table 4.2.

${ }^{30}$ Equal to CHL (2013), I use the 2003 values of the regulatory quality index because I regard a similar time frame as they do in their study. 
Table 4.1: Composition of treatment and control groups

\begin{tabular}{|c|c|c|c|c|c|}
\hline \multicolumn{4}{|c|}{ Treatment Group (I) } & \multicolumn{2}{|c|}{ Control Group (I) } \\
\hline Country & $\begin{array}{c}\text { IFRS } \\
\text { adoption }\end{array}$ & $\begin{array}{c}\text { Enforce- } \\
\text { ment } \\
\text { change }\end{array}$ & $\begin{array}{l}\text { Kaufmann } \\
\text { Index }\end{array}$ & Country & $\begin{array}{l}\text { Kauf- } \\
\text { mann } \\
\text { Index } \\
\end{array}$ \\
\hline Sweden & 2005 & 2007 & 1.69 & New Zealand & 1.71 \\
\hline Lithuania & 2005 & 2007 & 1.10 & Czech Republic & 1.12 \\
\hline Ireland & 2005 & 2007 & 1.66 & Switzerland & 1.63 \\
\hline Hungary & 2005 & 2008 & 1.08 & Italy & 1.02 \\
\hline Hong Kong & 2005 & 2008 & 1.76 & Denmark & 1.79 \\
\hline Turkey & 2006 & 2008 & 0.08 & Philippines & -0.06 \\
\hline Luxembourg & 2005 & 2009 & 1.94 & Singapore & 1.84 \\
\hline Austria & 2005 & 2013 & 1.52 & Australia & 1.60 \\
\hline
\end{tabular}

Panel B: Non-IFRS countries with or without following enforcement changes

\begin{tabular}{|c|c|c|c|c|}
\hline \multicolumn{3}{|c|}{ Treatment Group (II) } & \multicolumn{2}{|c|}{ Control Group (II) } \\
\hline Country & $\begin{array}{c}\text { Enforcement } \\
\text { change }\end{array}$ & $\begin{array}{l}\text { Kaufmann } \\
\text { Index }\end{array}$ & Country & $\begin{array}{l}\text { Kaufmann } \\
\text { Index }\end{array}$ \\
\hline Japan & 2005 & 0.99 & Taiwan & 0.94 \\
\hline Chile & 2009 & 1.48 & United States & 1.48 \\
\hline \multicolumn{5}{|c|}{$\begin{array}{l}\text { This table displays the composition of the two country groups under investigation as well as the respective } \\
\text { control groups. Treatment Group (I) in Panel A consists of countries that had enforcement changes several } \\
\text { years after IFRS adoption. This group is compared to a control group of countries which adopted IFRS } \\
\text { but had no substantive enforcement changes in the regarded timeframe. Treatment Group (II) includes } \\
\text { countries with substantive enforcement changes but without IFRS adoption and is compared to a control } \\
\text { group of countries with neither enforcement changes nor IFRS adoption in the regarded time frame (Panel } \\
\text { B). Countries were matched based on the regulatory quality index developed by Kaufmann et al. (2009). }\end{array}$} \\
\hline
\end{tabular}


Table 4.2: Variation in first annual report after enforcement change

\begin{tabular}{lcc}
\hline \multicolumn{1}{c}{ Country } & $\begin{array}{c}\text { Enforcement change by } \\
\text { quarter }\end{array}$ & $\begin{array}{c}\text { First annual report after } \\
\text { enforcement change }\end{array}$ \\
\cline { 1 - 1 } $\begin{array}{l}\text { Sweden \& Ireland } \\
\text { Lithuania }\end{array}$ & $\mathrm{Q} 3 / 07$ & $\mathrm{Q} 4 / 07-\mathrm{Q} 3 / 08$ \\
Hungary \& Turkey & $\mathrm{Q} 4 / 07$ & $\mathrm{Q} 1 / 08-\mathrm{Q} 4 / 08$ \\
Hong Kong & $\mathrm{Q} 1 / 08$ & $\mathrm{Q} 2 / 08-\mathrm{Q} 1 / 09$ \\
Luxembourg & $\mathrm{Q} 3 / 08$ & $\mathrm{Q} 4 / 08-\mathrm{Q} 3 / 09$ \\
Austria & $\mathrm{Q} 4 / 09$ & $\mathrm{Q} 1 / 10-\mathrm{Q} 4 / 10$ \\
Japan & $\mathrm{Q} 2 / 13$ & $\mathrm{Q} 3 / 13-\mathrm{Q} 2 / 14$ \\
Chile & $\mathrm{Q} 3 / 05$ & $\mathrm{Q} 4 / 05-\mathrm{Q} 3 / 06$ \\
& $\mathrm{Q} 2 / 09$ & $\mathrm{Q} 3 / 09-\mathrm{Q} 2 / 10$
\end{tabular}

This table displays the different countries subject to a substantive change in enforcement and the respective calendar quarter of the enforcement change. Moreover, this table depicts the variation in the date of publication of the first annual report under the new enforcement regime for the firms in the respective countries.

When carrying out my analyses, I regard the last two years prior to substantive enforcement changes and the first two years in the presence of a new or a strengthened enforcement regime. If I chose a longer time frame, I would face problems of overlapping with the date of IFRS adoption in Treatment group (I). For the control countries, I regard the same years as for the matched counterparts. My yearly panel regression model estimating the association between Enforcement and Conservatism looks as follows:

$$
\begin{gathered}
\text { (1) } \text { Conservatism }_{i t}=\beta_{1}+\beta_{2} \text { Enforcement }_{i t}+\beta_{2} \text { Post }_{i t}+\sum \text { Controls }_{i t}+ \\
\sum \text { Fixed effects }+e_{i t}
\end{gathered}
$$

In line with my first hypothesis, I expect a positive association between Enforcement and Conservatism. I expect to find this association for both the IFRS sample and the NonIFRS sample. To test my second hypothesis, investigating whether the role substantive changes in enforcement play in shaping conservative accounting choices depends on a firm's corporate governance strength, I carry out a sub-sample analysis based on Aggarwal et al.'s $(2011)^{31}$ data set on corporate governance ratings. This data set contains

31 Aggarwal et al. (2011) investigate whether institutional investors have an impact on corporate governance. They analyse firms' portfolio holdings from 23 countries from 2003 to 2008 and find that international institutional ownership is positively associated with firm-level governance. 
corporate governance ratings for firms from 23 countries from 2003 to 2008 . Their governance measure $\mathrm{GOV}_{41}$ is based on 41 individual governance-related firm attributes. In this analysis, I only look at the countries with substantive enforcement changes: Treatment groups (I) and (III), namely Sweden, Lithuania, Ireland, Hungary, Hong Kong, Turkey, Luxembourg, Austria, Japan and Chile. As Lithuania, Hungary, Turkey, Luxembourg and Chile are not included in the Aggarwal et al. (2011) data set and the relevant years for Austria (enforcement change was in 2013) are missing in the mentioned data set, I carry out my analysis with the sub-sample of firms from Sweden, Ireland, Hong Kong and Japan. I estimate regression model (1) for this sample including the variable Governance and the interaction term Enforcement*Governance.

\subsubsection{Variables measurement}

When investigating accounting conservatism, researchers generally differentiate between balance sheet and earnings conservatism (García Lara and Mora, 2004). Balance sheet or unconditional (news-independent) conservatism indicates a persistent understatement of book value of shareholders' equity (Feltham and Ohlson, 1995). Earnings or conditional (news-dependent) conservatism, on the other hand, is reflected by earnings recognising bad news timelier than good news (Basu, 1997). ${ }^{32}$ In my analyses, I focus on conditional conservatism which is less noisy and the more prominent measure in the literature. Moreover, the introduction of IFRS represented a major shock to balance sheets and thus also to the variables that ought to measure unconditional conservatism such as market to book ratio. IFRS and enforcement effects would therefore be hard if not impossible to disentangle in an analysis regarding unconditional conservatism.

Basu (1997) derives his well-spread conservatism definition from the old accountants' rule "anticipate no profits but anticipate all losses" (e.g., Bliss, 1924) and hence defines conservatism in accounting as "the accountant's tendency to require a higher degree of verification to recognize good news as gains than to recognize bad news as losses”. Thus, he constructs a regression equation that estimates how strongly earnings reflect good news and bad news, measured by stock returns. The higher the reflection of bad news in

32 The terminology for basically the same constructs varies greatly throughout the conservatism literature. Richardson and Tinaikar (2004) speak of ex-post and ex-ante conservatism, while Chandra (2011) defines the very same ideas as news-dependent and news-independent conservatism. Beaver and Ryan (2005) deliver the terminology of conditional and unconditional conservatism. 
earnings, the more conservative the underlying accounting. His cross-sectional regression is specified as

$$
X_{i}=\beta_{1}+\beta_{2} D_{i}+\beta_{3} R_{i}+\beta_{4} D_{i} R_{i}+e_{i}
$$

where $\mathrm{i}$ indexes the firm, $\mathrm{X}$ is earnings, $\mathrm{R}$ is returns (measuring news), $\mathrm{D}$ is a dummy variable equal to 1 when $\mathrm{R}<0$ and equal to 0 otherwise, and e is the residual. $\beta_{3}$ represents the good news timeliness measure referred to as G_Score by Khan and Watts (2009). The measure of incremental timeliness for bad news over good news, or conservatism, is $\beta_{4}$ referred to as C_Score by Khan and Watts (2009).

The Basu (1997) conservatism measure, which is the most widely used conservatism measure in the literature (Ryan, 2006), can be estimated either for a firm by using a timeseries of firm-years or for an industry-year by using a cross-section of firms in the industry. With this approach, however, it is not possible to estimate a firm-year measure of accounting conservatism. Therefore, I need to carry out my analyses with C_Score, a firm-year measure of accounting conservatism introduced by Khan and Watts (2009), which builds on the Basu (1997) measure. This requires data on firm size (Size), market to book ratio $(M / B)$ and leverage (Lev) as Khan and Watts (2009) show that both G_Score and C_Score are linear functions of these firm-specific characteristics. Moreover, they describe these variables "as summary measures of the four Watts (2003a) factors (contracting, litigation, taxation and regulation) that drive conservatism". Size is measured as the natural logarithm of the market value of equity, while $M / B$ is the market value of equity divided by the book value of equity. Finally, Lev is measured as total assets minus book value of equity divided by book value of equity.

$$
\begin{aligned}
& G_{-} \text {Score }=\beta_{3}=\mu_{1}+\mu_{2} \text { Size }_{i}+\mu_{3} M / B_{i}+\mu_{4} \text { Lev }_{i} \\
& C_{-} \text {Score }=\beta_{4}=\pi_{1}+\pi_{2} \text { Size }_{i}+\pi_{3} M / B_{i}+\pi_{4} \text { Lev }_{i}
\end{aligned}
$$

These linear functions for $\mathrm{G}_{-}$Score $\left(\beta_{3}\right)$ and $\mathrm{C} \_$Score $\left(\beta_{4}\right)$ in a next step need to be substituted into the original Basu model from above:

$$
\begin{aligned}
& X_{i}=\beta_{1}+\beta_{2} D_{i}+R_{i}\left(\mu_{1}+\mu_{2} \text { Size }_{i}+\mu_{3} \frac{M}{B_{i}}+\mu_{4} \text { Lev }_{i}\right) \\
& +D_{i} R_{i}\left(\pi_{1}+\pi_{2} \text { Size }_{i}+\pi_{3} \frac{M}{B_{i}}+\pi_{4} \text { Lev }_{i}\right) \\
& +\left(\delta_{1} \text { Size }_{i}+\delta_{2} \frac{M}{B_{i}}+\delta_{3} \text { Lev }_{i}+\delta_{4} D_{i} \text { Size }_{i}+\delta_{5} D_{i} \frac{M}{B_{i}}+\delta_{6} D_{i} \text { Lev }_{i}\right) \\
& +e_{i}
\end{aligned}
$$


This equation also includes additional terms in the last parenthesis. Khan and Watts (2009) explain that these terms are needed as the regression model includes interaction terms between firm characteristics and returns. Thus, it is necessary to control for these firm characteristics separately. Finally, I solve the brackets and unitise the coefficients to arrive at the following extended equation:

$$
\begin{aligned}
X_{i}= & \beta_{1}+\beta_{2} D_{i}+\beta_{3} R_{i}+\beta_{4} R_{i} \operatorname{Size}_{i}+\beta_{5} R_{i} \frac{M}{B_{i}}+\beta_{6} R_{i} \text { Lev }_{i}+\boldsymbol{\beta}_{7} D_{i} R_{i} \\
& +\boldsymbol{\beta}_{\mathbf{8}} D_{i} R_{i} \text { Size }_{i}+\boldsymbol{\beta}_{\mathbf{9}} D_{i} R_{i} \frac{M}{B_{i}}+\boldsymbol{\beta}_{10} D_{i} R_{i} \text { Lev }_{i}+\beta_{11} \operatorname{Size}_{i}+\beta_{12} \frac{M}{B_{i}} \\
& +\beta_{13} \text { Lev }_{i}+\beta_{14} D_{i} \text { Size }_{i}+\beta_{15} D_{i} \frac{M}{B_{i}}+\beta_{16} D_{i} \text { Lev }_{i}+e_{i}
\end{aligned}
$$

This regression model is estimated on a yearly basis across all firms to arrive at the coefficients in bold $\beta_{7}$ to $\beta_{10}$ for each year. These coefficients are then substituted into the C_Score equation and applied to the yearly data on firm size (Size), market to book ratio $(M / B)$ and leverage $(\mathrm{Lev})$ to arrive at a firm-year value of C_Score indicating accounting conservatism.

Furthermore, regression model (1) includes Enforcement as the main independent variable of interest. This is a binary dummy variable that equals " 1 " in all firm-years ending after substantive changes in enforcement. Enforcement represents an interaction term of the two main effects Post and Treat in my difference-in-differences design, where Post is a binary variable indicating firm-years after substantive changes in enforcement for both the treatment group where the changes occurred and the matched control countries without these changes. Treat is a binary variable indicating all firm-years in countries where substantive changes in enforcement took place. To test my second hypothesis, I include the dummy variable Governance, which indicates whether a firm's corporate governance rating in the Aggarwal et al. (2011) data set is lower than the sample's median. However, in the case at hand 660 observations have a corporate governance rating equivalent to the median. Therefore, I estimate the regression model in two different ways. Firstly, I include these observations and assign them to the low corporate governance firms and once I omit these 660 observations. Khan and Watts (2009) propose to directly control for the inputs of $\mathrm{C}_{-}$Score in the regression (Size, $M / B$ and Leverage). Finally, industry, country and year fixed effects are added to the regression model. Due to the country fixed effects Treat drops out of the regression. However, the inclusion of year 
fixed effects does not cause Post to drop out of the regression due to the staggered enforcement changes and matching of control countries, which results in some years being in the post period for some countries while being in the pre period for others. Standard errors are clustered at firm-level. Table 4.3 summarises the variables used in the regression analyses.

Table 4.3: Variables measurement

\begin{tabular}{ll}
\hline Variable name & Definition \\
\hline Conservatism & $\begin{array}{l}\text { C_Score (firm-year measure for conditional conservatism based on Khan } \\
\text { and Watts, 2009) } \\
\text { Dummy variable indicating all firm-years ending after a substantive } \\
\text { change in enforcement in the respective country } \\
\text { Dummy variable indicating all firm-years ending after a substantive } \\
\text { change in enforcement in treatment countries and all firm-years ending } \\
\text { after the same ficticious treatment date in the control countries }\end{array}$ \\
Size & $\begin{array}{l}\text { Natural logarithm of the market value of equity } \\
\text { M/B }\end{array}$ \\
$\begin{array}{l}\text { Meverage } \\
\text { Governance }\end{array}$ & $\begin{array}{l}\text { Total assets minus book value of equity divided by book value of equity } \\
\text { Dummy variable indicating whether a firm's corporate governance rating } \\
\text { based on the Aggarwal et al. (2011) data set is lower than the sample's } \\
\text { median corporate governance rating }\end{array}$ \\
\hline $\begin{array}{l}\text { This table summarises the variables used in the regression analyses. All continuous variables are winsorised } \\
\text { at the 1\% and 99\% levels to reduce the impact of outliers. }\end{array}$ \\
\hline
\end{tabular}

\subsection{Results and discussion}

\subsubsection{Sample selection}

Based on the treatment and control groups defined above, Table 4.4 displays how I arrive at the different samples for my analyses. The IFRS sample consists of IFRS-adopting countries with following enforcement changes (Treatment group (I)) and without following enforcement changes (Control group (I)). Treatment group (II) consists of non-IFRS countries that had substantive enforcement changes and is compared to Control group (II) comprising countries that neither adopted IFRS nor had substantive changes in enforcement in the defined time frame. Treatment group (II) and Control group (II) form the Non-IFRS sample.

For all samples, I delete firm-years pertaining to shortened fiscal years. I do that because I need to use earnings data when estimating the conditional conservatism measure C_Score. Earnings data would, hence, be biased if I chose to include shortened fiscal years. Moreover, firm-years with missing data, those pertaining to financial institutions 
and those including negative values for total assets or book value of equity are deleted from my samples. Finally, I exclude non-IFRS-adopting firms from the IFRS sample. ${ }^{33}$

33 In the EU/EEA only countries listed on EU-regulated markets fall under the scrutiny of enforcement mechanisms. These are the very firms that also have to adopt IFRS. As the sample potentially also comprises voluntary IFRS adopters who are not subject to enforcement scrutiny, my approach is a simplified one. Ideally, I would like to work with lists published by the European Securities and Markets Authority (ESMA), which specify all countries on regulated markets in the EU in a given year. However, these lists are not obtainable anymore for some of the years included in my research design. Therefore, I work with the explained simplification in my sample selection process as other studies do too (e.g., André et al., 2015). I address potential concerns in a robustness test using the ESMA lists of the years of enforcement changes I do have available under the assumption that the firms listed on the EUregulated market segments did not change dramatically in the years surrounding the enforcement changes. 
Table 4.4: Sample selection

\begin{tabular}{|c|c|c|c|}
\hline $\begin{array}{l}\text { Treatment } \\
\text { group (I) }\end{array}$ & $\begin{array}{c}\text { Control } \\
\text { group (I) }\end{array}$ & $\begin{array}{l}\text { Treatment } \\
\text { group (II) }\end{array}$ & $\begin{array}{c}\text { Control } \\
\text { group (II) }\end{array}$ \\
\hline 10281 & 16524 & 17959 & 38761 \\
\hline 13 & 54 & 59 & 61 \\
\hline 1977 & 2755 & 2327 & 9365 \\
\hline 1507 & 3072 & 1429 & 5889 \\
\hline 269 & 448 & 134 & 3781 \\
\hline 328 & 71 & - & - \\
\hline 6187 & 10124 & 14010 & 19665 \\
\hline \multicolumn{2}{|c|}{ IFRS sample I } & \multicolumn{2}{|c|}{ Non-IFRS sample } \\
\hline
\end{tabular}

This table displays how I arrive at the different samples for my regression models. For the two treatment groups and their respective control groups I source from Thomson Reuters Datastream all firm-years of the included countries in the relevant time frame. Then I delete shortened fiscal years, firm-years with missing data, those pertaining to financial institutions and those with negative total assets or book value of equity. Moreover, for the IFRS sample I delete firm-years in EU/EEA countries where IFRS were not adopted by the firms as this suggests these firms are not listed on EU-regulated markets and hence do not fall under the enforcement regimes. Treatment group (I) and Control group (I) together represent the IFRS sample, while Treatment group (II) and Control group (II) combined represent the Non-IFRS sample. 


\subsubsection{Descriptive statistics}

Tables 4.5 and 4.6 report descriptive statistics and correlations for the variables used in my regression analyses. In both tables, Panels A and B display the figures for the two different samples: the IFRS sample and the Non-IFRS sample. Interestingly, it can be seen from Panel B in Table 4.5 that only in the Non-IFRS sample the mean of Conservatism is positive, whilst it is negative in the IFRS sample. This goes along with André et al.'s (2015) finding that the adoption of IFRS decreases conditional conservatism. The standard deviation of Conservatism is the highest in the IFRS sample (0.047). This might stem from the fact that, in comparison to the other sample, the IFRS sample is more diverse with respect to the countries included therein. It is the only sample that comprises both countries from inside and outside the EU/EEA. 
Table 4.5: Descriptive statistics of variables used in the regression models

\section{Panel A: Descriptives IFRS sample}

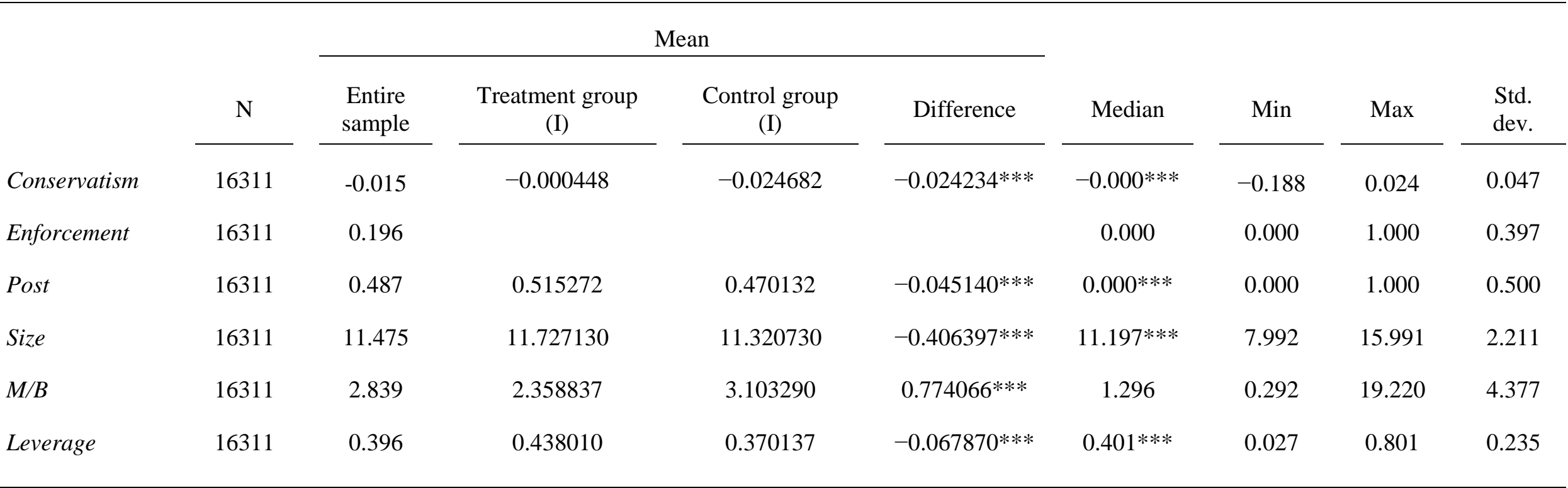


Table 4.5 cont'd.: $\quad$ Descriptive statistics of variables used in the regression models

\section{Panel B: Descriptives Non-IFRS sample}

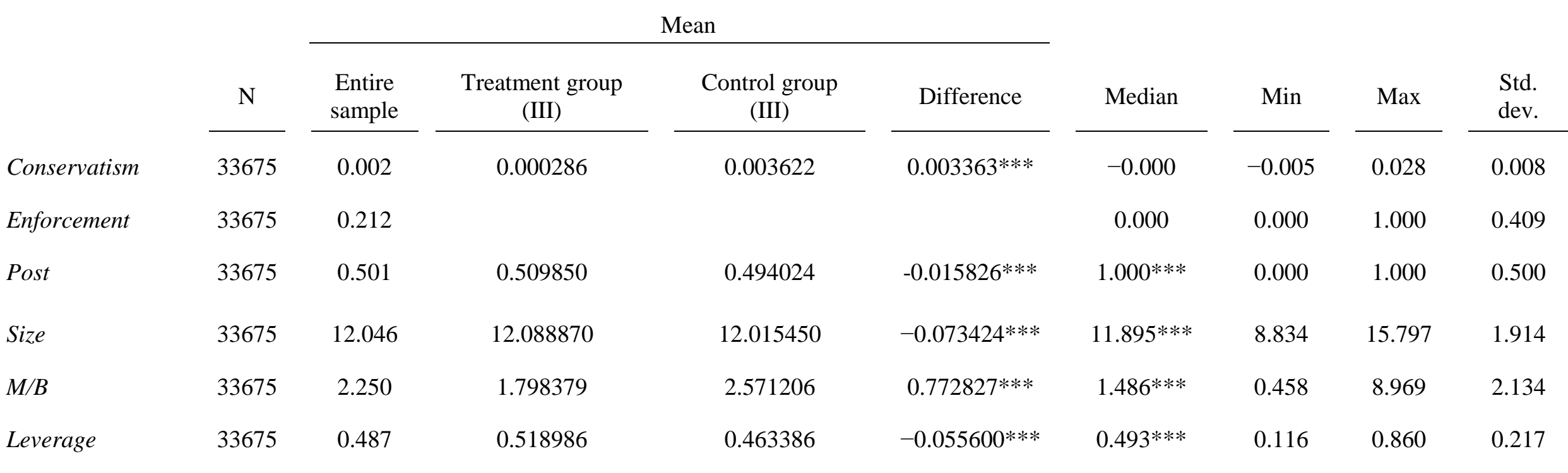

This table displays the descriptives for the variables used in the regression models in Table 4.7 for each sample in question separately. Moreover, the results of mean and median difference tests for the variables used in the regression models are reported. Definitions of variables are reported in Table 4.4 . ***, **, and * indicate significance at the $1 \%, 5 \%$, and $10 \%$ levels, respectively. 
Table 4.6: Correlations of variables used in the regression models

\section{Panel A: Correlations IFRS sample}

(1)

(1)

Conservatism

Enforcement

(2)

(3)

(4)

Size

$M / B$

Leverage
(2)

(3)

(4)

(5)

(6)

Panel C: Correlations Non-IFRS sample

(1)

(1)

(2) $\quad-\mathbf{0 . 1 0 9 0}$

(3)

(4)

0.3088

0.5183

Size

(5)

0.1658

0.0276

(3)

(4)

(5)

(6)

$M / B$

$\mathbf{0 . 1 3 8 2}$

$-0.0851$

0.0462

0.1559

Leverage

(6)

0.0601

0.0628

$-0.0188$

0.0579

0.1013

This table displays the correlations of the variables used in the regression models in Table 4.7 for each sample in question separately. Definitions of variables are reported in Table 4.3. Bold letters indicate significance at the $10 \%$ level. 


\subsubsection{Multivariate analyses}

\section{Testing hypothesis 1}

The results of my main analyses are displayed in Table 4.7, which reports coefficient estimates and t-statistics from estimating regression model (1) for the two different samples at hand. The dependent variable hence in both models is Conservatism, indicating the level of conditional conservatism in a firm's accounting measured by C_Score. In line with my first hypothesis, I find a significant positive association between Enforcement and Conservatism for the Non-IFRS sample (1\% significance level). However, for the IFRS sample I do not find a significant association between Enforcement and Conservatism. Thus, it appears as if substantive enforcement changes lead firms to employ more conservative accounting only in countries where IFRS are not mandated. Possibly, IFRS adoption did not only decrease conditional conservatism as suggested by André et al. (2015) but also limit the leeway firms have in changing their level of conservatism. Hence, firms in IFRS jurisdiction may not be able to respond as conservatively to substantive changes in enforcement as firms in non-IFRS jurisdictions.

The control variables Size, $M / B$ and Leverage as well as the Constant load in strongly significant ways throughout the models, which is line with prior literature using C_Score as a measure of conditional conservatism (e.g., André et al., 2015). This is not surprising, however, as these exact same control variables are used when estimating C_Score, which Khan and Watts (2009) show is a linear function of these variables. 
Table 4.7: The effect of enforcement on accounting conservatism

\begin{tabular}{lcc}
\hline Variable & $\begin{array}{c}\text { (IFRS } \\
\text { sample) }\end{array}$ & $\begin{array}{c}\text { (Non-IFRS } \\
\text { sample) }\end{array}$ \\
\hline Enforcement & -0.0009 & $0.0008^{* * *}$ \\
& $(-1.23)$ & $(7.84)$ \\
Post & $0.0057^{* * *}$ & $-0.0006^{* * *}$ \\
& $(4.07)$ & $(-5.25)$ \\
Size & $0.0045^{* * *}$ & $-0.0004^{* * *}$ \\
& $(28.00)$ & $(39.78)$ \\
M/B & $-0.0007^{* * *}$ & 0.0000 \\
& $(-5.57)$ & $(1.34)$ \\
Leverage & $-0.0161^{* * *}$ & $0.0036^{* * *}$ \\
& $(-13.37)$ & $(44.60)$ \\
Constant & $-0.0464 * * *$ & $-0.0063^{* * *}$ \\
& $(-23.83)$ & $(-46.30)$ \\
\hline Adj. $\mathrm{R}^{2}$ & 0.75 & 0.75 \\
$\mathrm{~N}$ & 16311 & 33675 \\
& Country, year, & Country, year, \\
Fixed effects & industry & industry \\
Clustered standard errors & Firm & Firm \\
\hline This table displays coefficient estimates and t-statistics from estimating regression \\
model (1) for the two different samples derived in Table 4.4. The dependent variable \\
is Conservatism measured by C_Score. Definitions of variables are reported in Table \\
4.3. t-values are reported in parentheses. ***,**, and * indicate significance at the \\
1\%, 5\%, and 10\% levels, respectively. The models include country, year and \\
industry fixed effects. Standard errors are clustered by firm. & \\
\hline & &
\end{tabular}

\section{Testing hypothesis 2}

Table 4.8 displays coefficient estimates and t-statistics from estimating regression model (1) for the Aggarwal et al. (2011) sub-sample on corporate governance ratings once when including the observations where the governance rating is equal to the sample's median (1) and once when omitting these observations (2), which is supposed to underpin the results' robustness. In both interaction models, the coefficient of Enforcement represents the effect of Enforcement on Conservatism for firms with high corporate governance ratings. This effect is not significant in either model. The interaction term's coefficient, however, is positive and significant at the $5 \%$ level in both models. To evaluate the effect of Enforcement on Conservatism for firms with low corporate governance ratings the sum of the two coefficients of Enforcement and Enforcement*Governance needs to be regarded. In model (1) this results in the enforcement effect on conservatism being stronger for firms with weak corporate governance at the $10 \%$ significance level, while 
this relation is significant at the 5\% level in model (2). In conjunction, this suggests that the enforcement effect on conservatism is slightly positive for weak corporate governance firms, while it is not significant for strong corporate governance firms. However, the robustness of these results is limited as I was not able to find equivalent significant results when adding a control group without enforcement changes in untabulated analyses. Moreover, the economic significance is fairly low.

Table 4.8: Enforcement's effect on accounting conservatism depending on a firm's governance strength

\begin{tabular}{|c|c|c|}
\hline Variable & (1) & $(2)$ \\
\hline \multirow[t]{2}{*}{ Enforcement } & -0.0000 & 0.0000 \\
\hline & $(-0.38)$ & $(0.12)$ \\
\hline \multirow[t]{2}{*}{ Governance } & $-0.0000^{* * *}$ & $-0.0001 * * *$ \\
\hline & $(-2.91)$ & $(-3.52)$ \\
\hline \multirow[t]{2}{*}{ Enforcement $*$ Governance } & $0.0001 * *$ & $0.0001 * *$ \\
\hline & $(2.17)$ & $(2.12)$ \\
\hline \multirow[t]{2}{*}{ Size } & $-0.0001 * * *$ & $-0.0001 * * *$ \\
\hline & $(-15.31)$ & $(-10.02)$ \\
\hline \multirow[t]{2}{*}{$M / B$} & $0.0001 * * *$ & $0.0001 * * *$ \\
\hline & $(7.03)$ & $(4.98)$ \\
\hline \multirow[t]{2}{*}{ Leverage } & $0.0003 * * *$ & $0.0003 * * *$ \\
\hline & $(9.74)$ & $(6.34)$ \\
\hline \multirow[t]{2}{*}{ Constant } & $0.0014 * * *$ & $0.0015^{* * *}$ \\
\hline & $(18.58)$ & $(12.64)$ \\
\hline Adj. $R^{2}$ & 0.76 & 0.76 \\
\hline $\mathrm{N}$ & 2023 & 1363 \\
\hline Fixed effects & Country, year, industry & Country, year, industry \\
\hline Clustered standard errors & Firm & Firm \\
\hline \multicolumn{3}{|c|}{$\begin{array}{l}\text { This table displays coefficient estimates and t-statistics from estimating regression model (1) for a sub- } \\
\text { sample of firms derived from Aggarwal et al.'s (2011) corporate governance rating data set. All these } \\
\text { firms are listed in countries that underwent substantive enforcement changes. Model (2) excludes firms } \\
\text { where the governance rating is equal to the median. The dependent variable is Conservatism measured } \\
\text { by C_Score. Definitions of variables are reported in Table } 4.3 \text {. t-values are reported in parentheses. ***, } \\
* * \text {, and } * \text { indicate significance at the } 1 \%, 5 \% \text {, and } 10 \% \text { levels, respectively. The models include country, } \\
\text { year and industry fixed effects and standard errors are clustered by firm. }\end{array}$} \\
\hline
\end{tabular}

\subsection{Robustness check for hypothesis 1}

As outlined in Chapter 4.3, I exclude non-IFRS-adopting firms from the IFRS sample. I do this as in the EU/EEA only countries listed on EU-regulated markets fall under the scrutiny of enforcement mechanisms. These are the very firms that also have to adopt IFRS. However, as the sample potentially also comprises voluntary IFRS adopters who 
are not subject to the supervision of an enforcement regime, my approach is a slightly simplified one. Ideally, one would work with lists published by the European Securities and Markets Authority (ESMA), which specify all countries on regulated markets in the EU in a given year. However, these lists are not obtainable anymore for some of the years included in my research design. Therefore, I work with the explained simplification in my sample selection process as other studies do too (e.g., André et al., 2015). It is worthwhile noting that the potential inclusion of such firms who are not subject to enforcement scrutiny in my treatment sample would rather bias the sample in a way that would work against finding significant results. As I did, in fact, not find a significant association between substantive changes in enforcement and conditional accounting conservatism for the IFRS sample, it is important to address the sample selection concerns in a robustness check. I do this using the ESMA lists of the years of enforcement changes, which I do have available (2007-2015), to arrive at a revised IFRS sample. I do this under the assumption that the firms listed on the EU-regulated market segments did not change dramatically in the years surrounding the enforcement changes, which are not covered by the 2007-2015 ESMA lists. This reduces the size of IFRS sample I to 15,409 firm-year observations. Results are displayed in Table 4.9. Again, I find no significant association between substantive enforcement changes and conditional conservatism, supporting the results of my previous analyses. 
Table 4.9: Robustness check

\begin{tabular}{|c|c|}
\hline Variable & (IFRS sample I) \\
\hline \multirow[t]{2}{*}{ Enforcement } & -0.0009 \\
\hline & $(-1.00)$ \\
\hline \multirow[t]{2}{*}{ Post } & $0.0052 * * *$ \\
\hline & $(3.18)$ \\
\hline \multirow[t]{2}{*}{ Size } & $0.0048 * * *$ \\
\hline & $(25.53)$ \\
\hline \multirow[t]{2}{*}{$M / B$} & $-0.0007 * * *$ \\
\hline & $(-4.70)$ \\
\hline \multirow[t]{2}{*}{ Leverage } & $-0.0212 * * *$ \\
\hline & $(-14.10)$ \\
\hline \multirow[t]{2}{*}{ Constant } & $-0.0586^{* * *}$ \\
\hline & $(-23.53)$ \\
\hline Adj. $R^{2}$ & 0.75 \\
\hline $\mathrm{N}$ & 15409 \\
\hline Fixed effects & $\begin{array}{l}\text { Country, year, } \\
\text { industry }\end{array}$ \\
\hline Clustered standard errors & Firm \\
\hline \multicolumn{2}{|c|}{$\begin{array}{l}\text { This table displays coefficient estimates and t-statistics } \\
\text { from estimating regression model (1) for the IFRS } \\
\text { sample from Table } 4.4 \text { after deducting firms not listed } \\
\text { on EU-regulated markets as indicated by the ESMA } \\
\text { lists of the years with the substantive enforcement } \\
\text { changes. The dependent variable is Conservatism } \\
\text { measured by C_Score. Definitions of variables are } \\
\text { reported in Table } 4.3 \text {. t-values are reported in } \\
\text { parentheses. } * * * * * \text {, and * indicate significance at the } \\
1 \%, 5 \% \text {, and } 10 \% \text { levels, respectively. The models } \\
\text { include country, year and industry fixed effects. } \\
\text { Standard errors are clustered by firm. }\end{array}$} \\
\hline
\end{tabular}

\subsection{Conclusion}

This paper delivers evidence on the role of substantive changes in enforcement in shaping firms' accounting conservatism. In line with prior literature, I hypothesise and find at least for a sample of non-IFRS countries that substantive enforcement changes are significantly and positively associated with C_Score, a firm-year measure of conditional conservatism. I do not find this association for a sample of IFRS-adopting countries though, suggesting that IFRS adoption may limit a firm's leeway in making conservative accounting choices. Hence, firms in IFRS countries would not be able to respond to substantive changes in enforcement as conservatively as firms in non-IFRS countries. As more conservative accounting choices are expected to result in less erroneous or less fraudulent 
accounting, my findings suggest that enforcement's preventive function is efficient throughout the regarded non-IFRS countries.

Moreover, the findings can be interpreted as enforcement having several other positive effects. As García Lara et al. $(2011,2014,2016)$ find that increased levels of accounting conservatism are associated with a higher efficiency in the allocation of capital, reduced levels of information asymmetry and lower cost of capital, enforcement's association with conservatism subsequently also promotes these positive developments.

Furthermore, I find weak evidence that firms with weak corporate governance show a more pronounced increase in accounting conservatism following substantive changes in enforcement than firms with strong corporate governance. However, the robustness and economic significance of these results is limited and, therefore, they need to be interpreted with caution.

My study is subject to several limitations. First and foremost, I use a slightly simplified approach in the selection process of the IFRS sample, which cannot entirely rule out the possibility of some firms being included that are not subject to the enforcement changes at hand. I carry out a robustness test to address these concerns. Another limitation lies in the fact that I was not able to carry out the analysis for my second hypothesis across the entire samples I used in my analyses regarding the first hypothesis. Due to data availability constraints, I had to run a sub-sample analysis, which might not fully be generalisable across all regarded jurisdictions. Lastly, whether or not to make conservative accounting choices remains an endogenous managerial decision influenced by a number of other factors which cannot be observed nor fully ruled out.

Future studies should look at the influence of enforcement changes on unconditional conservatism once appropriate settings are identified. Furthermore, it would be highly interesting and relevant to shed further light on how enforcement's association with conservatism may result in higher efficiency of capital allocation, reduced cost of capital, decreasing information asymmetry and other positive capital market effects. 


\section{Conclusions}

\subsection{Summary of major findings}

While capital market effects associated with enforcement regulation and enforcement actions have been extensively studied in the literature (e.g., Ernstberger et al., 2012; Hitz et al., 2012; H. B. Christensen et al., 2013), this thesis identifies several gaps in the literature on the direct effects of enforcement on the decision making of financial statement preparers and auditors and aims to help fill these gaps. The broad majority of studies investigating the direct effects of enforcement regard post-error announcement effects; that is, they examine the effects that enforcement actions and sanctions have on the stakeholders involved (e.g., Arthaud-Day et al., 2006; Srinivasan, 2005; Johnstone et al., 2011; Brocard et al., 2018). However, little is known about the direct effects on stakeholders' decision making before enforcement institutions even take action. Therefore, this thesis aims to shed light on these effects by investigating the role that ongoing enforcement reviews, the likelihood of being subject to an enforcement review, and substantive changes in enforcement regulation play in managers' and auditors' disclosure and accounting choices. For instance, this thesis examines the voluntary disclosure of firm managers on ongoing and concluded enforcement reviews which has not previously been investigated in the literature. Moreover, this thesis mainly focuses on the role enforcement plays in shaping both auditor and accounting conservatism, thereby contributing to the literature on enforcement's effects on accounting properties (e.g., Ernstberger et al., 2012). It is important to add to this literature stream as many argue that the evidence brought forward in this field of research to date is scarce and inconclusive (Brüggemann et al., 2013; Leuz and Wysocki, 2016; Hitz et al., 2018).

The main findings indicate that: (1) managers deem information on ongoing and concluded enforcement reviews valuable for investors and disclose it deliberately in line with their strategic incentives; (2) auditor conservatism is not increased by enforcement until the individuals have actually been involved in a review; and (3) substantive changes in enforcement regulation may lead firms to prepare more conservative accounts. In conclusion, enforcement appears to have direct effects on the decision making of financial statement preparers and auditors. Managers are influenced in their disclosure decisions and in their accounting choices, while auditors are influenced in what accounting choices they require from their clients. The latter finding, however, only constitutes itself if auditors were directly affected by enforcement in the past. 
The thesis uses three different methodological approaches to address the research questions in the respective studies. In the first study (Chapter 2), content analyses of handcollected annual reports and error announcements display what steps are openly taken by managers in response to enforcement reviews. The experimental approach of the second study (Chapter 3) supports the internal validity of the thesis, while external validity is attained through the archival empirical approach of the third study (Chapter 4), which analyses large cross-country data sets obtained from commercial databases such as Thomson Reuters Datastream.

Contributing to the literature streams on voluntary disclosure and its incentives (e.g., Lev and Penman, 1990; Skinner, 1994; Botosan, 1997) and on enforcement actions (e.g., Hitz et al., 2012), the first study of this thesis delivers exploratory evidence for a disclosure phenomenon that to date has not been investigated. Content analyses of annual reports of all firms subject to the German enforcement mechanism from 2006 to 2016 establish the existence of voluntary disclosures about ongoing and concluded enforcement reviews. Such disclosures occur on a regular basis for concluded reviews (one out of four cases), while they represent a rarer incident for ongoing reviews (one out of 13 cases). Detailed analyses of firms that choose to share with the market information on ongoing reviews indicate that managers may deliberately utilise such disclosures led by their own strategic incentives. The format of the disclosures as well as their locations in the annual report possibly carry information on an enforcement review's likely outcome. Finally, the study finds weak evidence of managers using voluntary disclosures on ongoing enforcement reviews to prepare the market for adverse news. The findings provide insights into an interesting, as yet unexplored disclosure phenomenon and its variation at the firm level as well as insights into the direct effects of enforcement on managers' disclosure decisions.

As with all studies presented in this thesis, the second study contributes to the broad literature stream on the enforcement of accounting standards (e.g., Ernstberger et al, 2012; Hitz et al., 2012; H. B. Christensen et al., 2013). However, this study also contributes to the literature on auditors' decision making and more specifically on auditor conservatism (e.g., Hackenbrack and Nelson, 1996; Nelson and Kinney Jr, 1997) by conducting an experiment with 72 practising auditors. The findings suggest that auditors, on average, already employ conservative decision making, irrespective of the likelihood of an enforcement review. Other potential risk factors such as litigation risk or reputation risk 
already lead them to make more conservative choices. Moreover, professional codes of conduct and ethics as well as firms' internal training might promote conservatism. Importantly, the study's findings show that those auditors who were directly affected by enforcement reviews in the past are significantly more likely to make conservative accounting choices.

The third study contributes to the literature streams on enforcement's impact on accounting properties (e.g., Ernstberger et al., 2012), on conditional conservatism (e.g., Khan and Watts, 2009; Garcìa Lara et al., 2014) and most specifically on the impact of regulation on conditional conservatism (e.g., André et al., 2015). In a broad cross-country setting, this study uses archival data and multivariate analyses to investigate whether substantive changes in enforcement regulation are associated with increasing conditional conservatism. Findings indeed suggest that stronger enforcement regulation is associated with higher conservatism. These findings only substantiate themselves in a sample of nonIFRS jurisdictions. Moreover, firms with weak corporate governance are more affected in their conservatism than firms with strong corporate governance. The latter finding suggests that enforcement may atone for the weaknesses of other corporate governance mechanisms.

\subsection{Implications}

The studies presented in this thesis each have their own important implications which, taken together, lead to greater general insights into the role that enforcement plays in the financial reporting environment. Moreover, the second study and the third study provide insights into the efficacy of enforcement's preventive function which aims at preventing erroneous and fraudulent accounting.

The first study shows that managers deem information on enforcement reviews to be relevant for investors and, therefore, voluntarily disclose such information in line with specific strategic considerations. For instance, some managers may carry out such disclosure to prepare capital markets for adverse news. This indicates that managers are aware of the risks that enforcement holds for them and their firms. They respond to the associated risks with an adjustment of their own disclosure strategies; that is, their decision making is directly influenced by ongoing and concluded enforcement reviews. Such an increase in transparency should benefit investors and strengthen capital markets. 
The second study finds that the likelihood of an enforcement review does not have a significant impact on auditor conservatism. However, if auditors were directly affected by enforcement actions in the past, they tend to employ more conservative decision making. Hence, auditors seemingly need to experience enforcement and its implications and risks before it actually influences their decisions. If an increase in auditor conservatism was desirable, a potential way for this to be achieved would be to increase the frequency of enforcement actions. In this way, more auditors would eventually have had their own experiences with enforcement which would seem to lead them to employ more conservative decision making. More conservatism on the part of auditors would represent a means to achieve enforcement's preventive function as it may lead to less erroneous or aggressive accounting choices.

Finally, according to the third study substantive changes in enforcement regulation seemingly increase accounting conservatism. The study's findings show that enforcement plays an important role when firm managers make accounting choices. As conservative accounting should help prevent erroneous and fraudulent accounting, the findings indicate the efficacy of enforcement's preventive function at least throughout the observed non-IFRS countries. As García Lara et al. (2011, 2014, 2016) find that conservatism is associated with efficient capital allocation and reduced information asymmetry and cost of capital, the findings of this study also suggest that enforcement may be an efficient supportive channel in achieving such positive capital market effects.

Taken together, the findings of this thesis show that enforcement, in fact, influences the decision making of both firm managers and auditors with respect to disclosure and accounting choices. Seemingly, managers are influenced more strongly and more directly than auditors. While accounting conservatism seemingly increases with substantive changes in enforcement regulation, auditor conservatism may be increased by raising the frequency of enforcement reviews. Hence, the evidence presented herein emphasises the relevance of strong enforcement in the financial reporting environment. To support the consistent and efficient application of accounting standards and to prevent erroneous or even fraudulent accounting numbers, it appears essential that strong enforcement bodies frequently carry out reviews of financial statements. Thus, this thesis delivers evidence relevant to regulators' assessment of the outcomes of IFRS adoption and enforcement mandates. 


\subsection{Limitations}

As outlined in the respective chapters, the findings presented in this thesis are subject to several limitations. For instance, the analyses presented in the first study are exploratory and descriptive in nature. Hence, they do not provide insights into any causal relationships such as between unobservable managerial disclosure incentives and observable disclosure choices. Moreover, the results of this study rely on comparably small samples. Caution is advised when trying to derive general insights from these findings.

The second study's main limitation is also with respect to the relatively small sample size which is the result of the need to have auditors as participants as only they could fully grasp the implications of the audit case employed in this experimental study. However, in the trade-off between quantity and quality, in this case, one surely should favour quality and, hence, the preference was a small sample of auditors rather than a large sample of students who would be easier to source but who would not yield such informative data. Moreover, the study did not distinguish between auditors from different cultural backgrounds or between auditors who are working for larger or smaller firms. Consequently, as with all experiments, another typical issue concerns the generalisability of the results. An experimental design will also never be able to completely mimic actual audit tasks and simulate all factors that are relevant in the decision-making process. Thus, while having high internal validity, the study may lack external validity and, hence, it remains uncertain how the findings apply in the real world.

However, external validity is provided to the thesis by the third study. Nevertheless, this final study also has a few limitations especially with respect to the sample selection. Firstly, the sample selection process for the main analyses is slightly simplified. Firms located in countries that adopted IFRS prior to the defined time frame comprise the IFRS sample which is broken down into Treatment group (I) (countries with enforcement changes) and Control group (I) (countries without enforcement changes). It is not possible to rule out that some firms in Treatment group (I) were not subject to the substantive enforcement change. The resulting bias may work against finding significant results in the study. However, this limitation is addressed in a robustness test. Another limitation lies in the fact that, due to data availability constraints, it was not possible to run the analyses for testing Hypothesis 2 with the same sample used for testing Hypothesis 1. Hence, the findings with regard to Hypothesis 2 might not be generalisable to all juris- 
dictions investigated in the rest of the study. Finally, managers' accounting choices remain endogenous in nature, and may be influenced by a variety of factors which cannot always be observed. Therefore, they cannot be ruled out either.

\subsection{Avenues for future research}

The findings of the studies included in this thesis point to several future research opportunities. In general, it still appears worthwhile to further investigate the direct effects of enforcement on the decision making of involved stakeholders in order to understand how these direct effects may drive capital market effects associated with enforcement, as established in previous literature (e.g., Ernstberger et al., 2012; H. B. Christensen et al., 2013). This thesis adds to the literature on the direct effects of enforcement by investigating the effects on managers' and auditors' disclosure and accounting choices. However, this fruitful literature stream still needs to be, and can be, broadened as discussed below. Each study included herein points to specific narrower avenues for future research.

The first study established the existence of a disclosure phenomenon that to date has not been investigated. Hence, great potential lies in exploring this novel angle of enforcement research. As this study largely focused on voluntary disclosures about ongoing reviews, an interesting future research opportunity may be to investigate the motives and effects of voluntary disclosures about concluded reviews, especially for those firms stating that a concluded review without an error finding establishes the high quality of the firm's financial statements. Moreover, it seems promising to investigate channels other than the annual report which firms could use to disclose information on enforcement reviews to investors. Related to this, information intermediaries might play a role in the dissemination process and their role should therefore also be examined in future research.

As the second study does not find a significant association between the likelihood of an enforcement review and auditor conservatism, future research should further investigate how other related factors, as outlined in the study, influence conservatism. For instance, these factors include different risk factors such as reputation risk, and firm-internal factors, such as codes of conduct and ethics or employee training. Furthermore, it may be worthwhile for future research to investigate whether cultural differences impact auditors' decision making in the context of the presented study.

Lastly, the third study of this thesis investigates the association between substantive changes in enforcement regulation and conditional conservatism. Future research should 
examine the association between such enforcement changes and unconditional conservatism. In the current study, appropriate settings were unable to be located in which to conduct such analyses. However, once such settings are identified, this appears to be an obvious path for future studies. Moreover, related to the findings of García Lara et al. (2011, 2014, 2016), further research should seek to develop insights into how enforcement's effect on conservatism may support efficient capital allocation, and reduce information asymmetry as well as the cost of capital. 


\section{Erklärung über den geleisteten Eigenanteil an der Arbeit}

Study 1: "Firm Disclosures about Enforcement Reviews":

This study was conducted in cooperation with Jörg-Markus Hitz. I was continuously involved and took part in the development of the concept of this study, the theoretical framework, and the writing of the text document. In particular, I was solely responsible for the data collection and the execution of the empirical analyses.

Study 2: "Auditor Conservatism in the Presence of Financial Reporting Enforcement":

This study was conducted in cooperation with Andreas Hellmann. I was continuously involved and took part in the development of the concept of this study and the theoretical framework. In particular, I was solely responsible for designing and carrying out the experiment, analyzing the data and the writing of the text document.

Study 3: "The Role of Enforcement in Shaping Conservative Accounting Choices":

This study is single-authored.

(Henning Schnack) 


\section{Versicherung}

gemäß §16 der Prüfungs- und Studienordnung (Version AM I 38/17.08.2015) für den Promotionsstudiengang „Wirtschaftswissenschaften” der Georg-August-Universität Göttingen.

1. Die Gelegenheit zum vorliegenden Promotionsvorhaben ist mir nicht kommerziell vermittelt worden. Insbesondere habe ich keine Organisation eingeschalten, die gegen Entgelt Betreuerinnen und Betreuer für die Anfertigung von Dissertationen sucht oder die mir obliegenden Pflichten hinsichtlich der Prüfungsleistungen für mich ganz oder teilweise erledigt.

2. Ich versichere, dass ich die eingereichte Dissertation (,Regulation of Disclosure and Corporate Governance: An Empirical Investigation of Economic Consequences") selbstständig und ohne unerlaubte Hilfsmittel verfasst habe; fremde Hilfe habe ich dazu weder unentgeltlich noch entgeltlich entgegengenommen und werde dies auch künftig so halten. Anderer als der von mir angegebenen Hilfsmittel und Schriften habe ich mich nicht bedient. Alle wörtlich oder sinngemäß den Schriften anderer Autoren entnommenen Stellen habe ich kenntlich gemacht.

3. Die Richtlinien zur Sicherung der guten wissenschaftlichen Praxis an der Universität Göttingen werden von mir beachtet.

4. Eine entsprechende Promotion wurde an keiner anderen Hochschule im In- oder Ausland beantragt; die eingereichte Dissertation oder Teile von ihr wurden nicht für ein anderes Promotionsvorhaben verwendet.

5. Des Weiteren ist mir bekannt, dass Unwahrhaftigkeiten hinsichtlich der vorstehenden Erklärung die Zulassung zur Promotion ausschließen bzw. später zum Verfahrensabbruch oder zur Rücknahme des erlangten Titels berechtigen.

Göttingen, den 08. Januar 2019

(Henning Schnack) 


\section{Curriculum Vitae}

Work Experience

10/2015 - 04/2019 Georg-August University, Göttingen, Germany

Research assistant (Chair of Accounting and Auditing)

10/2016 - 03/2018 Macquarie University, Sydney, Australia

Sessional academic staff (Department of Accounting \& Corporate Governance)

02/2012 - 09/2015 Georg-August University, Göttingen, Germany

Student assistant (Chair of Accounting and Auditing)

10/2013 - 02/2014 LSG Lufthansa Service Holding AG, Frankfurt am Main, Germany

Corporate M\&A intern

09/2012 - 10/2012 PricewaterhouseCoopers AG WPG, Hannover, Germany

Valuation \& Strategy intern

Peer-Reviewed Research Activity

Peer-Reviewed Academic Journal Publications

$09 / 2018$

Firm Disclosures about Enforcement Reviews

(with J.-M. Hitz), in: Accounting in Europe. DOI: 10.1080/17449480.2018.1519320.

Peer-Reviewed Academic Conference Presentations

06/2018 $6^{\text {th }}$ Journal of International Accounting Research (JIAR) Conference, Venice (Italy)

"Auditor conservatism in the presence of enforcement scrutiny" (joint work with A. Hellmann)

$06 / 2018$

41 $^{\text {st }}$ European Accounting Association (EAA) Annual Congress, Milan (Italy)

"Auditor conservatism in the presence of enforcement scrutiny" (joint work with A. Hellmann) 
$03 / 2018$

$05 / 2017$

$03 / 2017$

$05 / 2016$ $2^{\text {nd }}$ Macquarie University Conference on Contemporary Accounting Research, Sydney (Australia)

"Auditor conservatism in the presence of enforcement scrutiny" (joint work with A. Hellmann)

$4^{\text {th }}$ European Accounting Association (EAA) Annual Congress, Valencia (Spain)

"The right to remain silent: Firm disclosures on concurrent and past enforcement reviews" (joint work with J.-M. Hitz)

$1^{\text {st }}$ Macquarie University Conference on Contemporary Accounting Research, Sydney (Australia)

"The right to remain silent: Firm disclosures on concurrent and past enforcement reviews" (joint work with J.-M. Hitz)

\section{$3^{\text {th }}$ European Accounting Association (EAA) Annual} Congress, Maastricht (Netherlands)

"Why do firms go private? - Delisting determinants and market reactions on the German capital market" (joint work with J.-M. Hitz)

Education

Since 10/2015

Georg-August University, Göttingen, Germany \& Macquarie University, Sydney, Australia (Cotutelle Ph.D. program)

Degrees: - Ph.D. in Accounting \& Corporate Governance (awarded in 12/2018; conferral in 02/2019)

- Dr. rer. pol. (expected in 03/2019)

Thesis title: "The Role of Enforcement in the Decision Making of Financial Statement Preparers and Auditors"

04/2013 - 09/2015 Georg-August University, Göttingen, Germany

Degree: M.Sc. Master of Science in Finance, Accounting and Taxes

Final mark: 1.4 (high distinction)

Thesis title: "Going Private - Institutional Background and Empirical Evidence Pertaining to Delisting Decisions on the German Market" 
10/2009 - 03/2013 Georg-August University, Göttingen, Germany

Degree: B.Sc. Bachelor of Science in Business Administration with a major in Finance, Accounting and Taxes

Final mark: 1.4 (high distinction)

Thesis title: "The German Enforcement Panel (DPR) and the Cash Flow Statement: Critical Investigation and Analysis of Error Announcements"

Awards and Grants

$10 / 2012$

Study grant from the Deloitte Foundation, Germany (stipend = EUR 4,800)

04/2016 iMQRES scholarship (Macquarie University Research Excellence, $\$ 89,000$ ), Stipend (Macquarie University, $\$ 26,000$ per year on campus)

$09 / 2017$

Macquarie University Postgraduate Research Fund (PGRF) Grant $(\$ 2,140)$

Other International Experience

08/2011 - 01/2012 Mälardalen University Västerås, Sweden

Exchange student

07/2008 - 06/2009 “Working Holiday" in Canada 


\section{References}

Abdolmohammadi, M., \& Wright, A. (1987). An examination of the effects of experience and task complexity on audit judgments. The Accounting Review, 62(1), 1-13.

Acharya, V. V., DeMarzo, P., \& Kremer, I. (2011). Endogenous information flows and the clustering of announcements. The American Economic Review, 101(7), 29552979.

Aggarwal, R., Erel, I., Ferreira, M., \& Matos, P. (2011). Does governance travel around the world? Evidence from institutional investors. Journal of Financial Economics, 100(1), 154-181.

Ahmed, A. S., \& Duellman, S. (2007). Evidence on the role of accounting conservatism in corporate governance. Journal of Accounting and Economics, 43(2-3), 411437.

André, P., Filip, A., \& Paugam, L. (2015). The effect of mandatory IFRS adoption on conditional conservatism in Europe. Journal of Business Finance \& Accounting, 42(3-4), 482-514.

Arthaud-Day, M. L., Certo, S. T., Dalton, C. M., \& Dalton, D. R. (2006). A changing of the guard: Executive and director turnover following corporate financial restatements. Academy of Management Journal, 49(6), 1119-1136.

Badia, M., Duro, M., Penalva, F., \& Ryan, S. (2017). Conditionally conservative fair value measurements. Journal of Accounting and Economics, 63(1), 75-98.

Ball, R., \& Brown, P. (1968). An empirical evaluation of accounting income numbers. Journal of Accounting Research, 6(2), 159-178.

Ball, R., Kothari, S., \& Nikolaev, V. V. (2013). Econometrics of the Basu asymmetric timeliness coefficient and accounting conservatism. Journal of Accounting Research, 51(5), 1071-1097.

Ball, R., Kothari, S., \& Robin, A. (2000). The effect of international institutional factors on properties of accounting earnings. Journal of Accounting and Economics, 29(1), 1-51.

Bamber, L. S. (1987). Unexpected earnings, firm size, and trading volume around quarterly earnings announcements. The Accounting Review, 62(3), 510-532.

Bannister, J. W., \& Wiest, D. N. (2001). Earnings management and auditor conservatism: Effects of SEC enforcement actions. Managerial Finance, 27(12), 57-71.

Barth, M. E., \& Israeli, D. (2013). Disentangling mandatory IFRS reporting and changes in enforcement. Journal of Accounting and Economics, 56(2), 178-188. 
Barton, J. A. N. (2005). Who cares about auditor reputation? Contemporary Accounting Research, 22(3), 549-586.

Basu, S. (1997). The conservatism principle and the asymmetric timeliness of earnings. Journal of Accounting and Economics, 24(1), 3-37.

Beaver, W. H. (1998). Financial Reporting: An Accounting Revolution (3rd ed.). Upper Saddle River: Prentice Hall International Inc.

Beaver, W. H., \& Ryan, S. G. (2005). Conditional and unconditional conservatism: Concepts and modeling. Review of Accounting Studies, 10(2), 269-309.

Beekes, W., Pope, P., \& Young, S. (2004). The link between earnings timeliness, earnings conservatism and board composition: evidence from the UK. Corporate Governance: An International Review, 12(1), 47-59.

Berger, A. (2010). The development and status of enforcement in the European Union. Accounting in Europe, 7(1), 15-35.

Beyer, A., Cohen, D. A., Lys, T. Z., \& Walther, B. R. (2010). The financial reporting environment: Review of the recent literature. Journal of Accounting and Economics, 50(2), 296-343.

Bliss, J. H. (1924). Management through accounts. New York: Ronald Press Company.

Bonner, S. E., Palmrose, Z.-V., \& Young, S. M. (1998). Fraud type and auditor litigation: An analysis of SEC accounting and auditing enforcement releases. The Accounting Review, 73(4), 503-532.

Botosan, C. A. (1997). Disclosure level and the cost of equity capital. Accounting Review, 323-349.

Brazel, J. F., Jones, K. L., \& Prawitt, D. F. (2014). Auditors' reactions to inconsistencies between financial and nonfinancial measures: The interactive effects of fraud risk assessment and a decision prompt. Behavioral research in accounting, 26(1), 131156.

Brocard, M., Franke, B., \& Voeller, D. (2018). Enforcement actions and auditor changes. European Accounting Review, 27(3), 407-436.

Brown, P., Preiato, J., \& Tarca, A. (2014). Measuring country differences in enforcement of accounting standards: An audit and enforcement proxy. Journal of Business Finance \& Accounting, 41(1-2), 1-52.

Brown, S. J., \& Warner, J. B. (1985). Using daily stock returns: The case of event studies. Journal of Financial Economics, 14(1), 3-31. 
Brüggemann, U., Hitz, J.-M., \& Sellhorn, T. (2013). Intended and unintended consequences of mandatory IFRS adoption: A review of extant evidence and suggestions for future research. European Accounting Review, 22(1), 1-37.

Bushman, R. M., \& Piotroski, J. D. (2006). Financial reporting incentives for conservative accounting: The influence of legal and political institutions. Journal of Accounting and Economics, 42(1), 107-148.

Bushman, R. M., Piotroski, J. D., \& Smith, A. J. (2011). Capital allocation and timely accounting recognition of economic losses. Journal of Business Finance \& Accounting, 38(1-2), 1-33.

Cahan, S. F., Emanuel, D., \& Sun, J. (2009). Are the reputations of the large accounting firms really international? Evidence from the Andersen-Enron affair. Auditing: A Journal of Practice \& Theory, 28(2), 199-226.

Cahan, S. F., \& Zhang, W. (2006). After Enron: Auditor conservatism and ex-Andersen clients. The Accounting Review, 81(1), 49-82.

Carver, B. T. (2014). The retention of directors on the audit committee following an accounting restatement. Journal of Accounting and Public Policy, 33(1), 51-68.

Chandra, U. (2011). Income conservatism in the US technology sector. Accounting Horizons, 25(2), 285-314.

Christensen, B. E., Glover, S. M., Omer, T. C., \& Shelley, M. K. (2016). Understanding audit quality: Insights from audit professionals and investors. Contemporary Accounting Research, 33(4), 1648-1684.

Christensen, B. E., Glover, S. M., \& Wolfe, C. J. (2014). Do critical audit matter paragraphs in the audit report change nonprofessional investors' decision to invest? Auditing: A Journal of Practice \& Theory, 33(4), 71-93.

Christensen, H. B., Hail, L., \& Leuz, C. (2013). Mandatory IFRS reporting and changes in enforcement. Journal of Accounting and Economics, 56(2), 147-177.

Chung, R., Firth, M., \& Kim, J.-B. (2003). Auditor conservatism and reported earnings. Accounting and Business Research, 33(1), 19-32.

Collins, D., Masli, A., Reitenga, A. L., \& Sanchez, J. M. (2009). Earnings restatements, the Sarbanes-Oxley Act, and the disciplining of chief financial officers. Journal of Accounting, Auditing \& Finance, 24(1), 1-34.

Corrado, C. J. (1989). A nonparametric test for abnormal security-price performance in event studies. Journal of Financial Economics, 23(2), 385-395. 
Daske, H., Hail, L., Leuz, C., \& Verdi, R. (2008). Mandatory IFRS reporting around the world: Early evidence on the economic consequences. Journal of Accounting Research, 46(5), 1085-1142.

DeAngelo, L. E. (1988). Managerial competition, information costs, and corporate governance: The use of accounting performance measures in proxy contests. Journal of Accounting and Economics, 10(1), 3-36.

Dechow, P. M., Sloan, R. G., \& Sweeney, A. P. (1996). Causes and consequences of earnings manipulation: An analysis of firms subject to enforcement actions by the SEC. Contemporary Accounting Research, 13(1), 1-36.

DeFond, M. L., Francis, J. R., \& Hallman, N. J. (2018). Awareness of SEC Enforcement and Auditor Reporting Decisions. Contemporary Accounting Research, 35(1), 277-313.

Depoers, F. (2000). A cost benefit study of voluntary disclosure: Some empirical evidence from French listed companies. European Accounting Review, 9(2), 245263.

Desai, H., Hogan, C. E., \& Wilkins, M. S. (2006). The reputational penalty for aggressive accounting: Earnings restatements and management turnover. The Accounting Review, 81(1), 83-112.

Dietrich, J. R., Muller, K. A., \& Riedl, E. J. (2007). Asymmetric timeliness tests of accounting conservatism. Review of Accounting Studies, 12(1), 95-124.

Donnellan, M. B., Oswald, F. L., Baird, B. M., \& Lucas, R. E. (2006). The mini-IPIP scales: tiny-yet-effective measures of the Big Five factors of personality. Psychological assessment, 18(2), 192-203.

Ebner, G., Hoeltken, M., \& Zülch, H. (2015). Determinants of investor reactions to error announcements-Evidence from Germany. Available at SSRN 2583667.

Emby, C., \& Gibbins, M. (1987). Good judgment in public accounting: Quality and justification. Contemporary Accounting Research, 4(1), 287-313.

Ernstberger, J., Stich, M., \& Vogler, O. (2012). Economic consequences of accounting enforcement reforms: the case of Germany. European Accounting Review, 21(2), 217-251.

Ettredge, M., Huang, Y., \& Zhang, W. (2012). Earnings restatements and differential timeliness of accounting conservatism. Journal of Accounting and Economics, 53(3), 489-503. 
Fafatas, S. A. (2010). Auditor conservatism following audit failures. Managerial Auditing Journal, 25(7), 639-658.

Farmer, T. A., Rittenberg, L. E., \& Trompeter, G. M. (1987). An Investigation of the impact of economic and organizational-factors on auditor independence. Auditing: A Journal of Practice \& Theory, 7(1), 1-14.

Feltham, G. A., \& Ohlson, J. A. (1995). Valuation and clean surplus accounting for operating and financial activities. Contemporary Accounting Research, 11(2), 689-731.

Feroz, E. H., Park, K., \& Pastena, V. S. (1991). The financial and market effects of the SEC's accounting and auditing enforcement releases. Journal of Accounting Research, 29(Supplement), 107-142.

Firth, M. (1990). Auditor reputation: The impact of critical reports issued by government inspectors. Rand Journal of Economics, 21(3), 374-387.

Francis, J. R., \& Martin, X. (2010). Acquisition profitability and timely loss recognition. Journal of Accounting and Economics, 49(1-2), 161-178.

García Lara, J. M., García Osma, B., \& Penalva, F. (2007). Board of directors' characteristics and conditional accounting conservatism: Spanish evidence. European Accounting Review, 16(4), 727-755.

García Lara, J. M., García Osma, B., \& Penalva, F. (2009a). Accounting conservatism and corporate governance. Review of Accounting Studies, 14(1), 161-201.

García Lara, J. M., García Osma, B., \& Penalva, F. (2009b). The economic determinants of conditional conservatism. Journal of Business Finance \& Accounting, 36(3-4), 336-372.

García Lara, J. M., García Osma, B., \& Penalva, F. (2011). Conditional conservatism and cost of capital. Review of Accounting Studies, 16(2), 247-271.

García Lara, J. M., García Osma, B., \& Penalva, F. (2014). Information consequences of accounting conservatism. European Accounting Review, 23(2), 173-198.

García Lara, J. M., García Osma, B., \& Penalva, F. (2016). Accounting conservatism and firm investment efficiency. Journal of Accounting and Economics, 61(1), 221238.

García Lara, J. M., \& Mora, A. (2004). Balance sheet versus earnings conservatism in Europe. European Accounting Review, 13(2), 261-292.

Gibbins, M., \& Emby, C. (1984). Evidence on the nature of professional judgment in public accounting. Journal of Accounting Research, 22(1), 165-186. 
Gietzmann, M. B., \& Trombetta, M. (2003). Disclosure interactions: accounting policy choice and voluntary disclosure effects on the cost of raising outside capital. Accounting and Business Research, 33(3), 187-205.

Hackenbrack, K., \& Nelson, M. W. (1996). Auditors' incentives and their application of financial accounting standards. The Accounting Review, 71(1), 43-59.

Hatfield, R. C., Jackson, S. B., \& Vandervelde, S. D. (2011). The effects of prior auditor involvement and client pressure on proposed audit adjustments. Behavioral research in accounting, 23(2), 117-130.

Healy, P. M., \& Wahlen, J. M. (1999). A review of the earnings management literature and its implications for standard setting. Accounting Horizons, 13(4), 365-383.

Hitz, J.-M., Ernstberger, J., \& Stich, M. (2012). Enforcement of accounting standards in Europe: Capital-market-based evidence for the two-tier mechanism in Germany. European Accounting Review, 21(2), 253-281.

Hitz, J.-M., Kaumanns, S., \& Lehmann, N. (2018). A Missing Link? How Selection Effects Shape Evidence on the Market Benefits of Mandatory IFRS Adoption. Available at SSRN: 2816616.

Holt, T., \& Loraas, T. M. (2018). Using Qualtrics Panels to Source External Auditors: A Replication Study. Journal of Information Systems In-Press.

Hughes, P. J. (1986). Signalling by direct disclosure under asymmetric information. Journal of Accounting and Economics, 8(2), 119-142.

Hui, K. W., Matsunaga, S., \& Morse, D. (2009). The impact of conservatism on management earnings forecasts. Journal of Accounting and Economics, 47(3), 192-207.

Huijgen, C., \& Lubberink, M. (2005). Earnings Conservatism, Litigation and Contracting: The Case of Cross-Listed Firms. Journal of Business Finance \& Accounting, 32(7-8), 1275-1309.

IFRS-Foundation. (2018). Who uses IFRS Standards? Retrieved from: https://www.ifrs.org/use-around-the-world/use-of-ifrs-standards-byjurisdiction/\#analysis.

Ittonen, K., \& Peni, E. (2012). Auditor's gender and audit fees. International Journal of Auditing, 16(1), 1-18.

Jayaraman, S. (2012). The effect of enforcement on timely loss recognition: Evidence from insider trading laws. Journal of Accounting and Economics, 53(1-2), 77-97. 
Jensen, M. C., \& Meckling, W. H. (1976). Theory of the firm: Managerial behavior, agency costs and ownership structure. Journal of Financial Economics, 3(4), 305360.

Johnson, V. E., \& Kaplan, S. E. (1991). Experimental evidence on the effects of accountability on auditor judgments. Auditing: A Journal of Practice \& Theory, 10(Supplement), 96-107.

Johnstone, K., Li, C., \& Rupley, K. H. (2011). Changes in corporate governance associated with the revelation of internal control material weaknesses and their subsequent remediation. Contemporary Accounting Research, 28(1), 331-383.

Kaufmann, D., Kraay, A., \& Mastruzzi, M. (2009). Governance matters VIII: Aggregate and individual governance indicators 1996-2008: The World Bank.

Khan, M., \& Watts, R. L. (2009). Estimation and empirical properties of a firm-year measure of accounting conservatism. Journal of Accounting and Economics, $48(2), 132-150$.

Kida, T. (1980). An investigation into auditors' continuity and related qualification judgments. Journal of Accounting Research, 18(2), 506-523.

Kläs, E., \& Werner, J. R. (2014). Financial Statement Error Findings and Auditor Reputation: Evidence from the German Enforcement Regime. Available at SSRN: 2417878.

Krishnan, J., \& Krishnan, J. (1997). Litigation risk and auditor resignations. The Accounting Review, 72(4), 539-560.

LaFond, R., \& Roychowdhury, S. (2008). Managerial ownership and accounting conservatism. Journal of Accounting Research, 46(1), 101-135.

LaFond, R., \& Watts, R. L. (2008). The information role of conservatism. The Accounting Review, 83(2), 447-478.

Lambert, R., Leuz, C., \& Verrecchia, R. E. (2007). Accounting information, disclosure, and the cost of capital. Journal of Accounting Research, 45(2), 385-420.

Lambert, T. A., Luippold, B. L., \& Stefaniak, C. M. (2017). Audit partner disclosure: An experimental exploration of accounting information contagion. Behavioral research in accounting, 30(1), 27-38.

Land, J. K. (2010). CEO turnover around earnings restatements and fraud. Pacific Accounting Review, 22(3), 180-198. 
Leuz, C., \& Wysocki, P. D. (2016). The economics of disclosure and financial reporting regulation: Evidence and suggestions for future research. Journal of Accounting Research, 54(2), 525-622.

Lev, B., \& Penman, S. H. (1990). Voluntary forecast disclosure, nondisclosure, and stock prices. Journal of Accounting Research, 28(1), 49-76.

Lewis, B. L. (1980). Expert judgment in auditing: An expected utility approach. Journal of Accounting Research, 18(2), 594-602.

Lord, A. T. (1992). Pressure: A methodological consideration for behavioral research in auditing. Auditing: A Journal of Practice \& Theory, 11(2), 90.

MacKinlay, A. C. (1997). Event studies in economics and finance. Journal of Ecconomic Literature, 35(1), 13-39.

Mande, V., \& Son, M. (2012). Do financial restatements lead to auditor changes? Auditing: A Journal of Practice \& Theory, 32(2), 119-145.

McCreevy, C. (2005). Official opening of FEE's (Fédération des Experts Comptables Européens) new offices [Press release]. Retrieved from: http://europa.eu/rapid/press-release_SPEECH-05-621_en.htm.

Messier Jr, W. F., Quilliam, W. C., Hirst, D. E., \& Craig, D. (1992). The effect of accountability on judgment: Development of hypotheses for auditing. Auditing: A Journal of Practice \& Theory, 11(Supplement), 123-138.

Mora, A., \& Walker, M. (2015). The implications of research on accounting conservatism for accounting standard setting. Accounting and Business Research, 45(5), 620650.

Nelson, M., \& Kinney Jr, W. R. (1997). The effect of ambiguity on loss contingency reporting judgments. The Accounting Review, 72(2), 257-274.

Nelson, M., Kinney, W., Smith, S., \& Palmrose, Z. (2005). Quantitative materiality perspectives and auditors' disposition of detected misstatements. The Accounting Review, 80(3), 897-920.

Nelson, M., \& Tan, H.-T. (2005). Judgment and decision making research in auditing: A task, person, and interpersonal interaction perspective. Auditing: A Journal of Practice \& Theory, 24(1), 41-71.

Ng, T. B.-P., \& Tan, H.-T. (2003). Effects of authoritative guidance availability and audit committee effectiveness on auditors' judgments in an auditor-client negotiation context. The Accounting Review, 78(3), 801-818. 
Peecher, M. E., Solomon, I., \& Trotman, K. T. (2013). An accountability framework for financial statement auditors and related research questions. Accounting, Organizations and Society, 38(8), 596-620.

Preston, A. M., Cooper, D. J., Scarbrough, D. P., \& Chilton, R. C. (1995). Changes in the code of ethics of the US accounting profession, 1917 and 1988: The continual quest for legitimation. Accounting, Organizations and Society, 20(6), 507-546.

Ramalingegowda, S., \& Yu, Y. (2012). Institutional ownership and conservatism. Journal of Accounting and Economics, 53(1-2), 98-114.

Ramsay, R. J. (1994). Senior/manager differences in audit workpaper review performance. Journal of Accounting Research, 32(1), 127-135.

Regulation (EC) No. 1606/2002 of the European Parliament and of the Council of 19 July 2002. Official Journal of the European Communities, L243/1-L243/4.

Rich, J. S., Solomon, I., \& Trotman, K. T. (1997). The audit review process: A characterization from the persuasion perspective. Accounting, Organizations and Society, 22(5), 481-505.

Richardson, G., \& Tinaikar, S. (2004). Accounting based valuation models: what have we learned? Accounting \& Finance, 44(2), 223-255.

Robertson, J. C. (2010). The effects of ingratiation and client incentive on auditor judgment. Behavioral research in accounting, 22(2), 69-86.

Rollins, T. P., \& Bremser, W. G. (1997). The SEC's enforcement actions against auditors: an auditor reputation and institutional theory perspective. Critical Perspectives on Accounting, 8(3), 191-206.

Ryan, S. G. (2006). Identifying conditional conservatism. European accounting review, 15(4), 511-525.

Schmidt, M. (2005). "Whistle blowing" regulation and accounting standards enforcement in Germany and Europe - an economic perspective. International Review of Law and Economics, 25(2), 143-168.

Skinner, D. J. (1994). Why firms voluntarily disclose bad news. Journal of Accounting Research, 32(1), 38-60.

Skinner, D. J., \& Srinivasan, S. (2012). Audit quality and auditor reputation: Evidence from Japan. The Accounting Review, 87(5), 1737-1765.

Srinivasan, S. (2005). Consequences of financial reporting failure for outside directors: Evidence from accounting restatements and audit committee members. Journal of Accounting Research, 43(2), 291-334. 
Sterling, R. R. (1970). Theory of the measurement of enterprise income. Lawrence: University Press of Kansas.

Sun, J., Cahan, S. F., \& Xu, J. (2016). Individual auditor conservatism after CSRC sanctions. Journal of Business Ethics, 136(1), 133-146.

Teoh, S. H., \& Hwang, C. Y. (1991). Nondisclosure and adverse disclosure as signals of firm value. The Review of Financial Studies, 4(2), 283-313.

Trueman, B. (1986). Why do managers voluntarily release earnings forecasts? Journal of Accounting and Economics, 8(1), 53-71.

Velayutham, S. (2003). The accounting profession's code of ethics: Is it a code of ethics or a code of quality assurance? Critical Perspectives on Accounting, 14(4), 483503.

Vyas, D. (2011). The Timeliness of Accounting Write-Downs by US Financial Institutions During the Financial Crisis of 2007-2008. Journal of Accounting Research, 49(3), 823-860.

Wagenhofer, A. (1990). Voluntary disclosure with a strategic opponent. Journal of Accounting and Economics, 12(4), 341-363.

Wang, K., Sewon, O., \& Claiborne, M. C. (2008). Determinants and consequences of voluntary disclosure in an emerging market: Evidence from China. Journal of International Accounting, Auditing and Taxation, 17(1), 14-30.

Wang, Y.-F., \& Chou, L.-T. L. (2011). Impact of restatement characteristics and subsequent earnings management on post-SOX executive turnover. Review of Business, 31(2), 24-50.

Watts, R. L. (2003a). Conservatism in accounting part I: Explanations and implications. Accounting Horizons, 17(3), 207-221.

Watts, R. L. (2003b). Conservatism in accounting part II: Evidence and research opportunities. Accounting Horizons, 17(4), 287-301.

Weber, J., Willenborg, M., \& Zhang, J. (2008). Does auditor reputation matter? The case of KPMG Germany and ComROAD AG. Journal of Accounting Research, 46(4), 941-972.

Wright, A., \& Wright, S. (1997). An examination of factors affecting the decision to waive audit adjustments. Journal of Accounting, Auditing \& Finance, 12(1), 1536. 
Wright, S., \& Wright, A. M. (1997). The effect of industry experience on hypothesis generation and audit planning decisions. Behavioral research in accounting, 9, 273-294.

Zhang, J. (2008). The contracting benefits of accounting conservatism to lenders and borrowers. Journal of Accounting and Economics, 45(1), 27-54. 